\title{
Structures, Properties, and Performances-Relationships of Polymeric Membranes for Pervaporative Desalination
}

\author{
Nayan Ranjan Singha ${ }^{1, *} \mathbb{\infty}$, Mrinmoy Karmakar ${ }^{1} \mathbb{C}$, Pijush Kanti Chattopadhyay ${ }^{2, *} \mathbb{(}$,

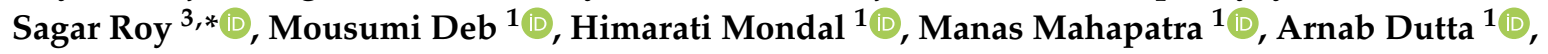 \\ Madhushree Mitra ${ }^{2}$ and Joy Sankar Deb Roy ${ }^{1,2}$ \\ 1 Advanced Polymer Laboratory, Department of Polymer Science and Technology, Government College of \\ Engineering and Leather Technology (Post Graduate), Maulana Abul Kalam Azad University of Technology, \\ Salt Lake City, Kolkata 700106, West Bengal, India; mrinmoy.enterprise@gmail.com (M.K.); \\ mousumidev1994@gmail.com (M.D.); himaratimondal236@gmail.com (H.M.); \\ mmahapatra101@gmail.com (M.M.); duttaarnab1991@gmail.com (A.D.); j.s.d.roy@gmail.com (J.S.D.R.) \\ 2 Department of Leather Technology, Government College of Engineering and Leather Technology \\ (Post Graduate), Maulana Abul Kalam Azad University of Technology, \\ Salt Lake City, Kolkata 700106, West Bengal, India; madhushreemitra84@gmail.com \\ 3 Department of Chemistry \& Environmental Science, New Jersey Institute of Technology, \\ Newark, NJ 07102, USA \\ * Correspondence: drs.nrs@gmail.com (N.R.S.); pkantichattopadhyay@gmail.com (P.K.C.); \\ sagar@njit.edu (S.R.); Tel.: +91-974-8097-101 (N.R.S.)
}

Received: 28 February 2019; Accepted: 19 April 2019; Published: 1 May 2019

\begin{abstract}
For the fulfilment of increasing global demand and associated challenges related to the supply of clean-and-safe water, PV has been considered as one of the most attractive and promising areas in desalinating salty-water of varied salinities. In pervaporative desalination, the sustainability, endurance, and structural features of membrane, along with operating parameters, play the dominant roles and impart paramount impact in governing the overall PV efficiency. Indeed, polymeric- and organic-membranes suffer from several drawbacks, including inferior structural stability and durability, whereas the fabrication of purely inorganic membranes is complicated and costly. Therefore, recent development on the high-performance and cost-friendly PV membrane is mostly concentrated on synthesizing composite- and NCP-membranes possessing the advantages of both organic- and inorganic-membranes. This review reflects the insights into the physicochemical properties and fabrication approaches of different classes of PV membranes, especially compositeand NCP-membranes. The mass transport mechanisms interrelated to the specialized structural features have been discussed. Additionally, the performance potential and application prospects of these membranes in a wide spectrum of desalination and wastewater treatment have been elaborated. Finally, the challenges and future perspectives have been identified in developing and scaling up different high-performance membranes suitable for broader commercial applications.
\end{abstract}

Keywords: fabrication and properties of inorganic membranes; nanocomposite membrane; physicochemical alterations of desalination membranes; hollow-fiber supported composite membrane; pervaporative desalination-mechanism

\section{Introduction}

The world-wide demand of pure water is continuously increasing because of the exponential increase in population, urbanization, and industrialization. Such enhanced water demand is deteriorating the availability of pure water that should impart the greatest threat in the recent future. Instead of the coverage of more than $70 \%$ of Earth's surface by water, only $3 \%$ is available as 
fresh water, of which a very small fraction is accessible to human beings, since the major portion of such freshwater is stored as frozen glaciers and is accumulated in deep underground water reservoirs. As per the recent survey of USA, 2-7 billion people will face water scarcity by the middle of the $21^{\text {st }}$ century, as surface water is often contaminated by various hazardous contaminants, such as dyes, heavy metal ions, salts, and other organic/inorganic contaminants [1-8]. To mitigate such an alarming issue, membrane-based desalination and waste-water recycling can be thought to be one of the most effective technologies to offer safe and cleaner water $[9,10]$. Membrane, a permselective barrier, allows the selective passage of a particular component from the mixture(s). Membrane-based technologies are one of the fastest growing separation technologies, extensively utilized in desalination, environmental remediation, green energy, food, and chemical and pharmaceutical sectors [11-16]. In this context, high TDS concentration beyond 50,000 ppm of saline-, brackish-, and sea-water restricts the uses of various conventional desalinating membrane processes, such as pressure-driven (i.e., RO, NF, UF, and MF), osmotically-driven (i.e., FO and PRO), because of the excessively high hydraulic pressure required to overcome the osmotic pressure of the feed solution [17-22]. In order to overcome such problem, the development of non-pressure driven processes, such as MD [23-25] and most recently PV [26-43], have been developed.

In MD, a hydrophobic microporous membrane is necessary to act as the barrier against the entrance of feed liquid through membrane pores. At the same time, the membrane pores allow water vapor to pass through. However, membrane fouling and wetting are the major challenges encountered in MD processes. As a result of prolonged usage, hydrophobicity of microporous membrane used in MD is deteriorated, resulting in the increment of membrane wetting. Moreover, the pores of hydrophobic membrane can easily be clogged via colloidal and particulate deposition on the membrane surface, thereby affecting the salt rejection ability [44,45]. In addition, membrane fouling may occur via accumulation and blockage of membrane pores by biological matters susceptible to putrefaction or rotting.

Unlike MD, a hydrophilic dense membrane or molecular sieving membrane is utilized as basic component during PV desalination. Accordingly, the hydrophilic membrane preferentially allows water molecules to permeate, discouraging superficial deposition of relatively hydrophobic components on the membrane, leading to the reduced possibility of membrane fouling. Moreover, any hydrophilic membrane does not allow hydrophobic volatile VOCs to permeate through. Therefore, $\mathrm{PV}$ is an attractive alternative for extensive removal of even small quantity of VOCs from the feed water. Thus, water vapor can only be permeated through the hydrophilic membrane, followed by condensation of the permeated water vapor in the collection chamber (Figure 1). During PV, passage through the membrane is actuated by the vapor pressure difference between feed and permeate sides. Such difference in vapor pressure is generally created by maintaining either vacuum or by sweeping an inert gas on the permeate side of the membrane [46].

Additionally, PV suffers from some limitations including lower flux as compared to MD. Therefore, for improving permeation flux, modification of PV membranes is essential to provide good affinity and suitable molecular structure for water transport [41,42]. Additionally, there is no need to overcome the osmotic pressure of the feed solution and create a suitably high osmotic gradient across the membrane for attaining a reasonable flux. Therefore, PV works brilliantly for desalinating high-salinity brines and is more foul-resistant compared to the conventional pressure-driven desalination techniques [47]. 


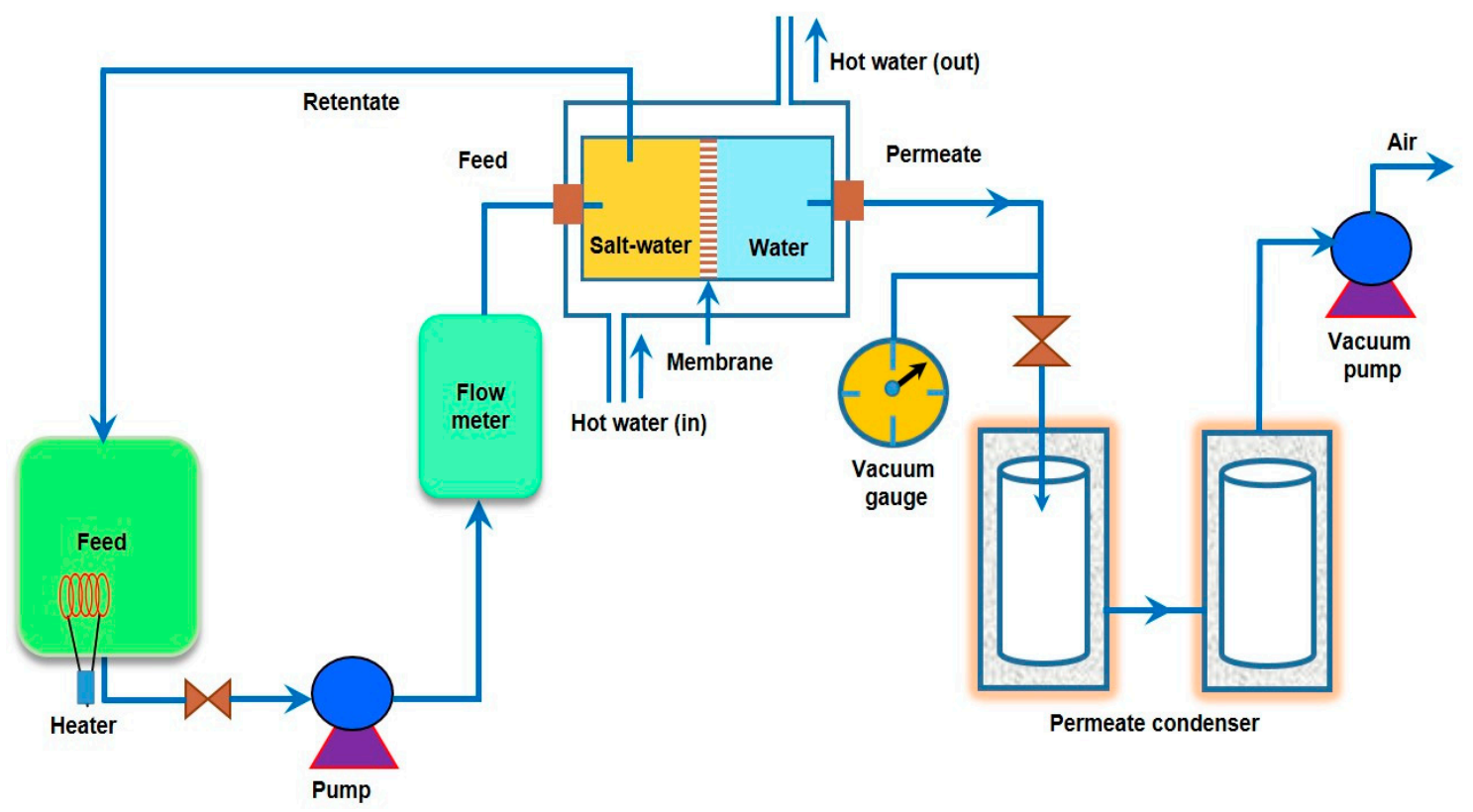

Figure 1. PV desalination apparatus.

Desalination of seawater was previously carried out using MSFD and RO. Due to the high energy-demand of MSFD, RO is becoming more useful for seawater desalination [48]. Approximately, $60 \%$ of the total desalination plants of the world are RO-based [49]. According to Veolia Environment, the RO market share is expected to climb up to $70 \%$ of the total desalination by 2020. In RO, the passage of pure water is allowed to come out from solution using higher mechanical pressure on the feed side as compared to the osmotic pressure of feed solution. However, in RO, pre-treatment and pressurization of raw seawater up to $5000 \mathrm{kPa}$ is essential. Indeed, because of the attainment of biofouling, life-time of polymeric membranes is reduced. Additionally, the membranes have poor recyclability and low chemical stability. Moreover, the typical desalinating efficiency of RO system is only within 35-50\% [50]. Furthermore, for RO-based desalination of concentrated sea water, formation of a byproduct causes secondary pollution [51]. Therefore, there is a serious demand for the development of new, cost-friendly, and recyclable membrane-based seawater desalination technology to replace RO [52]. In this regard, membrane-based pervaporative desalination techniques involving thermomechanically and chemically sustainable membranes showing high salt-rejection efficiencies are gaining high insight and paramount impact. Desalination is highly efficient for selective removal of unwanted salt species from non-potable saline sources, such as brackish- (i.e., 1-10 $\mathrm{g} \mathrm{L}^{-1}$ ), sea- (i.e., $35 \mathrm{~g} \mathrm{~L}^{-1}$ ), and brine- (i.e., $75-150 \mathrm{~g} \mathrm{~L}^{-1}$ ) water [53-56].

$\mathrm{PV}$ is a membrane-based process, which involves the selective separation/rejection of liquids/solids from their mixtures through a dense asymmetric membrane. Except desalination, PV has been extensively used for the systems, which are difficult to be separated through the existing separation processes, such as distillation, adsorption, and extraction. In fact, the use of PV for separating azeotropic and close boiling liquids, heat sensitive materials, and organic mixtures, along with the removals of dilute VOCs from wastewater and recovery of volatile aroma compounds from fruit juices, can be found in literature [57-64]. Rubber membrane-based separation of hydrocarbon from its alcohol mixture was firstly studied by Kahlenberg in early 1906 [65]. Thereafter, frequent utilization of PV has been monitored because of its eco-/cost-friendly performance potential and simple design. For pervaporative desalination, the membranes should possess high hydrophilicity, facilitating the selective permeation of water molecules through the membrane by the solution-diffusion mechanism, resulting in the salt rejection. Mass transport is governed by $\triangle \mathrm{VP}$ between feed and permeate streams, achieved by maintaining a low continuous pressure on the permeate side of the membrane [66]. Such controlled pressure on the permeate side is maintained by a dry and cold sweeping gas or simply by applying 
vacuum. The primary problems associated with the pervaporative desalination of seawater are the requirements of pre-treating and heating and the condensation of permeate. Recently, the use of solar thermal collectors reduced the problem of feed-heating [67]. Undoubtedly, PV is an auspicious contender for seawater desalination. Significantly, the use of pervaporative desalination results in the formation of ultra-high purity water in the laboratory and seawater desalination at the small-scale.

Due to the complex mechanism, few empirical models, such as the pore flow model, total solvent volume fraction model, and solution-diffusion model [68-73], have been employed to explain the PV mechanism. Of these, solution-diffusion model, originally proposed by Rautenbach et al., resembles the most real PV phenomenon. The solution-diffusion model considers the fugacity gradient between the two sides of the membrane [74]. Indeed, solution-diffusion model was modified further by Mizsey et al. and used in pervaporative dehydration of alcohols [75,76]. Such a model exhibited fair applicability for low feed water concentrations [77]. Since, industrial PV systems are operated in both high and low concentration ranges, the design of more accurate model is essential. Valentínyi et al. modified further the solution-diffusion model to work within high and low concentration ranges [78].

PV-based desalination occurs in three stages: firstly, the adsorption of water into the membrane, followed by the diffusion of the absorbed water through the membrane evaporation into vapor phase on the other side of membrane and, finally, condensation of the water vapor to produce fresh water. The PV-based desalination is advantageous because of high salt rejection and simple instrumentation of high-salinity feed solutions. In fact, salt rejection efficiency of PV-based desalination for monovalent salts is $\sim 99 \%$ and is independent of the operating conditions because of the non-volatility of salt, high selectivity of membranes, and high density of hydrophilic polymeric membranes or the tunable pore sizes of inorganic membranes [79]. Chemical properties of the membrane materials play the pivotal role in designing high-performance membranes for pervaporative desalination. The most commonly used PV membranes are composed of different types of materials, such as polymer (i.e., crosslinked PVA), inorganic (i.e., NaA zeolite), and polymer-inorganic hybrid materials (i.e., PVA-MA) [80-85].

Recent developments in separation and purification technologies coupled with advanced nanotechnology are becoming one of the most potential areas for resolving burning issues of water decontamination. The emerging tailor-made nanostructured membranes are continuously changing the concept of separation techniques, building up new methodologies, which surpass the conventional achievements. Though novel nano-enabled composite membranes have attracted wide attention in UF [86-88], NF [89,90], and FO [91], few studies have addressed their potential applications towards PV-based desalination. The quest for the development of superior membrane materials to overcome the 'trade-off' relationship in membrane separation is going on. Fabrication of novel polymeric materials and distinct nanomaterials, and the development of cost-effective superior stable modular design open the path towards the feasible commercialization of PV separation system. This review article discusses the current research and development of polymeric membranes for desalination via PV in relation to their synthesis and fabrication techniques, application approaches, challenges, and possibilities.

\section{A Brief History of Membranes in Pervaporative Desalination}

Desalination had been used thousands years ago by the Greek sailors to obtain fresh water via boiling of saline water and the Romans to trap salt using clay filters. The desalination of sea water to obtain drinking has a long and rich history (Table 1). Desalination was firstly used by Aristotle in 350 B.C.E. Man has always considered the sea for the hope of obtaining drinking water. The concept of desalination is based on evaporation and was initially proposed centuries ago. However, it could not be incorporated into boats until the sixteenth century, allowing them to be self-sufficient in the event of an emergency. Before World War-II, desalination-based evaporation was frequently employed in boats, crossing oceans on long trans-Atlantic voyages. In this context, MSFD, the first large-scale modern desalinating process, was evolved in 1955 in USA. Although MED had been discovered earlier and had greater potential than MSF, it took longer for the MED process to be efficient industrially. The first MED plant was constructed in Aruba in 1959. The modern sophisticated methods still use the concepts 
of distillation (Figure 1). There are about 15,000 desalination plants around the world, of which the biggest plants are mostly located in UAE, Saudi Arabia, and Israel. Australia's first major seawater desalination plant was commissioned in Perth in 2006 that has the capacity of producing 45 billion liters per year.

Distillation-based technologies remained the primary approach to water desalination until the development of membranes, though such techniques suffer from certain limitations (Table 1). One such major limitation includes thermal desalination, which consumes a very high amount of energy and is, therefore, replaced by RO membranes. Membrane technologies arose because of a breakthrough in the use of polymer films for separating salt from water in the late 1950s/early 1960s. Reid and Breton in 1959 [92] first demonstrated the possibility of desalination using polymeric cellulose films, which led to the development of the first ever polymeric RO membranes in 1960 from CA. This membrane was capable of selective passage of water at a reasonable rate of flow under high pressure via blocking salts. In 1963, Loeb and Sourirajan [93] reported the use of an asymmetric CA membrane for desalination. However, the permeability of such early membranes were low, and RO membranes were better considered to be a novelty separation technique rather than desalination. Later, development of novel innovation in packaging of large membrane areas into small volumes as spiral wound modular configuration by General Atomics in 1963 opened the path for commercial applications. Such a spiral-wound configuration is now common in RO applications. Previously, membranes were either several-micron-thick polymer layers with a uniform architecture or similar-size polymer layers with an "asymmetric" structure with a nonporous salt-rejecting top surface opening up to a more porous support. In 1981, Cadotte patented the design of a three-layer TFC membrane of high permeability and, simultaneously, high water selectivity that is now the standard for industrial applications.

PV is another membrane-based process, which has attracted increasing interest as a potential separation technique because of high selectivity and low energy consumption. The history of PV initiated in way back 1910, when Kober defined the term 'per-vaporation' via abbreviating 'permeation' and 'evaporation' after observing the selective permeation of water through the collodion and parchment membrane [94]. The process was first studied systematically to separate organic mixtures by Binning and co-workers at American Oil in the 1950s [95] and followed up in the 1970s by Aptel, Neel, and others [96]. By the 1980s, advances in membrane technology made it possible to prepare economically viable PV systems. The first commercial system for dehydration of azeotropic ethanol-water mixtures was installed by GFT in 1982. Since then, more than 100 plants have been installed for this application, of which the largest one was mounted in Bethenville, France, carrying the capacity of producing $5000 \mathrm{~kg} \mathrm{~h}^{-1}$ of ethanol [97]. The second commercial application of PV was the removal of traces of VOCs from contaminated water. This technology was developed by Membrane Technology and Research with the first commercial plant was installed in 1996 [98].

Desalination by PV is a combination of diffusion of water through a membrane, followed by evaporation into vapor phase on the other side of the membrane to produce fresh water (Figure 2). Although its application in desalination is rare, PV has been proved to be feasible and possesses few advantages for desalination, of which the primary advantage is significantly high salt rejection of monovalent salts $(>99 \%)$ in PV $[99,100]$. The extent of salt rejection is independent of any variation in operating conditions. Issues, such as membrane wetting, salt leakage, and pore-plugging, are not serious in PV. The hydrophilic nature of PV membrane imparts beneficial desalination from feed solutions, along with the better anti-fouling property as compared to other membrane-based techniques, such as MD. Moreover, PV desalination does not require overcoming the osmotic pressure of the feed water. Thus, it can handle highly concentrated salt water without much adjustment in the driving force, which is related to $\triangle \mathrm{VP}$ across the membrane. PV is projected as a feasible method in treating produced water from the mineral oil and natural gas extraction industries [101,102]. Pervaporative desalination is an efficient way of getting fresh water from non-potable saline sources with the advantage lying in its excellent salt rejection and capability of handling high-salinity solution. 


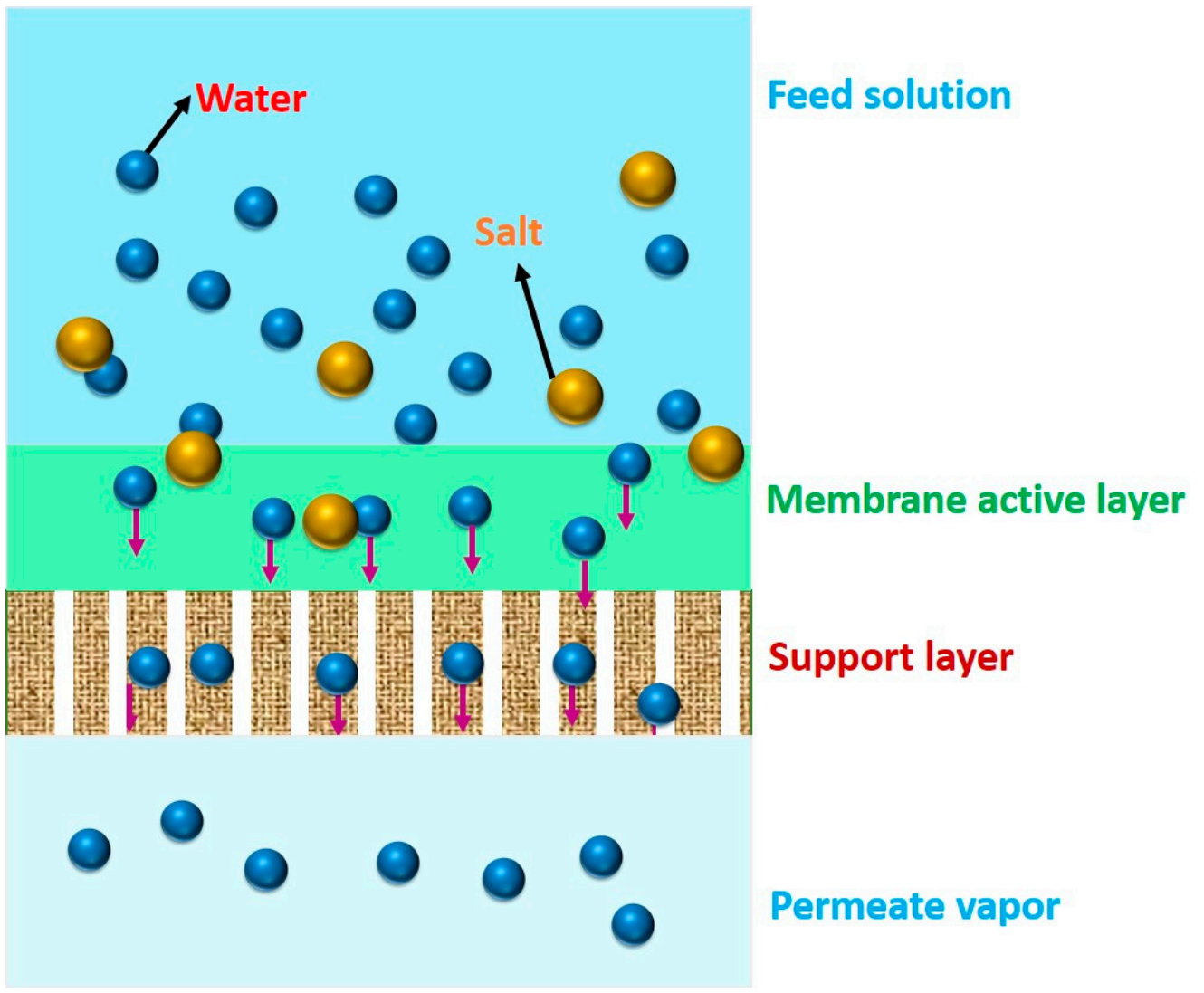

Figure 2. Desalination by the PV process where water passes through a dense PV membrane.

Although, PV possesses several advantages towards desalination, very few studies have been conducted in this field. So far, the best reported PV membranes are cellulose, organic-inorganic composite, silica, ionic polyethylene, and various polyether membranes, with the breakthrough water flux being reported for GO-PAN membrane. Such GO-PAN composite membranes have exhibited great potential for pervaporative desalination because of high flux of $3.62 \mathrm{~kg} \mathrm{~m}^{-2} \mathrm{~h}^{-1}$ and salt rejection of $~ 99.8 \%$ at $90{ }^{\circ} \mathrm{C}$ [50]. In recent years, there has been substantial interest in organic-inorganic hybrid membranes made of polymer matrix and inorganic NPs. Several kinds of inorganic NPs, such as $\mathrm{SiO}_{2}, \mathrm{Al}_{2} \mathrm{O}_{3}, \mathrm{Fe}_{3} \mathrm{O}_{4}, \mathrm{ZnO}, \mathrm{ZrO}_{2}, \mathrm{CdS}$, and $\mathrm{TiO}_{2}$, have been introduced into polymer matrices to prepare polymer-inorganic NP membranes. Inorganic particles have been dispersed in polymeric matrices for the preparation of dense or porous composite membranes carrying adaptable physical properties achieved during blending the properties of both organic polymers and inorganic dispersed particles. Polymer-clay hybrid NCPs have proven to be of immense interest because of the enhanced mechanical and thermal properties, reduced thermal expansion, gas permeability, and minimum swelling. There has been growing interest in discovering novel applications of porous carbon because of its ability to interact with molecules at their surfaces and within the bulk. PDMS-CMS, PVA-CNT, and PVA-graphite composites have been used for the removal of benzene from aqueous solution and separation of benzene-cyclohexane mixtures [103-106]. The development of a new type of polymer-inorganic hybrid membrane based on PVA-MA-silica for pervaporative desalination has been reported recently [46]. The hybrid membrane was synthesized via the sol-gel route using TEOS as the silica precursor with MA as an additional crosslinking agent. A water flux of $6.93 \mathrm{~kg} \mathrm{~m}^{-2} \mathrm{~h}^{-1}$ with salt rejection of $>99.5 \%$ was achieved at $799.93 \mathrm{~Pa}$ vacuum and $22{ }^{\circ} \mathrm{C}$. Another study reported the development of clinoptilolite-phosphate composite membrane for PV-based water desalination that showed high water fluxes of $15 \mathrm{~kg} \mathrm{~m}^{-2} \mathrm{~h}^{-1}$ and over $95 \%$ sodium removal in desalination of $1400 \mathrm{ppm}$ saline water within $25-95{ }^{\circ} \mathrm{C}$ [107]. The future growth of the process will still be strongly dependent on the improvement of current membranes or development of novel membrane materials. 
Table 1. Chronological order relating to the development of pervaporative desalination by different membranes.

\begin{tabular}{|c|c|c|c|c|c|}
\hline Year & Polymer/Composite/ NCP Membranes & Fabrication Process & Advantages & Drawbacks & Ref \\
\hline 1996 & Sulfonated polyethylene hollow fibers & Not reported & $\begin{array}{l}\text { a. Superior control of operational parameters; } \\
\text { b. Optimized pressure drop and reduced energy } \\
\text { for water/ air circulation } \\
\text { c. Desalinated water is free of organic substances }\end{array}$ & a. low production rates per unit area & [41] \\
\hline 2005 & polyetheramide-based polymer film & Yet to be disclosed & $\begin{array}{l}\text { a. Utilization of renewable, non-conventional } \\
\text { energy resources } \\
\text { b. Simple construction, operation, } \\
\text { and maintenance } \\
\text { c. Utilization of dense membranes prevent } \\
\text { wetting induced salt leakage and pore-plugging } \\
\text { problems are anticipated not to occur }\end{array}$ & $\begin{array}{l}\text { a. yet to be commercialized } \\
\text { b. low production rates per unit area }\end{array}$ & [43] \\
\hline 2008 & NaA zeolite & $\begin{array}{l}\text { Direct hydrothermal synthesis on } \\
\text { porous } \alpha \text {-alumina support }\end{array}$ & $\begin{array}{l}\text { a. Higher thermal, chemical and mechanical } \\
\text { resistance } \\
\text { b. Improved SR }{ }^{\text {ab }} \text { efficiency }\end{array}$ & higher production cost & [108] \\
\hline 2009 & $\mathrm{CTS}^{\mathrm{a}}$ membranes & $\begin{array}{l}\text { Two-step sol-gel } \\
\text { catalyzed process }\end{array}$ & $\begin{array}{l}\text { Maximum } \mathrm{NaCl} \text { rejection and flux are } 97 \% \text { and } \\
3 \mathrm{~kg} \mathrm{~m}^{-2} \mathrm{~h}^{-1} \text {, respectively for membrane derived } \\
\text { from the longest carbon chain (C16) surfactant }\end{array}$ & $\begin{array}{l}\text { a. unstable during desalination, as water } \\
\text { interacted with the silanol groups and } \\
\text { enlarged pore sizes of microporous } \\
\text { silica film. }\end{array}$ & [109] \\
\hline 2010 & Hydroxy sodalite membrane & $\begin{array}{l}\text { Surface of a polished-alumina } \\
\text { disk ( } 25 \mathrm{~mm} \text { diameter, } 2 \mathrm{~mm} \\
\text { thickness, } 80 \mathrm{~nm} \text { top layer pore } \\
\text { size, and } 150 \mathrm{~nm} \text { bottom layer } \\
\text { pore size })\end{array}$ & - & $\begin{array}{l}\text { a. poor particle dispersion driven } \\
\text { inferior polymer-inorganic interactions } \\
\text { and structural defects in the membrane }\end{array}$ & [79] \\
\hline 2011 & NaA zeolite & $\begin{array}{l}\text { Secondary growth process, with a } \\
\text { single-channel porous } \alpha \text {-alumina } \\
\text { tube applied as a support. }\end{array}$ & $\begin{array}{l}\text { a. Improved thermal, chemical, and mechanical } \\
\text { resistance } \\
\text { b. Appreciable SR efficiency }\end{array}$ & $\begin{array}{l}\text { a. higher production cost } \\
\text { b. poor particle dispersion driven } \\
\text { inferior polymer-inorganic interactions } \\
\text { and structural defects in the membrane }\end{array}$ & [81] \\
\hline 2011 & Hybrid PVA ${ }^{b} / M^{c} /$ silica membrane & Aqueous sol-gel route & $\begin{array}{l}\text { a. Crosslinking among three components resulting } \\
\text { higher crosslinking density and better SR }\end{array}$ & - & [46] \\
\hline 2011 & $\begin{array}{l}\text { Silicalite-polyamide } \\
\text { composite membranes }\end{array}$ & Interfacial polymerization & $\begin{array}{l}\text { a. Capable to desalinate saline water of } \\
\text { exceptionally high initial concentration at } \\
\text { a significantly higher flux and SR }\end{array}$ & - & [110] \\
\hline 2011 & LTA $^{\mathrm{d}}$ and MFI zeolite & $\begin{array}{l}\text { Hydrothermal synthesis on the } \\
\text { surface of an } \alpha \text {-alumina } \\
\text { porous support. }\end{array}$ & $\begin{array}{l}\text { a. Better thermal, chemical, mechanical resistances } \\
\text { b. Improved SR efficiency }\end{array}$ & - & [111] \\
\hline
\end{tabular}


Table 1. Cont

\begin{tabular}{|c|c|c|c|c|c|}
\hline Year & Polymer/Composite/ NCP Membranes & Fabrication Process & Advantages & Drawbacks & Ref \\
\hline 2011 & Templated silica & $\begin{array}{l}\text { Interfacial polymerization on a } \\
\text { commercial polysulfone substrate }\end{array}$ & - & - & [112] \\
\hline 2012 & $\begin{array}{l}\text { hydrophilic polyester tubular } \\
\text { pervaporative membrane }\end{array}$ & $\begin{array}{l}\text { grown hydrothermally on the } \\
\text { surface of an } \alpha \text {-alumina } \\
\text { porous support }\end{array}$ & - & - & [102] \\
\hline 2012 & $\mathrm{~S}-1{ }^{\mathrm{e}}$ and $\mathrm{ZSM}-5^{\mathrm{f}}$ membranes & $\begin{array}{l}\text { Secondary growth on tubular } \\
\text { ceramic supports }\end{array}$ & a. Mechanically stronger and durable & a. higher production cost & [55] \\
\hline 2012 & Dense natural zeolite & $\begin{array}{l}\text { Membranes were sliced as sheets } \\
\text { from the as-mined material after } \\
\text { a visual inspection }\end{array}$ & $\begin{array}{l}\text { a. High temperature stability } \\
\text { b. Higher thermal, chemical, mechanical } \\
\text { resistances, along with significant SR efficiency }\end{array}$ & $\begin{array}{l}\text { a. poor particle dispersion driven } \\
\text { inferior polymer-inorganic interactions } \\
\text { and structural defects in the membrane }\end{array}$ & [113] \\
\hline 2014 & Cellulose triacetate membrane & Dip-coating membrane & - & - & [101] \\
\hline 2014 & $\begin{array}{l}\text { Natural zeolite clinoptilolite-phosphate } \\
\text { composite }\end{array}$ & $\begin{array}{l}\text { Dry powder pressing followed by } \\
\text { high temperature steaming }\end{array}$ & $\begin{array}{l}\text { a. Higher thermal, chemical, mechanical } \\
\text { resistances, along with significant SR efficiency }\end{array}$ & - & [107] \\
\hline 2014 & PVA $^{\mathrm{b}}$ (uncrosslinked)/PAN $\mathrm{g} / \mathrm{PET}^{\mathrm{h}}$ & $\begin{array}{l}\text { Electrospraying and } \\
\text { electrospinning }\end{array}$ & $\begin{array}{l}\text { a. PAN nanofiber provided necessary } \\
\text { mechanical strength }\end{array}$ & - & [80] \\
\hline 2015 & $\begin{array}{l}\text { MA }^{\mathrm{c}} \text { crosslinked PVA }{ }^{\mathrm{b}} / \mathrm{PVSF}^{j} \\
\text { hollow fiber }\end{array}$ & $\begin{array}{l}\text { Direct spinning and phase } \\
\text { inversion }\end{array}$ & $\begin{array}{l}\text { a. PVSF hollow fiber provided mechanical } \\
\text { strength, chemical resistance, and thermal stability }\end{array}$ & - & [114] \\
\hline 2015 & Mesostructured CTAB ${ }^{\mathrm{k}}$-silica membrane & - & - & - & [115] \\
\hline 2015 & $\mathrm{GO}^{1} / \mathrm{PAN}^{\mathrm{g}}$ composite membrane & $\begin{array}{l}\text { Vacuum filtration-assisted } \\
\text { assembly method }\end{array}$ & a. Exfoliated distribution of GO particles & $\begin{array}{l}\text { a. higher production cost } \\
\text { b. poor particle dispersion driven } \\
\text { inferior polymer-inorganic interactions } \\
\text { and structural defects in the membrane }\end{array}$ & {$[50]$} \\
\hline 2016 & GOF $^{\mathrm{m}}$ membrane & $\begin{array}{l}\text { Vacuum filtration of GOF } \\
\text { suspension }\end{array}$ & $\begin{array}{l}\text { a. Outstanding water permeability } \\
\text { b. Preferential water adsorption ability and fast } \\
\text { water diffusivity }\end{array}$ & $\begin{array}{l}\text { a. higher production cost } \\
\text { b. poor mechanical strength and } \\
\text { susceptible to destruction during } \\
\text { practical applications. }\end{array}$ & [116] \\
\hline 2016 & $\begin{array}{l}\mathrm{GOF}^{\mathrm{m}} \text { membranes PDI }{ }^{\mathrm{n}} \text {-modified } \\
\alpha-\mathrm{Al}_{2} \mathrm{O}_{3}\end{array}$ & $\begin{array}{l}\text { Vacuum filtration of GOF } \\
\text { suspension }\end{array}$ & $\begin{array}{l}\text { a. Thick GO membranes equipped with enhanced } \\
\text { mechanical stability. }\end{array}$ & - & [116] \\
\hline 2017 & nanohybrid GO ${ }^{1} / \mathrm{PI}^{\circ} \mathrm{MMMs}{ }^{\mathrm{p}}$ & $\begin{array}{l}\text { Phase inversion in a water } \\
\text { coagulation bath }\end{array}$ & $\begin{array}{l}\text { a. higher desalination performance } \\
\text { b. stable under harsh conditions }\end{array}$ & $\begin{array}{l}\text { a. low packing density. } \\
\text { b. higher production cost }\end{array}$ & [117] \\
\hline 2017 & $\mathrm{PVA}^{\mathrm{b}}-\mathrm{SiO}_{2} / \mathrm{PVSF}^{\mathrm{j}}$ hollow fiber & $\begin{array}{l}\text { Direct spinning and phase } \\
\text { inversion }\end{array}$ & $\begin{array}{l}\text { a. PVSF hollow fiber provided mechanical } \\
\text { strength, chemical resistance, and thermal stability } \\
\text { b. } \mathrm{SiO}_{2} \text { filler mediated crosslinks }\end{array}$ & $\begin{array}{l}\text { a. complicated and time-consuming } \\
\text { to fabricate }\end{array}$ & [118] \\
\hline
\end{tabular}


Table 1. Cont

\begin{tabular}{|c|c|c|c|c|c|}
\hline Year & Polymer/Composite/ NCP Membranes & Fabrication Process & Advantages & Drawbacks & Ref \\
\hline 2017 & $\begin{array}{l}\text { PEBA }{ }^{q} / \text { PAN }^{\mathrm{g}} / \mathrm{PE}^{\mathrm{r}}, \text { PEBA }^{\mathrm{q}} / \mathrm{PSF}^{\mathrm{s}} / \mathrm{PE}^{\mathrm{r}}, \\
\text { PEBA }^{\mathrm{q}}+\mathrm{NaX} / \mathrm{PSF}^{\mathrm{s}} / \mathrm{PE}^{\mathrm{r}}\end{array}$ & Solution mixing and casting & $\begin{array}{l}\text { a. Soft and flexible segments } \\
\text { b. High sorption of water vapor }\end{array}$ & $\begin{array}{l}\text { a. yet to be scaled up and } \\
\text { commercialized }\end{array}$ & [119] \\
\hline 2017 & zeolite 3A/PEBA q & Solution mixing and casting & $\begin{array}{l}\text { a. Molecular sieving effect of the zeolite 3A cages } \\
\text { improved SR } \\
\text { b. Better chemical resistance and higher } \\
\text { SR efficiency }\end{array}$ & a. higher production cost & [120] \\
\hline 2017 & GNPs ${ }^{\mathrm{t}} / \mathrm{PEBA}^{\mathrm{q}}$ & Solution mixing and casting & a. superior antifouling property & - & [121] \\
\hline 2017 & $\mathrm{SSA}^{\mathrm{u}}$ crosslinked PVA ${ }^{\mathrm{b}} / \mathrm{PAN}^{\mathrm{g}}$ & Solution mixing and casting & $\begin{array}{l}\text { a. Improved flux owing to Sulfonic acid bearing } \\
\text { crosslinks } \\
\text { b. PAN provided mechanical strength and } \\
\text { thermal stability }\end{array}$ & $\begin{array}{l}\text { water-soluble PVA is to be crosslinked to } \\
\text { increase the stability in water }\end{array}$ & [122] \\
\hline 2017 & $\mathrm{GA}^{\mathrm{i}}$ crosslinked PVA $^{\mathrm{b}} / \mathrm{PVDF}^{\mathrm{v}}$ & Dip coating and cast-coating. & $\begin{array}{l}\text { a. Excellent storage stability, anti-fouling } \\
\text { properties, and cleaning efficiency }\end{array}$ & $\begin{array}{l}\text { a. low desalination productivity and } \\
\text { poor operational stability with brine } \\
\text { feeds. }\end{array}$ & [123] \\
\hline 2018 & thin PIM- $1{ }^{\mathrm{w}}$ membrane & $\begin{array}{l}\text { Dispersing GO into PI through } \\
\text { wet phase inversion method }\end{array}$ & $\begin{array}{l}\text { a. PI possesses good thermal and mechanical } \\
\text { stability, easy processing and good solubility in } \\
\text { various common solvents }\end{array}$ & $\begin{array}{l}\text { a. PI membrane was affected by polymer } \\
\text { concentration, evaporation time and post } \\
\text { casting annealing, substantiated by the } \\
\text { molecular weight cut-off curve }\end{array}$ & [124] \\
\hline 2018 & MWCNT-PVA $^{x}$ & Solution mixing and casting & $\begin{array}{l}\text { Good film formability; higher hydrophilicity } \\
\text { introduced by OH and COOH; superior } \\
\text { antifouling property; improved SR, durability, } \\
\text { electrical conductivity; higher adsorption and } \\
\text { water fluxes }\end{array}$ & costly & [125] \\
\hline 2018 & $\mathrm{GO}^{1} / \mathrm{PI}^{\circ}$ hollow fiber & $\begin{array}{l}\text { Direct spinning and phase } \\
\text { inversion }\end{array}$ & - & - & [126] \\
\hline 2018 & $\mathrm{GO}^{1 / C S} \mathrm{CS}^{2}$ & Solution mixing and casting & $\begin{array}{l}\text { a. mechanically stable via covalent crosslinking } \\
\text { between epoxy of GO with amine of CS }\end{array}$ & - & [114] \\
\hline 2018 & PMDA $^{\mathrm{z}}$ crosslinked PVA ${ }^{\mathrm{b}} / \mathrm{PAN}^{\mathrm{g}}$ & Solution mixing and casting & a. PAN provided mechanical strength & - & [127] \\
\hline 2018 & SPTA $^{\text {aa }}$ crosslinked PVA ${ }^{b} /$ PAN $^{g}$ & Solution mixing and casting & $\begin{array}{l}\text { a. Sulfonic acid containing crosslinks improved } \\
\text { flux } \\
\text { b. PAN provided mechanical strength }\end{array}$ & - & [128] \\
\hline
\end{tabular}

${ }^{\mathrm{a}}$ carbon template silica, ${ }^{\mathrm{b}}$ polyvinyl alcohol, ${ }^{\mathrm{c}}$ maleic acid, ${ }^{\mathrm{d}}$ linde type $\mathrm{A},{ }^{\mathrm{e}}$ silicalite- $1,{ }^{\mathrm{f}}$ Zeolite Socony Mobil-5, ${ }^{\mathrm{g}}$ polyacrylonitrile, ${ }^{\mathrm{h}}$ polyethylene terephthalate, ${ }^{\mathrm{i}}$ glutaraldehyde,

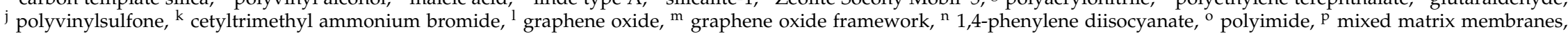
${ }^{\mathrm{q}}$ polyether block amide, ${ }^{\mathrm{r}}$ polyester, ${ }^{\mathrm{s}}$ polysulfone, ${ }^{\mathrm{t}}$ graphene nanoplates, ${ }^{\mathrm{u}}$ sulfosuccinic acid, ${ }^{\mathrm{v}}$ polyvinylidene difluoride, ${ }^{\mathrm{w}}$ polymers of intrinsic microporosity, ${ }^{\mathrm{x}}$ multi-walled carbon nanotubes loaded polyvinyl alcohol membranes, ${ }^{\mathrm{y}}$ chitosan, ${ }^{\mathrm{z}}$ pyromellitic dianhydride, ${ }^{\text {aa }} 4$-sulfophthalic acid, and ${ }^{\text {ab }}$ salt rejection. 


\section{Polymeric Membranes for Pervaporative Desalination}

The use of polymeric membranes for pervaporative desalination is gaining high insight (Table 2). In the past, Korngold, Korin, and coworkers attempted desalination using polyethylene-based ion-exchange membranes [41,42]. Zwijnenberg et al. [43] studied pervaporative desalination using a tubular non-porous polyether amide membrane composed of $\varepsilon$-caprolactam and a mixture of poly(ethylene oxide) and poly(propylene oxide), bearing $40 \mu \mathrm{m}$ thickness in a solar-driven PV chamber. Indeed, membranes based on polyether amide-based polymers were selected because of their higher swelling ability in water, accompanied by reasonably elevated permeability. Zwijnenberg et al. [43] showed that the pretreatment of highly-concentrated feed-water was not essential for the solar-driven pervaporation setup, as the deposition of fouling salts onto the membrane were almost negligible. Another polyether ester-based polymeric membrane developed by DuPont was utilized in pervaporative desalination of brackish- and contaminated-waters to obtain suitable water for irrigation [129]. Materials, such as polyester-based thermoplastic block copolymer and polyester supported cellulose triacetate membrane were employed as effective pervaporation membranes shoeing substantial flux and selectivity $[101,130]$. Again, cellulose containing the microstructures of densely packed polymer chains assembled via intermolecular $\mathrm{H}$-bonds can potentially be used as membrane material for pervaporative desalination. Desalination performances of a series of hydrated cellulose derived from plant cellulose (i.e., wood or cotton), and bacterial cellulose membranes fabricated via surface cultivation of Acetobacterxylinum have been studied [131]. All of these membranes have demonstrated $\sim 100 \%$ salt rejection at $40^{\circ} \mathrm{C}$ at the feed concentration of $40 \mathrm{~g} \mathrm{~L}^{-1}$. Thereafter, Naim et al. [132] obtained the maximum flux of $5.97 \mathrm{~kg} \mathrm{~m}^{-2} \mathrm{~h}^{-1}$ for the pervaporative desalination of $40 \mathrm{~g} \mathrm{~L}^{-1} \mathrm{NaCl}$ solution at $70^{\circ} \mathrm{C}$ through a super-hydrophilic CA membrane synthesized via simple phase inversion method.

\subsection{Synthesis}

Various synthesis methodologies are available for preparing polymeric membranes suitable for pervaporative desalination, of which phase-inversion technique is the most widely used. For synthesizing cellulosic membrane via this method, CA powder was completely dissolved in the mixture of solvents containing acetone, dimethyl phthalate, and DMF. Then, the as-prepared solution was left for 2 days to remove air bubbles, so that the dried membrane will be devoid of defects incorporated through air bubbles. After that, the mixture was cast on a Petri dish for solvent evaporation, followed by immersion in ice-cold water, and finally, the membrane was deacetylated via alkali treatment for incorporating more $\mathrm{O}-\mathrm{H}$ required for intermolecular $\mathrm{H}$-bonding dependent film formation.

\subsection{Characterization}

\subsubsection{Morphology}

SEM micrograph of cellulosic membranes indicated the prevalence of asymmetric morphology showing pores of variegated sizes starting from superficial mini-pores at the skin layer to gradually enlarged pores at the bulk of the membrane. Such unique heterogeneous morphology played the pivotal role for elevating salt rejection efficiency. Interestingly, salt rejection ability is related to the presence of skinny layer bearing mini-pores, whereas higher flux was ascribed to the readily available porous structure of the remaining matrix. In this regard, crystalline deposition of organic matters, iron oxide, and other inorganic salts onto the pervaporative membrane [129], along with the associated membrane-fouling are usually investigated by the SEM analyses [43]. The crystalline deposition of characteristic cubic crystals of $\mathrm{NaCl}$ was noted to become scattered all over the surface of the membrane (Figure 6c from Sule 2013). In this regard, a fouling layer creates unwanted clogging at the membrane pores, leading to increased transport resistance against the flow of water. 
Table 2. Properties of polymeric membranes and their performances in pervaporative desalination.

\begin{tabular}{|c|c|c|c|c|c|c|}
\hline Composite/NCP Membranes & Components & $\mathrm{T}_{\mathrm{g}}$ & $\begin{array}{l}\text { Thickness } \\
(\mu \mathrm{m})\end{array}$ & $\begin{array}{l}\text { Degree of } \\
\text { Swelling (\%) }\end{array}$ & Contact Angle & Ref \\
\hline PEBA $^{\mathrm{a}} / \mathrm{PAN}^{\mathrm{b}} / \mathrm{PE}^{\mathrm{c}}$ & $\mathrm{PEBA}^{\mathrm{a}}, \mathrm{PAN}^{\mathrm{b}}, \mathrm{PE}^{\mathrm{c}}$ & - & 11.0 & 21.8 & 53.0 & [119] \\
\hline $\mathrm{PEBA}^{\mathrm{a}} / \mathrm{PSF}^{\mathrm{d}} / \mathrm{PE}^{\mathrm{c}}$ & $\mathrm{PEBA}^{\mathrm{a}}, \mathrm{PSF}^{\mathrm{d}}, \mathrm{PE}^{\mathrm{c}}$ & - & - & 21.8 & 53.0 & [119] \\
\hline $\mathrm{PEBA}^{\mathrm{a}}+\mathrm{NaX} \mathrm{e}^{\mathrm{e}} / \mathrm{PSF}^{\mathrm{d}} / \mathrm{PE}^{\mathrm{c}}$ & $\mathrm{PEBA}^{\mathrm{a}}+\mathrm{NaX}{ }^{\mathrm{e}}, \mathrm{PSF}^{\mathrm{d}}, \mathrm{PE}^{\mathrm{c}}$ & - & - & 21.2 & 53.0 & [119] \\
\hline PVA noncrosslinked TFNPVC ${ }^{f}$ & PVA $^{\mathrm{g}}, \mathrm{PAN}^{\mathrm{b}}, \mathrm{PET}^{\mathrm{h}}$ & - & 0.6 & 180.5 & 48.2 & [80] \\
\hline PVA crosslinked TFNPVC ${ }^{f}$ & PVA $^{g}$, PAN $^{b}$, PET $^{h}$ & - & 0.7 & 14.5 & 63.5 & {$[80]$} \\
\hline S-PVA ${ }^{i}(1: 10) / P A N ~ f i l m s$ & PAN $^{b}$, PVA $^{g}$, SPTA $^{j}$ & - & 0.8 & 150.0 & $46.4 \pm 3.4$ & [128] \\
\hline cellulose triacetate & cellulose triacetate & - & 10.0 & - & $46.1 \pm 3.0$ & [101] \\
\hline cellulose acetate & cellulose acetate & - & $20.0-25.0$ & 99.7 & - & [130] \\
\hline $\mathrm{PE}^{\mathrm{c}}$ & $\mathrm{PE}^{\mathrm{c}}$ & - & 750.0 & 60.0 & - & [102] \\
\hline PVA g/MA k (M-1) & $\mathrm{PVA}^{\mathrm{g}}, \mathrm{MA}^{\mathrm{k}}$ & $366.0-401.0$ & 0.1 & - & 71.5 & [114] \\
\hline PVA g/MA k (M-2) & $\mathrm{PVA}^{\mathrm{g}}, \mathrm{MA}^{\mathrm{k}}$ & $366.0-401.0$ & 0.1 & - & 65.1 & [114] \\
\hline PVA $\mathrm{g} / \mathrm{MA}^{\mathrm{k}}(\mathrm{M}-3)$ & $\mathrm{PVA}^{\mathrm{g}}, \mathrm{MA}^{\mathrm{k}}$ & $366.0-401.0$ & 0.3 & - & 63.2 & [114] \\
\hline PVA g/MA k (M-4) & $\mathrm{PVA}^{\mathrm{g}}, \mathrm{MA}^{\mathrm{k}}$ & $366.0-401.0$ & 0.4 & - & 61.1 & [114] \\
\hline PVA g/MA k $(\mathrm{M}-5)$ & $\mathrm{PVA}^{\mathrm{g}}, \mathrm{MA}^{\mathrm{k}}$ & $366.0-401.0$ & 0.9 & - & 56.5 & [114] \\
\hline PVA $\mathrm{g} / \mathrm{MA}^{\mathrm{k}}(\mathrm{M}-6)$ & $\mathrm{PVA}^{\mathrm{g}}, \mathrm{MA}^{\mathrm{k}}$ & $366.0-401.0$ & 1.0 & - & 52.7 & [114] \\
\hline clinoptilolite-phosphate & $\mathrm{MKP}^{1}, \mathrm{MgO}$ & - & 1300.0 & - & - & [107] \\
\hline CTAB $^{\mathrm{m}_{\text {-silica }}}$ & $\mathrm{CTAB}^{\mathrm{m}}, \mathrm{SiO}_{2}$ & - & 0.2 & - & - & [115] \\
\hline polyether amide & polyether amide & - & 40.0 & - & - & {$[43]$} \\
\hline NaA zeolite membrane & NaA zeolite membrane & - & - & - & - & [81] \\
\hline $\mathrm{GO}^{\mathrm{n}} / \mathrm{PAN}^{\mathrm{b}}$ & $\mathrm{GO}^{\mathrm{n}}, \mathrm{PAN}^{\mathrm{b}}$ & - & $0.1-1.4$ & - & - & {$[50]$} \\
\hline 2D MXene & $\begin{array}{l}M_{n+1} X_{n} T_{x}, \text { where } n=1,2 \text { or } 3, M=\text { early transition metal, } \\
X=C / N \text {, and } T=\text { surface group }(O H, O, \text { or } F)\end{array}$ & - & 0.1 & - & 45.9 & [133] \\
\hline $\mathrm{GO}^{\mathrm{n}} / \mathrm{PVA}^{\mathrm{b}} / \mathrm{PVDF}$ & $0.2 \mathrm{wt} \%$ GO incorporated PVA/PVDM composite & 60.0 & 100.0 & $38.2 \pm 2.1$ & $37.1 \pm 2.3$ & [134] \\
\hline
\end{tabular}


Table 2. Cont

\begin{tabular}{|c|c|c|c|c|c|c|}
\hline Composite/NCP Membranes & Components & $\mathbf{T}_{\mathrm{g}}$ & $\begin{array}{l}\text { Thickness } \\
(\mu \mathrm{m})\end{array}$ & $\begin{array}{l}\text { Degree of } \\
\text { Swelling (\%) }\end{array}$ & Contact Angle & Ref \\
\hline LiCl-SPVA & LiCl, SPTA, PVA & - & 33.1 & - & - & [135] \\
\hline $\mathrm{PEBA}^{\circ}$ & PEBA $^{\circ}$ & - & 100.0 & - & 86.0 & [120] \\
\hline $\begin{array}{l}\text { Zeolite 3A incorporated PEBA } \\
\text { composite membrane }\end{array}$ & Zeolite 3A, PEBA ${ }^{\circ}$ & - & 100.0 & - & $63.0-71.0$ & [120] \\
\hline $\mathrm{CS}^{\circ}$ membrane & CS & 140.6 & $10.0-13.0$ & - & 85.0 & [136] \\
\hline CS/GO MMM P & CS, GO & $143.5-145.3$ & $10.0-13.0$ & - & 77.5 & [136] \\
\hline PVA ${ }^{g}$ dense film & PMDA ${ }^{q}$, PVA $^{g}$ & - & 2.0 & - & 42.1 & [127] \\
\hline $\begin{array}{l}\text { PVA }^{\mathrm{g}} / \mathrm{PAN}^{\mathrm{b}} \text { composite PV } \\
\text { membrane (M-a) }\end{array}$ & $\begin{array}{l}0 \% \text { of the mole concentrations of }-\mathrm{COOH} \text { group of the } \\
\text { hydrolyzed PMDA } \mathrm{q}, \mathrm{PVA} \mathrm{g}, \mathrm{PAN}\end{array}$ & 75.0 & 2.0 & - & - & [127] \\
\hline $\begin{array}{l}\text { PVA }^{\mathrm{g}} / \mathrm{PAN}^{\mathrm{b}} \text { composite PV } \\
\text { membrane }(\mathrm{M}-\mathrm{b})\end{array}$ & $\begin{array}{l}5 \% \text { of the mole concentrations of }-\mathrm{COOH} \text { group of the } \\
\text { hydrolyzed PMDA } q, \text { PVA } \mathrm{g}, \text { PAN }\end{array}$ & 75.0 & 2.0 & 170.5 & 42.1 & [127] \\
\hline $\begin{array}{l}\text { PVA } \mathrm{g} / \mathrm{PAN}{ }^{\mathrm{b}} \text { composite } \mathrm{PV} \\
\text { membrane }(\mathrm{M}-\mathrm{c})\end{array}$ & $\begin{array}{l}10 \% \text { of the mole concentrations of }-\mathrm{COOH} \text { group of the } \\
\text { hydrolyzed PMDA } q, \text { PVA }^{\mathrm{g}}, \text { PAN }^{\mathrm{b}}\end{array}$ & 75.0 & 2.0 & 110.9 & 57.4 & [127] \\
\hline $\begin{array}{l}\text { PVA g/PAN }{ }^{b} \text { composite PV } \\
\text { membrane (M-d) }\end{array}$ & $\begin{array}{l}20 \% \text { of the mole concentrations of }-\mathrm{COOH} \text { group of the } \\
\text { hydrolyzed PMDA } 9 \text {, PVA } \mathrm{g} \text {, PAN }{ }^{\mathrm{b}}\end{array}$ & - & 2.0 & 88.0 & 55.0 & [127] \\
\hline $\begin{array}{l}\text { PVA }^{\mathrm{g}} / \mathrm{PAN}^{\mathrm{b}} \text { composite PV } \\
\text { membrane (M-e) }\end{array}$ & $\begin{array}{l}30 \% \text { of the mole concentrations of }-\mathrm{COOH} \text { group of the } \\
\text { hydrolyzed PMDA } q \text {, PVA }{ }^{\mathrm{g}}, \text { PAN }^{\mathrm{b}}\end{array}$ & - & 2.0 & 90.0 & 52.5 & [127] \\
\hline PVA g/MA k/ Silica & PVA ${ }^{g}$, MA $^{k}$, Silica & - & 10.0 & $36.0 \pm 5.0$ & 51.5 & [100] \\
\hline Polyether ester & Polyether ester & - & 160.0 & - & - & [137] \\
\hline $\mathrm{FAS}^{\mathrm{r}}-\mathrm{Al}_{2} \mathrm{O}_{3}{ }^{\mathrm{s}}$ & 1H,1H,2H,2H-perfluorodecyltriethoxysilane, alumina & - & 23.0 & - & - & [138] \\
\hline FAS- $\mathrm{TiO}_{2}{ }^{\mathrm{t}}$ & $1 \mathrm{H}, 1 \mathrm{H}, 2 \mathrm{H}, 2 \mathrm{H}-$ perfluorodecyltriethoxysilane, titania & - & 23.0 & - & - & [138] \\
\hline $\mathrm{CC}^{\mathrm{u}}$ membrane & Cotton & - & 30.0 & 44.0 & - & [131] \\
\hline WC ${ }^{\mathrm{v}}$ membrane & Wood & - & 30.0 & 28.0 & - & [131] \\
\hline $\mathrm{CDA}^{\mathrm{w}}$ membrane & Cellulose diacetate & - & $3.0-5.0$ & 6.5 & - & [131] \\
\hline GFBC- $-10^{x}$ & Bacterial cellulose & - & 240.0 & - & - & [131] \\
\hline
\end{tabular}


Table 2. Cont.

\begin{tabular}{|c|c|c|c|c|c|c|}
\hline Composite/NCP Membranes & Components & $\mathbf{T}_{\mathrm{g}}$ & $\begin{array}{l}\text { Thickness } \\
(\mu \mathrm{m})\end{array}$ & $\begin{array}{l}\text { Degree of } \\
\text { Swelling (\%) }\end{array}$ & Contact Angle & Ref \\
\hline$B C-D^{y}$ & Bacterial cellulose & - & 40.0 & - & - & [131] \\
\hline Sulfonated $\mathrm{PE}^{\mathrm{z}}$ & Sulfonated polyethylene & - & 100.0 & $25.0-36.0$ & - & [41] \\
\hline Quaternized PE ${ }^{\mathrm{z}}$ & Quaternized polyethylene & - & 70.0 & 31.5 & - & [42] \\
\hline Quaternized PE ${ }^{\mathrm{z}}$ & Quaternized polyethylene & - & 170.0 & 36.5 & - & {$[42]$} \\
\hline S-PVA/PAN ${ }^{b}$ & SSA $^{\text {aa }}$, PVA $^{a}$, PAN $^{b}$ & 113.0 & 4.9 & $83.5 \pm 5.1$ & $77.1 \pm 3.0$ & [122] \\
\hline PVA $\mathrm{g}$ & $\mathrm{PVA}^{\mathrm{g}}$ & 84.0 & 4.9 & $194.3 \pm 10.7$ & $44.3 \pm 2.7$ & [122] \\
\hline $\mathrm{PVA}{ }^{\mathrm{g}} / \mathrm{MA}^{\mathrm{k}}$ & PVA $\mathrm{g}, 20 \% \mathrm{MA}^{\mathrm{k}}$ & 94.0 & 5.0 & $61.0 \pm 5.0$ & $59.4 \pm 2$ & [139] \\
\hline PVA $\mathrm{g} / 20 \mathrm{MA}^{\mathrm{k}} / 10$ Silica & PVA $^{\mathrm{g}}, 20 \% \mathrm{MA}^{\mathrm{k}}, 10 \%$ Silica & 103.0 & 5.0 & $22.0 \pm 2.0$ & $63.5 \pm 2$ & [139] \\
\hline PVA $\mathrm{g} / 20 \mathrm{MA}^{\mathrm{k}} / 25$ Silica & PVA $^{\mathrm{g}}, 20 \% \mathrm{MA}^{\mathrm{k}}, 25 \%$ Silica & 107.0 & 5.0 & $11.0 \pm 1.0$ & $79.4 \pm 2$ & [139] \\
\hline PEBA $^{a}$ & & - & 0.1 & - & 86.0 & [121] \\
\hline $2 \mathrm{GNPs}^{\mathrm{ab}} / \mathrm{PEBA}^{\mathrm{a}}$ & $2.0 \mathrm{wt} \%$ GNP, PEBA ${ }^{a}$ & - & $0.1 / 0.2$ & - & 80.0 & [121] \\
\hline 5 GNPs $^{\text {ab }} /$ PEBA $^{\mathrm{a}}$ & $5.0 \mathrm{wt} \%$ GNP, PEBA $^{a}$ & - & 0.2 & - & 75.0 & [121] \\
\hline $0.3 \mathrm{MWCNT} / \mathrm{PVA}{ }^{\mathrm{ac}}$ & $0.3 \mathrm{wt} \% \mathrm{MWCNT}^{\mathrm{ac}}, \mathrm{PVA}^{\mathrm{g}}$ & - & 100.0 & $275.0-350.0$ & & [100] \\
\hline PI ad hollow fiber & $\begin{array}{l}14.6 \mathrm{wt} \% \mathrm{PI} \text { ad }, 2.0 \mathrm{wt} \% \mathrm{PVP} \text { ae }, 9.1 \mathrm{wt} \% \mathrm{EtOH}, \\
74.3 \mathrm{wt} \% \mathrm{NMP} \text { af }\end{array}$ & - & 1000.0 & - & 92.0 & [126] \\
\hline $\mathrm{GO}^{\mathrm{n}} / \mathrm{PI}^{\text {ad }}$ hollow fiber & $\begin{array}{l}1.0 w \mathrm{t} \% \mathrm{GO}, 14.4 \mathrm{wt} \% \mathrm{PI} \text { ad }, 2.0 \mathrm{wt} \% \mathrm{PVP} \text { af }, 9.0 \mathrm{wt} \% \mathrm{EtOH}, \\
73.6 \mathrm{wt} \% \mathrm{NMP} \text { af }\end{array}$ & - & 1000.0 & - & 59.0 & [126] \\
\hline $\mathrm{CS}^{\circ}$ & $0.1 \mathrm{wt}^{\circ} \% \mathrm{GO}^{\mathrm{n}}, \mathrm{CS}^{\circ}$ & 140.6 & - & - & 85.0 & [136] \\
\hline $1 \mathrm{GO}^{\mathrm{n}} / \mathrm{CS}^{\circ}$ & $1.0 \mathrm{wt}^{\mathrm{o}} \% \mathrm{GO}^{\mathrm{n}}, \mathrm{CS}^{\mathrm{o}}$ & 143.5 & - & - & 77.5 & [136] \\
\hline $2 \mathrm{GO}^{\mathrm{n}} / \mathrm{CS}^{\mathrm{o}}$ & $2.0 \mathrm{wt}^{\circ} \% \mathrm{GO}^{\mathrm{n}}, \mathrm{CS}^{\mathrm{o}}$ & 145.3 & - & - & 77.0 & [136] \\
\hline $\mathrm{PVA}^{\mathrm{g}}-\mathrm{SiO}_{2} / \mathrm{PVSF}$ ag hollow fiber & 52.4:1:1:(1000-67) $=\mathrm{C}_{2} \mathrm{H}_{5} \mathrm{OH}:$ TEOS: $\mathrm{PVA}^{\mathrm{g}}: \mathrm{H}_{2} \mathrm{O}(w / w)$ & 396.0 & $0.2-1.1$ & - & - & [118] \\
\hline
\end{tabular}

${ }^{\mathrm{a}}$ poly(ether block amide) ${ }^{\mathrm{b}}$ polyacrylonitrile,${ }^{\mathrm{c}}$ polyester,${ }^{\mathrm{d}}$ polysulfone, ${ }^{\mathrm{e}}$ sodium halide, ${ }^{\mathrm{f}}$ three-layer thin film nanofibrous PV composite, ${ }^{\mathrm{g}}$ polyvinyl alcohol, ${ }^{\mathrm{h}}$ polyethylene terephthalate, ${ }^{i}$ sulphonic acid functionalized polyvinyl alcohol, ${ }^{j} 4$-sulfophthalic acid, ${ }^{k}$ maleic acid ${ }^{1}$ monopotassium phosphate, ${ }^{m}$ cetyltrimethylammonium bromide-silica, ${ }^{n}$ graphene oxide, ${ }^{\circ}$ chitosan, $\mathrm{p}$ chitosan/graphene oxide mixed matrix membrane, ${ }^{\mathrm{q}}$ pyromellitic dianhydride ${ }^{r}{ }^{r}$ fluoroalkylsilane-ceramic ${ }^{{ }^{s}}$ alumina grafted fluoroalkylsilanes-modified PV ceramic nanofiltration

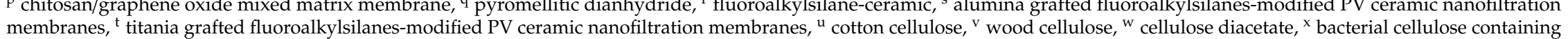
$10 \%$ residual water, ${ }^{\mathrm{y}}$ bacterial cellulose dried to constant weight, ${ }^{\mathrm{z}}$ sulfonated polyethylene hollow fibers, ${ }^{\text {aa }}$ sulfosuccinic acid, ${ }^{\text {ab }}$ graphene nanoplates, ${ }^{\text {ac }}$ multi-walled carbon nanotubes loaded polyvinyl alcohol membranes, ${ }^{a d}$ polyimide, ae polyvinylpyrrolidone, ${ }^{\text {af }}$ N-methyl-2-pyrrolidinone, ag polyvinylsulfone, and ah tetraethylorthosilicate. 


\subsubsection{Mechanical Properties}

Polymeric membranes suitable for pervaporative desalination should possess significant mechanical strength. In this context, the polyether ester-based polymeric membrane developed by DuPont was significantly endurable in terms of mechanical properties.

\subsubsection{Spectroscopy}

FTIR spectroscopy of dried cellulose membranes is essentially carried out to confirm the complete removal of unwanted solvents from membrane, incorporated during synthesis. Additionally, the prevalence of extra $\mathrm{O}-\mathrm{H}$ introduced during deacetylation in cellulose membranes can be monitored through FTIR spectroscopy. In this regard, water affinity of cellulose and their transport properties are mostly dependent on the content of hydroxyl-groups and supramolecular organization, which are in turn governed usually by the origin of the cellulosic materials, along with modifications and drying techniques adopted at the time of membrane fabrication [131]. Accordingly, improved hydrophilic character of super-hydrophilic cellulosic membrane was understood from the appearance of three $\mathrm{O}-\mathrm{H}$ specific str. peaks for each anhydro-glucose unit, coupled with physically adsorbed water-specific peaks within $1640-1630 \mathrm{~cm}^{-1}$ [132].

\subsection{Desalination Performance and Mechanisms}

\subsubsection{Membrane Structure}

Membrane selectivity and mass transfer intensity through membrane are dependent on the physicochemical properties of the membrane-forming monomers and components of liquid mixtures. Both the elevated charge density in the range of $0.8-1.1$ meq g $^{-1}$ and decreased membrane thickness led to a higher water flux through the polyethylene membrane [41,42]. Moreover, charge characteristics of a membrane imparts a substantial influence on the flux and selectivity. Accordingly, it is expected that co-ions would pass through the membranes more readily than the counter-ions, as counter-ions can readily attach with the available opposite charges in the membrane. Additionally, steric factors, such as radius of hydration, may play a dominant role in determining the efficiency of membrane [101]. According to Xie et al. [140], the reduction in FFV of a membrane reduces the diffusivity and permeability of $\mathrm{NaCl}$ as well as the water uptake. In fact, because of the larger kinetic diameter, $\mathrm{NaCl}$ diffusivity is more sensitive towards the change in FFV than water diffusivity. In this regard, the hydrated sizes of $\mathrm{Na}^{+}$and $\mathrm{Cl}^{-}$are $0.72 \mathrm{~nm}$ and $0.66 \mathrm{~nm}$, respectively, whereas the kinetic diameter of water is $0.27 \mathrm{~nm}[99,141,142]$. Thus, selective separation of the desired component from a liquid mixture depends on the competitive diffusion of those components through the free volume units of a membrane. Theoretically, for attaining high selectivity, sizes of the component to be permeated should be comparable to the kinetic diameter of water molecules (i.e., $0.27 \mathrm{~nm}$ ) [131]. Such a low free-volume dimension can only be achieved if the membranes contain structurally ordered segments at the supramolecular level. In case of plant cellulose (i.e., wood or cotton)-derived hydrated cellulose, the molecular architecture is composed of densely packed polymer chains, assembled via intermolecular H-bonds. In fact, relatively lower permeability of cellulose diacetate-treated wood cellulose membrane was attributed to the lower hydrophilic character of the cellulose diacetate components. Moreover, cotton cellulose-based membranes exhibited significantly higher permeability than wood cellulose-based membranes because of the variegated structural features of different celluloses. Furthermore, if the cellulosic membrane contains pores of variable sizes starting from minipores at the skinny layer to the larger pores at the bulk the higher flux and selectivity can be achieved [132]. Such low-cost membranes have been claimed to be more advantageous than some composite membranes prepared involving relatively complicated procedures $[42,80]$. 


\subsubsection{Influence of Feed Temperature}

Temperature is one part of the overall driving forces producing movement of a permeant during the pervaporation process [143]. In this regard, the activation energy of permeation is often used to characterize the temperature dependence of permeation flux. As per Feng and Huang (1996) [144], the permeability of the membrane depends on both diffusivity and solubility of permeate. Since, both diffusion and solubility are temperature dependent, the activation energy of permeation should be expressed by the combination of activation energy of diffusion and enthalpy of dissolution. This is because the enthalpy change due to phase change in pervaporation influences the permeation behavior.

Feed temperature has been found to influence strongly the flux and selectivity. With the increase in feed temperature, the total water flux was found to increase from 2.47 to $3.67 \mathrm{~kg} \mathrm{~m}^{-2} \mathrm{day}^{-1}$ because of the enhanced molecular diffusivity and temperature-assisted reduction in water viscosity [137]. Such phenomenon was also visible for cellulosic membranes, since permeation and diffusion of gases or liquids across polymeric membranes were facilitated with the elevated temperatures [131,132]. However, permeability markedly decreased when the feed volume was not agitated for a significant period of time. Such lowering in permeability was termed as temperature-related polarization caused by regional drop in temperature at the membrane-water interface because of the change in aggregation of water into vapor [145]. Indeed, there is an intimate relationship among water flux, water temperature, and membrane thickness [101]. In general, increased membrane thickness deteriorates the water flux. However, as per Sule et al., water permeation rates remained almost the same when tubes of variable wall thicknesses (i.e., 0.5, 0.6, and $0.75 \mathrm{~mm}$ ) were used as pervaporation membranes. Nevertheless, the permeate flux increases with increased difference in vapor pressures for membranes of varied thicknesses. However, an increase in flux is more pronounced when relatively thinner membranes are employed.

\subsubsection{Influence of Feed Concentration}

In general, it is observed that water permeate flux decreases with the increase in solute concentrations $[42,132,137,146]$ because of the increased concentration polarization adjacent to membrane surface. As expected, a reduced water uptake can be observed when concentrations of any of the salts, such as sodium chloride, magnesium chloride, and aluminum chloride, were increased [102]. It was observed that the sodium chloride tended to induce lower mass gains in the polyester membrane than those of magnesium chloride and aluminum chloride. In fact, the increased concentration of solute, such as sucrose and $\mathrm{NaCl}$, can suppress the swelling of the membrane. Accordingly, the mass transport is affected because of the lesser availability of free volume inside the polymer matrix [42]. Moreover, the impact of enhanced feed concentration in reducing flux is mostly decided by the molecular size of the solute molecules. The presence of relatively bulkier molecules will block the pores of the membrane, leading to significant reduction in water flux. For instance, being larger in size, glucose molecules varying kinetic diameter $=0.86 \mathrm{~nm}$ block water flux more than that of $\mathrm{NaCl}$, bearing a kinetic diameter of $0.30 \mathrm{~nm}$ [147]. Notably, minimal crystalline deposition onto the membrane after $96 \mathrm{~h}$ of uninterrupted pervaporation was actuated by the sweeping air flow at the outer surface of the membrane [137]. In fact, such sweeping air flow assists faster vaporization of moistures and, thus, creates an increased vapor pressure difference between the outer and inner surface of the membrane [101]. In this regard, fouling phenomenon is closely related to the increased feed concentration. Thus, both of these factors jointly contribute in lowering the driving force for transport of water through the membrane. However, the flux in solar-driven pervaporation setup was independent of feed concentrations and not affected by severe fouling resulted from the input of the concentrated feed [43].

\section{Polymer Composite/NCP Membranes}

Xie and co-workers [46,100] fabricated a series of hydrophilic PVA-MA-silica membranes for pervaporative desalination. Thereafter, Liang et al. reported the synthesis of GO-PAN composite 
membranes through a novel vacuum filtration-assisted assembly method which demonstrated high performance potential for pervaporative desalination [50]. Later, the same group fabricated a specialized three-layer composite membrane comprising of nonwoven PET, PVA, and nano-fibrous polyacrylonitrile (PAN) layers [80]. All the as-prepared multilayer composite membranes demonstrated excellent and consistent desalination proficiencies in terms of high water flux and salt rejection up to $99.5 \%$ for different feed concentrations even after $50 \mathrm{~h}$ of non-stop operation. Herein, the through-hole structures of nano-fibrous porous PAN layers encouraged faster evaporation of water passing through the topmost skin layer. Thus, this unique structure provided the possibility to overcome the defects of orthodox support layer prepared by phase inversion, leading to the enhancement of flux of the composite membranes.

Again, the fabrication of a series of PVA-PAN-based composite membranes made of either PMDA or SSA crosslinked PVA coating on the top of the PAN UF membrane have also been reported [122,127]. The PAN support enhanced further mechanical stability to the PVA matrix crosslinked by hydrolyzed PMDA or SSA. Thus, ester-based crosslinks were formed via condensation reaction between $\mathrm{O}-\mathrm{H}$ of PVA and -COOH of either hydrolyzed PMDA (Figure 3) or SSA (Figure 4). Moreover, the unreacted - $\mathrm{COOH}$ facilitated mass transport of water, while the phenyl ring of PMDA segments enhanced the FFV to actuate easier diffusion of water molecules. Accordingly, all PMDA-crosslinked PVA polymer demonstrated high water flux and fair stability in water. Among all of these membranes, the highest pervaporative desalination was achieved for composite membrane carrying $2 \mu \mathrm{m}$ PVA selective layer crosslinked with $20 \mathrm{wt} \%$ of PMDA at $100{ }^{\circ} \mathrm{C}$ for $2 \mathrm{~h}$. For this particular membrane, $\mathrm{NaCl}$ rejection was $\sim 99.98 \%$ and water flux was $32.26 \mathrm{~L} \mathrm{~m}^{-2} \mathrm{~h}^{-1}$ at $70{ }^{\circ} \mathrm{C}$ and $35,000 \mathrm{ppm}$ feed concentration.<smiles>O=c1oc(=O)c2cc3c(=O)oc(=O)c3cc12</smiles>

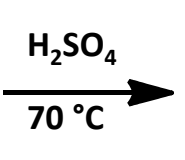<smiles>O=C(O)c1cc(C(=O)O)c(C(=O)O)cc1C(=O)O</smiles><smiles>CCC(O)C(O)C(C)CO[14c]1c[14c](C(=O)O)[14cH][14cH][14cH]1</smiles><smiles>CC(OCC(C)C(C)C)OC(=O)c1cc2c(cc1C(=O)O)C(=O)OC2=O</smiles><smiles>CC(C)[C@H](C)O</smiles>

Figure 3. Crosslinking reaction during PMDA crosslinked PVA fabrication.

On the other hand, the best desalination performance was demonstrated by PVA-PAN composite membrane crosslinked by $18 \%$ SSA [122]. Recently, the same group tried to improve further the overall performance of PAN supported composite membranes via crosslinking PVA components by SPTA [128]. In these composite membranes, the sulfonic acid groups were strategically introduced to maintain the hydrophilicity and high flux of the membrane simultaneously, along with the desired crosslinking level to improve salt rejection (Figures 4 and 5). 


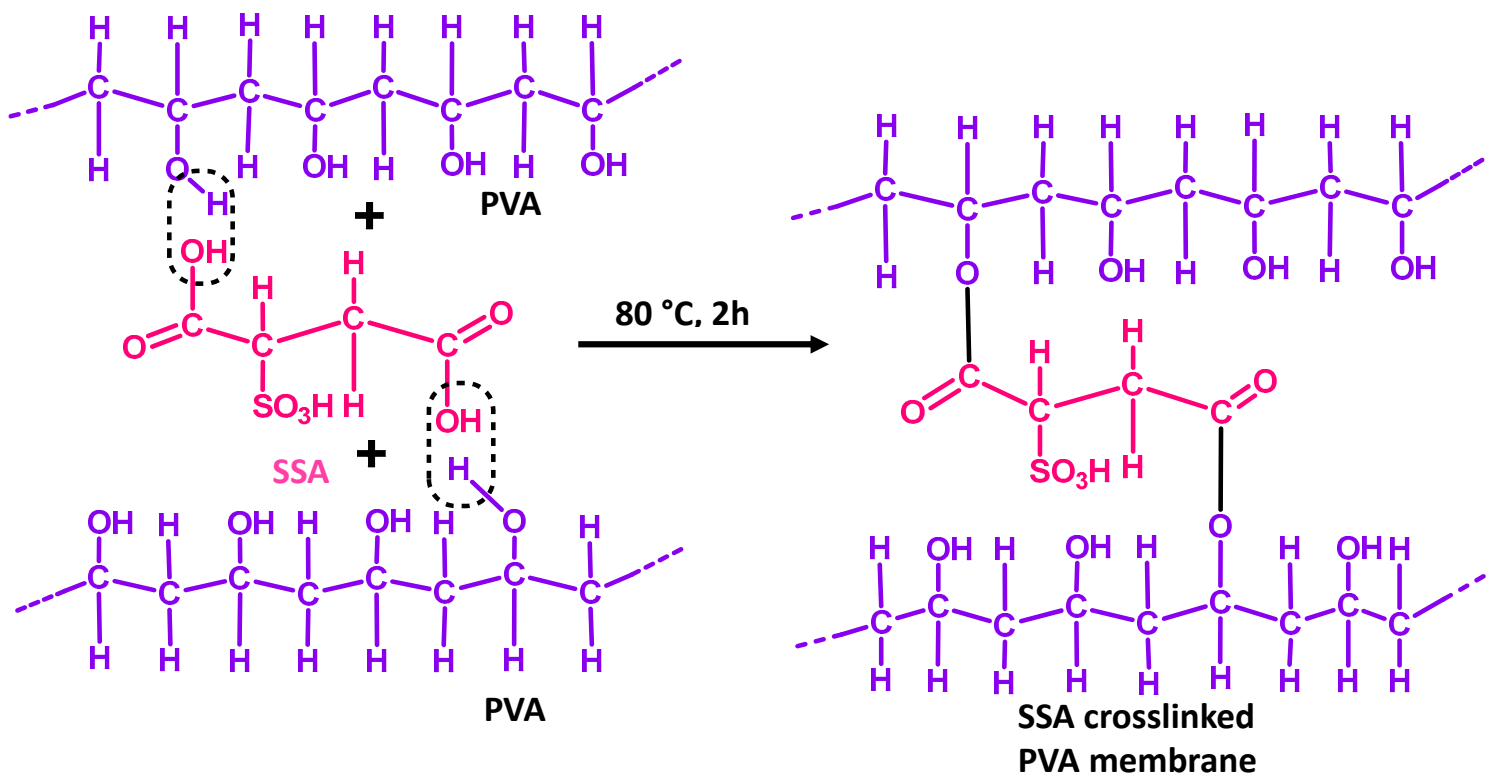

Figure 4. Crosslinking reaction during preparation of SSA crosslinked PVA membrane supported on PAN.<smiles>CCC(O)C(O)C(C)C</smiles><smiles>CCC(O)C(O)C(C)CO</smiles><smiles>O=C(O)c1ccc(S(=O)(=O)O)cc1C(=O)O</smiles><smiles>CCC(C)CC(C)C(C#N)C(=O)O</smiles><smiles>CCCCCCCCCCCC(C)C</smiles>

Figure 5. Crosslinking between alkali treated PAN and PVA by SPTA.

Encouraging results were obtained while working with PEBA-based NCP membranes for desalinating high-salinity water [119]. For all the experiments conducted below $45{ }^{\circ} \mathrm{C}, \sim 99.9 \%$ salt rejection was obtained, along with the attainment of considerable permeate flux. Recently, Nigiz et al. designed zeolite 3A loaded PEBA membrane for pervaporative seawater desalination [120]. In fact, Zeolite $3 \mathrm{~A}$ is a crystalline potassium aluminosilicate, which is derivated from zeolite $4 \mathrm{~A}$ or sodium aluminosilicate. Introduction of zeolite 3A was mostly because of the incorporation of a certain degree of hydrophilicity to the hydrophobic PEBA matrix for successful improvement of water flux and salt rejection. Herein, the molecular sieving effect and H-bonding capability of water within zeolite 3A cages were utilized to increase water flux coupled with higher salt rejection. 
For further improvement of the desalination performance, GNPs have been incorporated in PEBA nanohybrid membranes [121]. In contrast to the earlier used traditional hydrophilic membranes, a hydrophobic PEBA matrix was utilized, along with the added GNPs to enhance the selectivity of membrane. Very recently, a high-performance novel GO-PI hollow fiber composite membrane was fabricated by direct spinning of GO nanosheet-PI suspension via coaxial two-capillary spinning strategy [126]. Another group of researchers prepared an efficient GO hybridized CS-based stable membrane for pervaporative desalination of high-salinity water [136]. In this regard, the possible interactions responsible for higher stability of membrane, such as reaction between epoxy groups of GO sheet and $-\mathrm{NH}_{2}$ of CS chains, and thereby formation of a crosslinked structure comprising of covalent bonds between GO and CS was explored (Figure 6). Other possibilities encompassing the ionic interaction between the $-\mathrm{COO}^{-}$of $\mathrm{GO}$ and $-\mathrm{NH}_{3}{ }^{+}$of $\mathrm{CS}$, along with the strong $\mathrm{H}$-bonding network in stabilizing the MMMs, was analyzed by extensive spectroscopic, thermal, and morphological characterization techniques. Thus, as-prepared highly efficient MMMs demonstrated improved mechanical stability because of fair chemical compatibility of GO with the CS matrix.

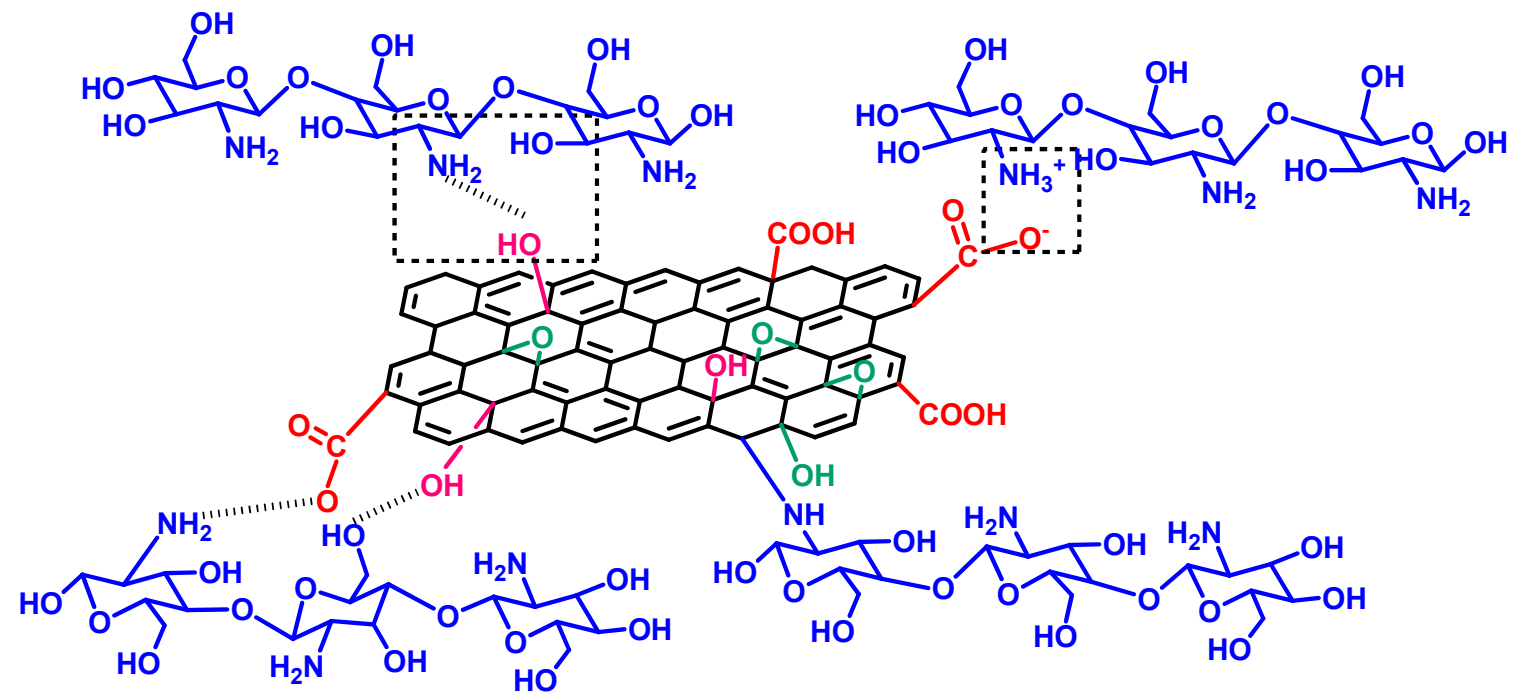

Figure 6. Covalently crosslinked graphene-CS membrane.

Herein, similar to the $\mathrm{O}-\mathrm{H}$ populated cellulose or modified cellulose membranes, composite membranes were fabricated based on O-H populated thin PVA membranes supported on PVS-based hollow fibers [114]. The idea behind the selection of such an assembly was to fabricate a mechanically reinforced membrane capable of faster and easier mass transport, while ensuring higher membrane surface area per molecule. In fact, hollow fibers containing PVS were selected as the supporting layer because of high mechanical strength, chemical resistance, and thermal stability. To improve the performance of the composite hollow membrane, PVS-made hollow fibers were coated with $\mathrm{SiO}_{2}$-incorporated PVA films [118]. Here, the main objective was to reinforce the top PVA layer of the composite membrane through crosslinking between $\mathrm{SiO}_{2}$ moieties and PVA chains, in which the silica precursor acted as both the crosslinker and inorganic filler.

In fact, such mechanical reinforcement was achieved by fabricating MMMs via incorporation of fillers, such as zeolites, (including silicalite-1 [148], ZSM-5 [149], and 4A zeolite [150], functionalized CNTs [151], and magnesium oxide [152]. Additionally, MMMs containing mesoporous inorganic materials, such as dual pore SBA-15 [153] and silica MCM-41 [154,155], have been proposed. Furthermore, MOFs were used to synthesize MMMs because of suitable size, shape, and chemical functionalities of the MOF cavities [156,157]. In this context, Kang et al. synthesized MMM using ZIFs, mainly ZIF-7 embedded in a CS polymer matrix with $5 \mathrm{wt} \%$ MOF loading, for pervaporative removals of water-ethanol mixtures, exhibiting almost a 19 times higher separation factor than that of pure polymer [158]. Hua et al. reported ZIF-90-PI P84 MMMs for the dehydration of isopropanol [159]. 
Again, Kasik and Lin reported the organoselective MMM carrying MOF-5-filler [160]. For ZIF-8-based MMMs, the PV performance of silicone rubber membranes was improved significantly for isobutanol and furfural recovery from their aqueous solutions via introducing ZIF-8 NPs [161,162]. Sorribas et al. reported the use of $\mathrm{MMM}$ containing $\mathrm{MOF} \mathrm{Cu}_{3}(\mathrm{BTC})_{2}$ (i.e., HKUST-1) within the commercial PI Matrimid ${ }^{\circledR} 5218$ as polymer matrix for pervaporative separation of water-ethanol separation with improved water flux [163].

In order to overcome the problems associated with the existence of micro-defects in PVA membrane, variegated procedures were adopted to achieve the best possible solution regarding fabrication of defect-free membranes. In this context, micro-defects of the PVA-PVDF-based composite membrane were explored by comparing the different coating methods, such as dip-coating and cast coating [164], along with the enhancement of the storage stability. Another PVA-like polymer material, i.e., PEBAX, was utilized for fabrication of PV membrane, since PEBAX is similar to PVA with respect to the properties, such as high hydrophilicity and water vapor permeability [165]. Instead of high water vapor permeability, PEBAX-based membranes are not suitable for desalination because of high free volume and flexible rubbery sections, which unselectively transport both water molecules and hydrated salt ions. At lower feed concentration and at higher temperature, sufficient water flux was observed for PEBAX membranes. However, when the $\mathrm{NaCl}$ concentration was increased up to $100 \mathrm{~g} \mathrm{~L}^{-1}$, flux was found to reduce drastically to $2 \mathrm{~L} \mathrm{~m}^{-2} \mathrm{~h}^{-1}$. Later, for the first time, Yilman et al. reported the fabrication of MWCNT doped PVA membrane for pervaporative desalination [100].

\subsection{Synthesis}

\subsubsection{Sol-Gel Method}

Various workers reported the synthesis of polymeric membranes through sol-gel method $[46,100]$. Xie et al. synthesized PVA-MA-silica hybrid membranes using an aqueous route, wherein TEOS and MA were used as silica precursor and additional crosslinker, respectively (Figure 7). Initially, PVA ( $>98 \%$ hydrolyzed and molecular weight $=130,000 \mathrm{~g} \mathrm{~mol}^{-1}$ ) was dissolved in $100 \mathrm{~mL}$ deionized water in a silicone oil bath at $90{ }^{\circ} \mathrm{C}$ to obtain $0.75 \mathrm{wt} \%$ PVA solution, followed by cooling and $\mathrm{pH}$ adjustment at $1.7 \pm 0.1$ by dropwise addition of $\sim 0.5 \mathrm{~mL}$ concentrated $\mathrm{HCl}$ (Figure 7). Then $0.15 \mathrm{~g}$ of MA (weight content of MA with respect to PVA $=20 \mathrm{wt} \%$ ) was added to as-prepared PVA solution and stirred till dissolved completely. In the next step, TEOS and ethanol mixture bearing mass ratio of TEOS:ethanol $=1: 9$ was added dropwise to the above solution with constant stirring. The amount of TEOS should be added to such extent that the weight content of $\mathrm{SiO}_{2}$ with respect to the amount of PVA in the solution should be varied within $10-25 \mathrm{wt} \%$. Thereafter, the reaction was continued at room temperature in acidic environment for $2 \mathrm{~h}$, and the resultant homogeneous mixture was filtered and casted on Petri dishes to attain the desired thickness, followed by air drying. The reaction was carried out in acidic environment for ensuring faster hydrolysis of TEOS rather than condensation of $\mathrm{Si}-\mathrm{OH}$ bonds, so that frequent amount of $\mathrm{Si}-\mathrm{OH}$ groups are allocated for obtaining linear or random branches of silica network [166]. Finally, the obtained film was dried further at $50{ }^{\circ} \mathrm{C}$ overnight and heated to $140{ }^{\circ} \mathrm{C}$ for $2 \mathrm{~h}$ in a fan-forced oven. The main objective of such higher temperature drying was to produce siloxane bonds through condensation reactions among silanol groups $[167,168]$. 


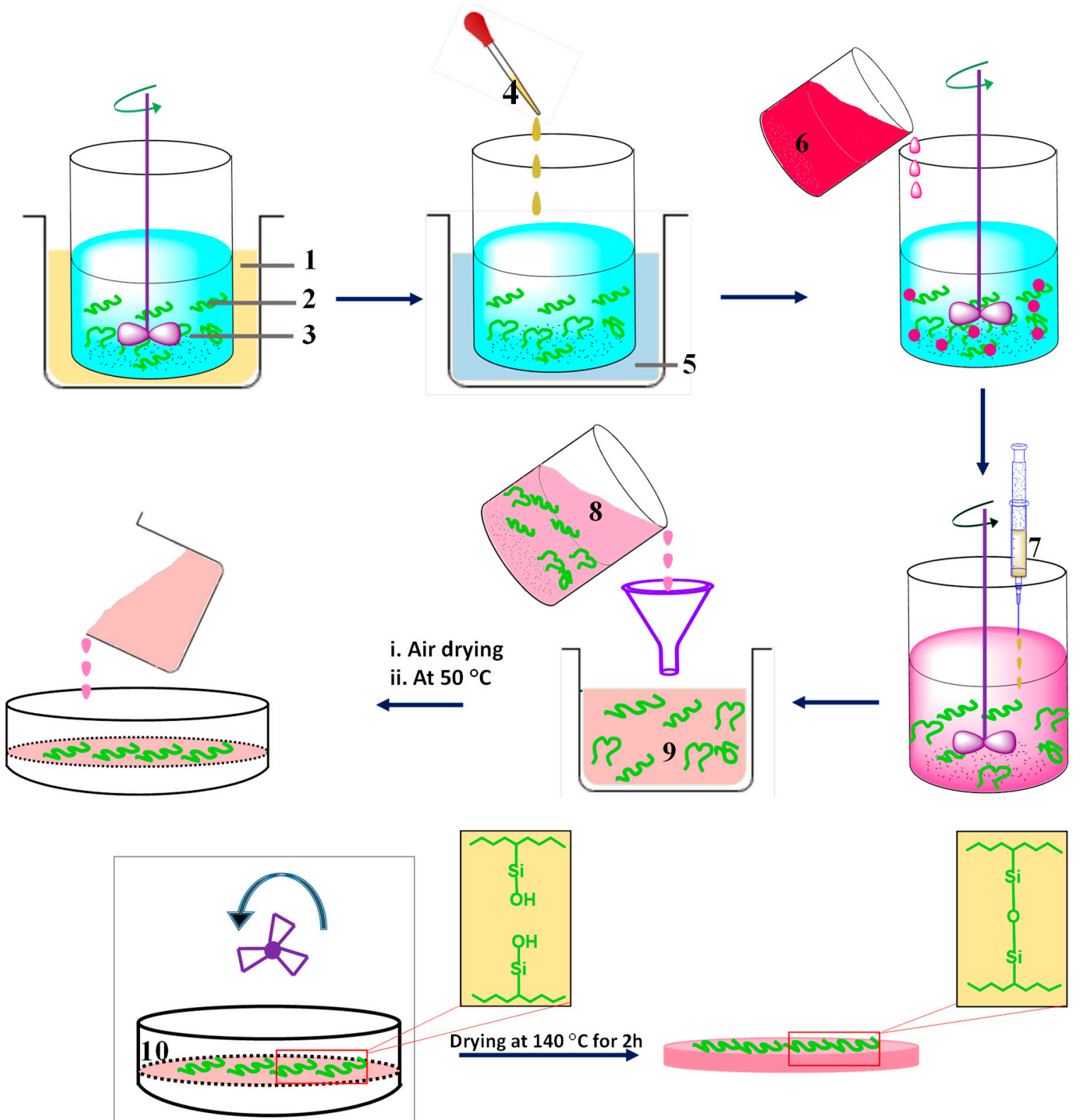

Figure 7. Sol-gel method for preparing PV-membrane: 1. PVA Chains, 2. Silicone oil bath at $90 \mathrm{C}$, 3. Water, 4. Cold water, 5. Concentrated $\mathrm{HCl}, 6$. MA, 7. TEOS-ethanol mixture, 8. Reaction mixture, 9. Filtrate, 10. Membrane film.

\subsubsection{Solution Mixing and Casting}

Few researchers synthesized PEBA-GNP membranes, bearing different quantities of GNPs, using the phase inversion technique (Figure 8) [121]. Initially, $10 \mathrm{wt} \%$ homogeneous PEBA solution was prepared in acetic acid by constant stirring for $5 \mathrm{~h}$ at $60^{\circ} \mathrm{C}$. In another setup, GNPs were dispersed in acetic acid by continuous mixing for $15 \mathrm{~min}$ in an ultrasonicator. Thereafter, the solution of PEBA was admixed to the dispersion of acetic acid-GNPs with constant stirring for another $2 \mathrm{~h}$ at room temperature, followed by solution casting on a Teflon plate to obtain flat membranes of uniform thickness (i.e., $120 \pm 5 \mu \mathrm{m}$ ). 


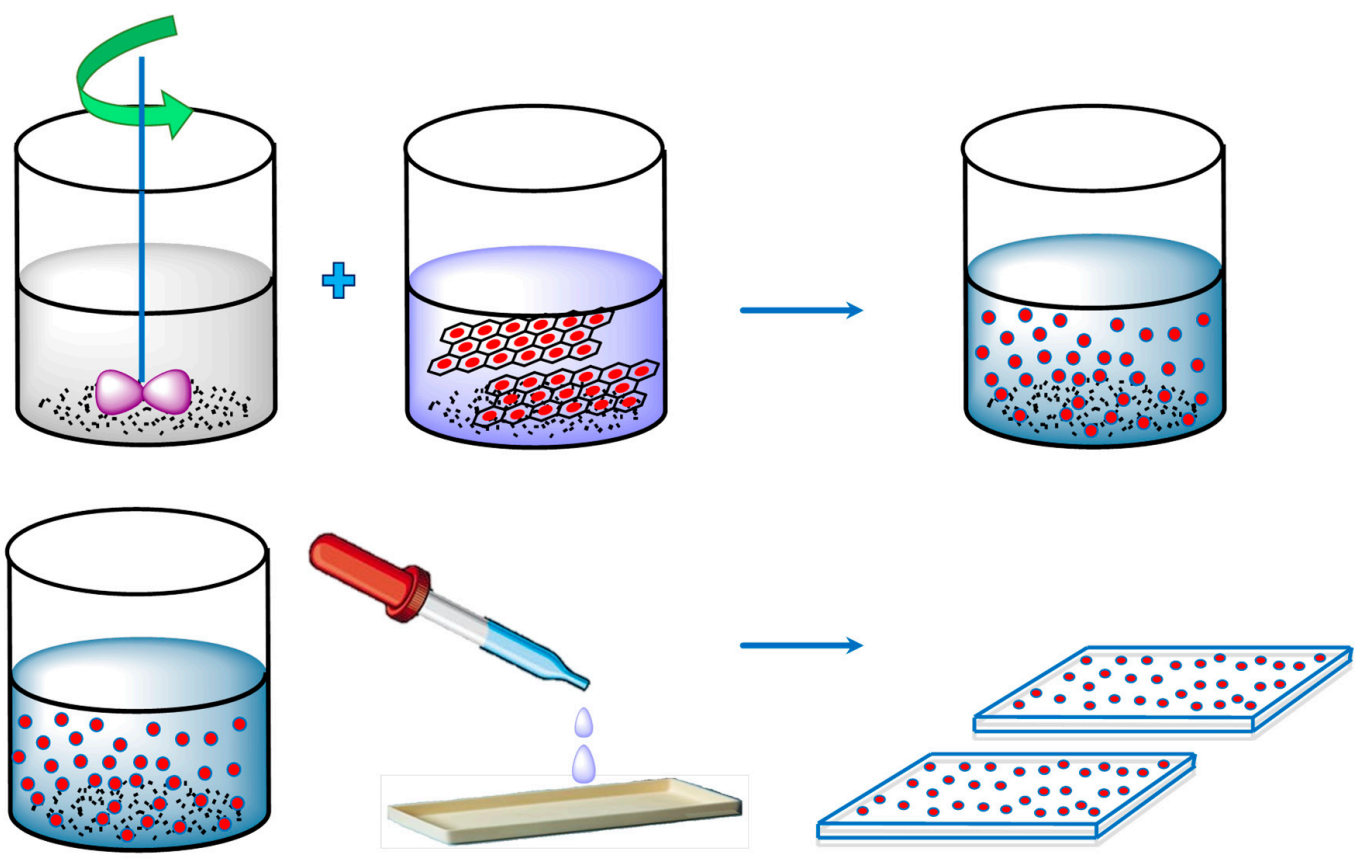

Figure 8. Preparation of membrane by solution mixing and casting.

Similar technique was also adopted for fabricating MWCNT-doped PVA membranes [100]. Herein, GA was added as crosslinker in MWCNT containing PVA dispersion casted on PMMA surface. Similar to the technique used for fabricating PEBA-GNP membranes [121], PEBA, acetic acid, zeolite 3A were used to prepare all the requisite pre-membrane solutions during preparation of zeolite 3A-filled PEBA membrane, followed by rigorous homogenization, admixing, and casting on a Teflon sheet [120]. The same technique was also adopted to produce different PEBA-based composite membranes containing suitable combinations of porous components, such as PAN, PE, PSF, and sodium NPs (NaX) [119].

GO-incorporated CS-based MMMs were fabricated by such a popular technique [136], after the usual preparation of GO-nanosheets by the modified Hummers method [169]. While preparing the PVA-PAN composite membrane [127], initially, a PMDA-crosslinked dense film of PVA was prepared by solution-casting, followed by preparation of composite membrane by the dip-coating method. In this step, an alkali-treated hydrolyzed PAN membrane was dipped into a dope solution of PVA for $30 \mathrm{~s}$, followed by the PVA-coated PAN membrane air drying for $48 \mathrm{~h}$ at room temperature, and subsequent heating to initiate crosslinking. During hydrolysis of PAN, the $-\mathrm{CN}$ were converted to $-\mathrm{COOH}$, which actively interacted with O-H of PVA for improving adhesion property of PAN [170]. In this regard, optimum flux and separation performance were achieved when crosslinking temperature was maintained at $100{ }^{\circ} \mathrm{C}$.

In order to compare the pervaporative desalinating efficiencies of GA crosslinked PVA membranes supported on PVDF, two types PVA coated PVDF membranes were prepared individually by dip- and cast-coating methods [123]. Of these, one set of composite membranes were prepared by dip-coating of PVDF hollow fibers, ensuring only single-side coating of hollow fibers by sealing the hollow fiber membrane prior to dip-coating (Figure 9a). Another set of PVA-PVDF membranes were prepared by coating the crosslinked PVA layer on the flat sheets of PVDF membranes (Figure 9b). While preparing the dip-coated PVA-PVDF membranes, dried and sealed hollow fibers of PVDFs were immersed in the previously prepared coating solution of variable PVA and GA concentrations, followed by soaking for stipulated time period. In this context, the molar ratio of GA and PVA was maintained consistently at 0.2 , so that the crosslinked structure of the final PVA coated layer remains unaltered. Subsequently, the soaked hollow fibers were dried at $50{ }^{\circ} \mathrm{C}$ for $24 \mathrm{~h}$ to actuate crosslinking among all the individual components. While preparing the same composite by cast-coating, casting of crosslinked PVA was 
conducted on flat sheets of PVDF by casting machine operated at $50 \mathrm{~mm} \mathrm{~s}^{-1}$ under $50 \%$ humidity. In the next step, the PVA coated membranes were dried at room temperature overnight, followed by oven drying for $30 \mathrm{~min}$ at $80^{\circ} \mathrm{C}$.

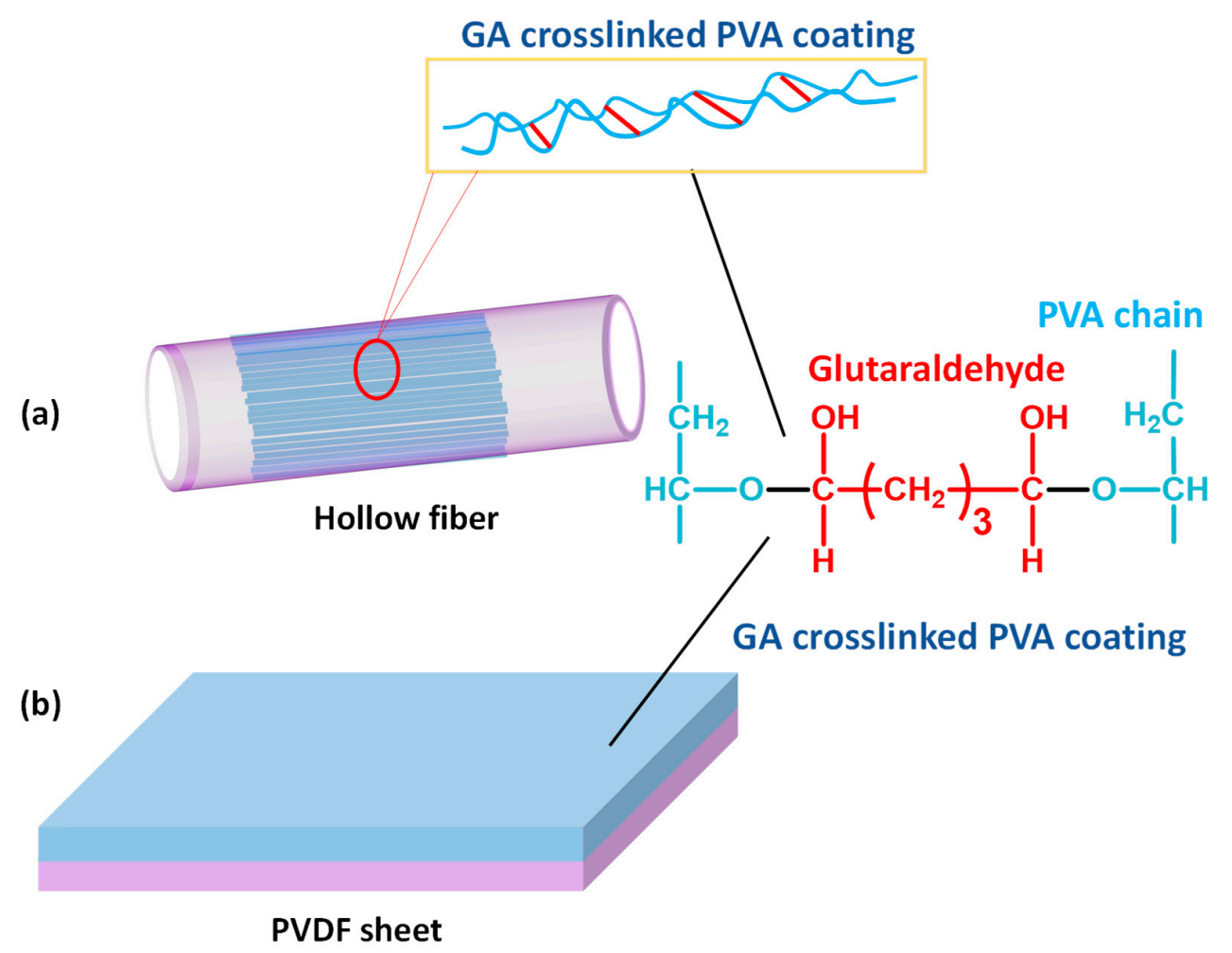

Figure 9. GA crosslinked PVA-coated PVDF membranes prepared by (a) dip coating and (b) cast coating.

\subsubsection{Vacuum Filtration-Assisted Assembly Method}

Additional attempts were devoted to prepare functionalized GO-deposited PAN membranes via the vacuum filtration-assisted UF method [50]. Initially, an aqueous suspension of GO was prepared by the modified Hummers' method [170,171]. Thereafter, GO-PAN composite membranes were prepared by vacuum filtration of the well dispersed aqueous GO suspensions through $\mathrm{NaOH}$ treated hydrolyzed PAN UF-membrane (Figure 10). In this regard, further homogenization of the aqueous GO suspension was carried out to ensure the minimum aggregation. Accordingly, functionalized GO residues were deposited and distributed throughout the PAN-UF membrane to fabricate GO-filled composite membranes.

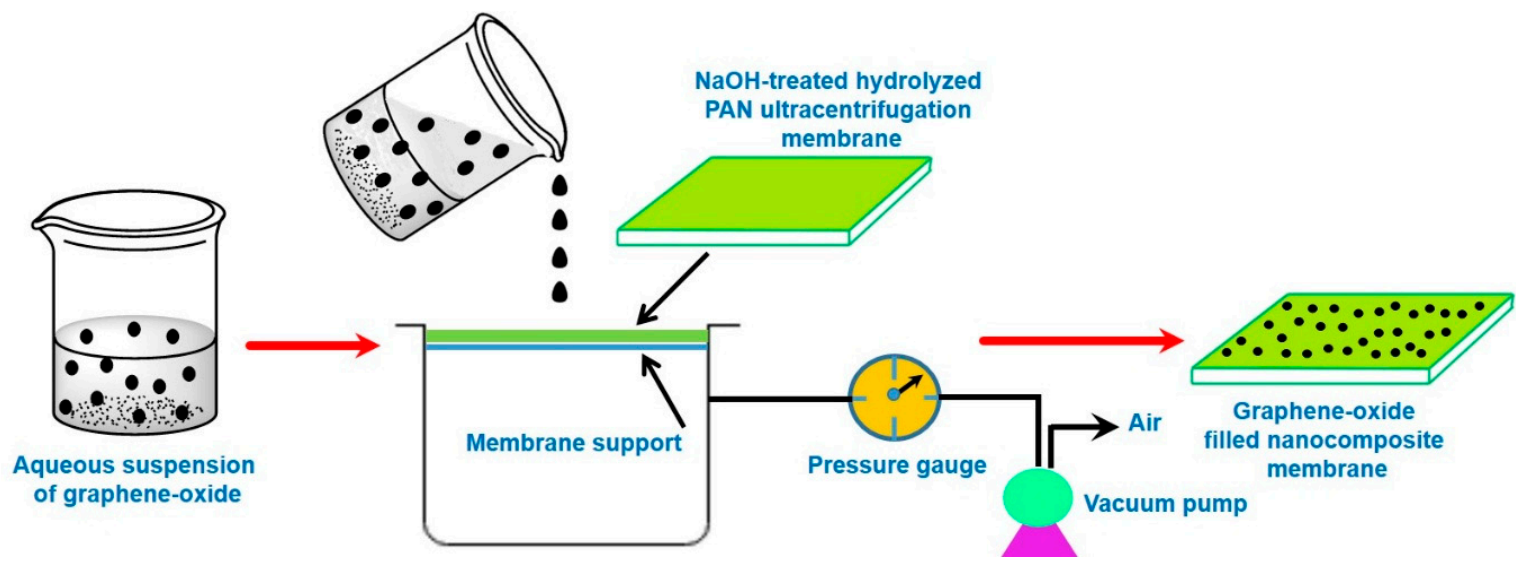

Figure 10. Vacuum filtration assisted assembly method. 


\subsubsection{Direct Spinning and Phase Inversion Method}

Direct spinning coupled with phase inversion technique was used to prepare GO- PI hollow fiber membranes suitable for efficient pervaporative desalination of salty water (Figure 11) [126]. Initially, aqueous suspensions of GO were prepared by the modified Hummers' method [116,171]. Thereafter, GO powder was produced after necessary purification of GO suspension, followed by freeze drying of the purified suspension. Later, the asymmetric GO-PI hollow fiber membranes were prepared by direct spinning of a GO-PI suspension via phase inversion in presence of water-NMP coagulation.

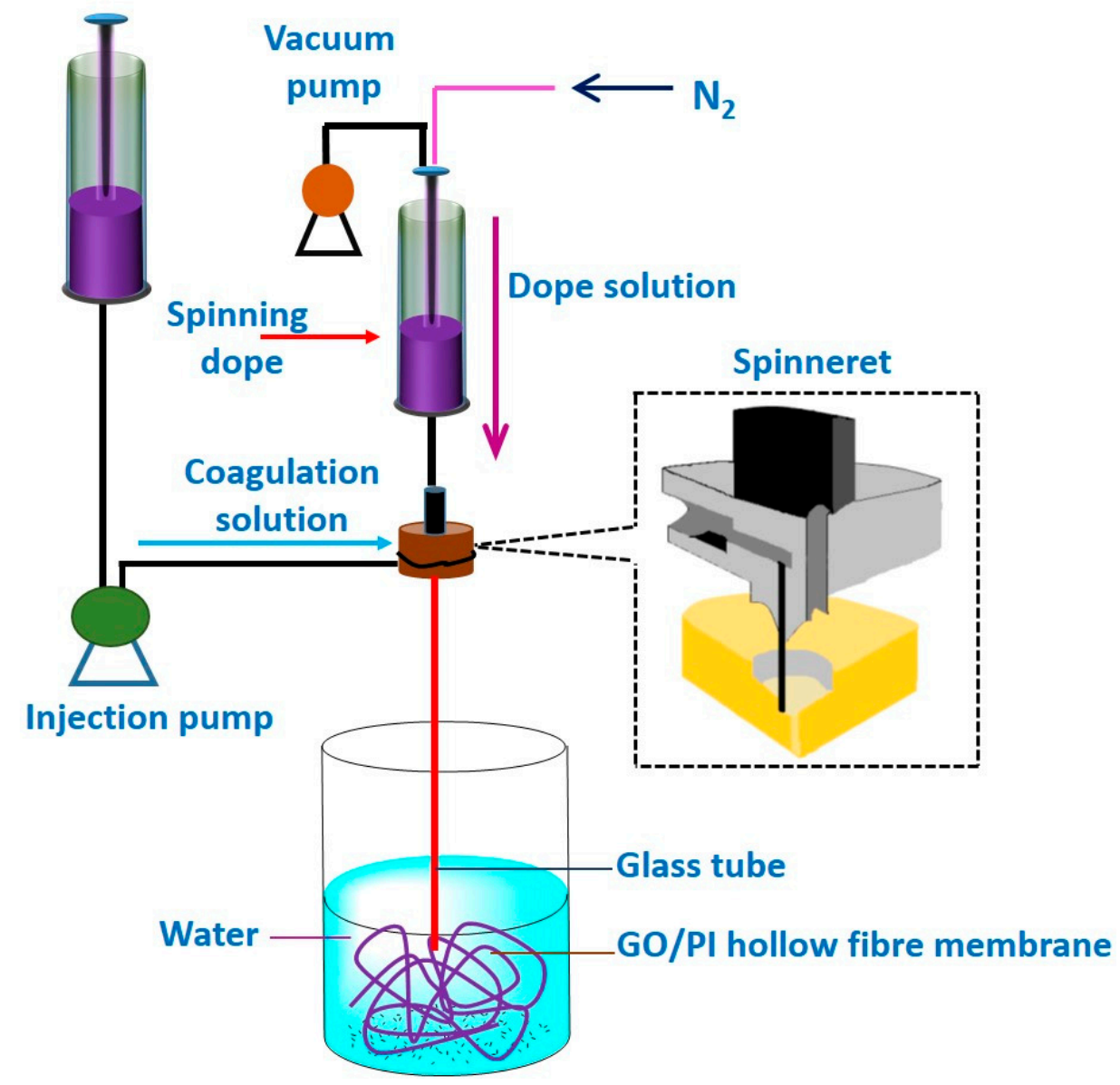

Figure 11. Schematic diagram of preparation of GO/PI hollow fiber membranes by direct spinning of a GO/PI suspension via phase inversion in water/NMP solution.

A similar method was adopted by Chaudhri et al. to prepare composite PVA membranes supported on PVS-based hollow fibers [114]. In this two-step method, initially, PVS-based hollow fibers were prepared by spinning through a double orifice spinneret from a transparent spinning dope composition of 20\% (w/w) PSF, $2 \%(w / w)$ polyvinylpyrrolidone, and 78\% (w/w) DMF under $\mathrm{N}_{2}$ environment, followed by automatic coating and crosslinking by PVA and MA, respectively [114]. To further enhance the efficiency of the membrane, $\mathrm{SiO}_{2}$ incorporated composite PVA membranes were fabricated via coating the PVS-based hollow fibers with a different coating solution comprising of aged $\mathrm{PVA}-\mathrm{SiO}_{2}$ sol in acidified and hydrated ethanol [118]. In fact, during preparation of the coating solution, the employed strategy was pretty much similar to the strategy adopted by Xie et al. [46,100], while crosslinking the membranes by TEOS in acidic environment.

A multi-step procedure was followed to achieve $\mathrm{PVA}_{-} \mathrm{SiO}_{2}$ coated composite hollow membrane. Herein, after preparing the acidified aqueous PVA and alcoholic TEOS solutions, TEOS solution was added dropwise and admixed to the PVA solution, so that constant ratio of PVA:TEOS:HCl = 1:1:2.14 was maintained in the mixture. In this context, the water:ethanol was maintained more than two to 
avoid immiscibility during addition of alcoholic TEOS in acidified PVA. In fact, such a higher amount of water also prevents unwanted self-condensation reaction of the silicate groups of hydrolyzed TEOS resulting in the high-dimensional spherical particle structure. In this way, the silicate groups generated from hydrolyzed TEOS get ample opportunity to react with the PVA chains to form the coating solution. Finally, the solution was undergone aging for $36 \mathrm{~h}$ for producing coating solution, which was subsequently applied for coating on the PVS-based hollow fiber. Thereafter, the coated fiber was dried at room temperature to evaporate and remove solvents to achieve sufficient hydrolysis of TEOS and thereby production of $\mathrm{Si}-\mathrm{OH}$, which interacts with $\mathrm{O}-\mathrm{H}$ of PVA to generate ether linkages during drying and degassing [118].

\subsubsection{Electrospraying and Electrospinning}

The above mentioned combined method was also utilized for synthesizing multilayer composite membranes comprising of PVA, PAN, and PET materials [80]. At first, PVA base layer was electrosprayed onto the surface of Al-foil, followed by deposition of the nanofibrous mid-layer of PAN on the PVA base layer via electrospinning. Herein, the major function of nanofibrous PAN layer was to provide the desired physico-chemical stability and mechanical strength. Thereafter, a nonwoven PET layer was attached at the top to produce the assembled composite membrane. PVA components of some of these assembled composite membranes were intentionally crosslinked by treating them with GA-based crosslinking solution. Such crosslinking of PVA was carried out to minimize the swelling and dissolving tendency of PVA in water, which often restricts the use of PVA in water treatment applications [172,173]. Another objective behind such crosslinking was to restrict the transportation of larger hydrated ions.

\subsection{Characterization}

\subsubsection{Morphology}

Within PEBA-GNP membranes (Figure 12a-f), GNPs were noted to become intercalated in the PEBA matrix, and the agglomerates of GNPs were observed in the NCPs bearing higher concentration of GNPs [121]. However, such agglomerates are not desirable for achieving the optimum performance of membranes [120]. In this context, both the bulk and surface of MWCNT-loaded PVA membrane were not free from such agglomerations [100], especially in MWCNT-PVA composites possessing higher amount of filler. However, for hybrid PVA-MA-silica membrane, no larger particulate agglomerates $(>10 \mathrm{~nm}$ ) were observed in TEM images (Figure 12g), suggesting uniform dispersion and distribution of silica NPs within PVA matrix.

The intimate polymer-filler interaction and uniform distribution of silica NPs resulted in partial destruction of inherent crystallinity of PVA matrix [100], as apprehended from the appreciable broadening and weakening of PVA-specific XRD peak at $20^{\circ}$ of hybrid PVA-MA-silica membrane [174]. Indeed, such increased amorphous characteristics could also be visualized from clear transparent nature of the membrane in contrast to the brown-colored opaque appearance of PVA-silica membrane. Crosslinking-driven destruction of crystallinity for PVA was also manifested in the GA-treated PVA [80]. Additionally, crystallinity of PVA was noted to deteriorate when PVA layer was electrosprayed on the Al-foil, associated with quicker evaporation of the volatile solvent of PVA layer, followed by rapid solidification.

While studying the composite PVA membranes supported on PVS-based hollow fibers, it was observed that the hollow fibers are not exactly circular since the extruded fibers experienced considerable mechanical stretching during winding [114]. Moreover, the hollow fiber structure was asymmetric in nature and were comprised of smaller pores near the surface and larger macropores in the interior, similar to the pore characteristics of the asymmetric cellulosic membranes fabricated by Naim et al. [132]. Herein, the smaller pores were the active pores, responsible for separation of unwanted species. 

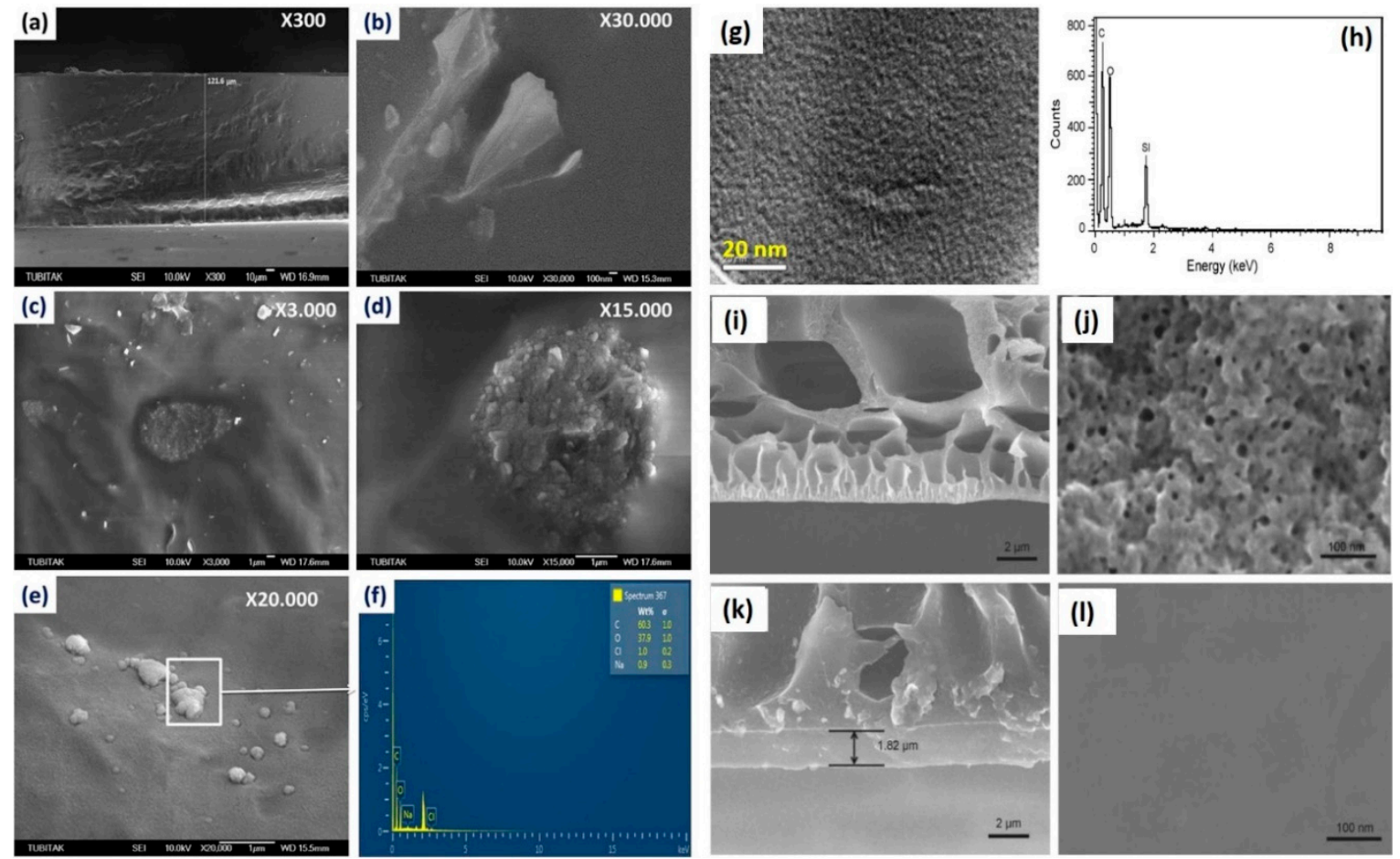

Figure 12. Cross-sectional SEM micrographs of the (a) pristine, (b) $2 \mathrm{wt} \%$ GNPs-PEBA, and (c,d) $5 \mathrm{wt} \%$ GNPs-PEBA; (e) surface micrograph of $2 \mathrm{wt} \%$ GNPs-PEBA (after desalination); and (f) EDX result of $2 \mathrm{wt} \%$ GNPs-PEBA membranes. Reprinted with permission from [121]. Copyright 2017 Elsevier B.V. (g) TEM image and (h) EDS spectra of the hybrid PVA-MA-silica membrane containing $20 \mathrm{wt} \% \mathrm{MA}$ and $10 \mathrm{wt} \% \mathrm{SiO}_{2}$ with respect to PVA. Reprinted with permission from [46]. Copyright 2011 Elsevier B.V. SEM images of (i) cross-section and (j) top surface of the PAN ultrafiltration membrane and of (k) cross-section and (1) surface of PVA-PAN composite membranes [127].

The morphological characteristics of PAN-PVA membranes (Figure 12i-1) [127] were composed of large finger-like micro-voids in the PAN portion underneath the skin layer of PVA. Such micro-voids were crucial in reducing the mass-transfer resistance against the water vapor during pervaporative desalination. Moreover, small pores of nano-dimensions were located at the top surface of the PAN membrane, which were generated because of alkaline hydrolysis of the PAN membrane during dip-coating. These pores contributed significantly in the permeation of water vapor during pervaporative desalination process. Interestingly, the mean pore size and the surface porosity of PAN membrane increased dramatically when hydrolysis time was increased from 1 to $2 \mathrm{~h}$. Such an abrupt increase in the mean pore size from 6.9 to $187.4 \mathrm{~nm}$ was associated with the rupture of PAN polymer chains during alkaline hydrolysis [128].

AFM characterization was sought to monitor the change in topological details for a membrane undergoing pervaporative desalination. In this context, the surface topology of composite PVA membrane was analyzed from the respective AFM images (Figures 13a and 14a-c) [114]. It was observed that the surface roughness was decreased with an increase in coating layer thickness. In case of GO-hybridized CS membranes (Figure 14) [136], enhanced roughening was observed with addition of higher amounts of GO that was attributed to the exposure of GO flakes onto the membrane surface consisting of ridges and valleys [175]. Additionally, the cross-section of the membrane envisaged enhanced roughness with greater population of GO sheets in the hybridized membrane (Figure 14). The increase in roughness onto hydrophilic surface could result in the increased wettability of water onto the membrane surface favoring improved water permeation through the membrane. 

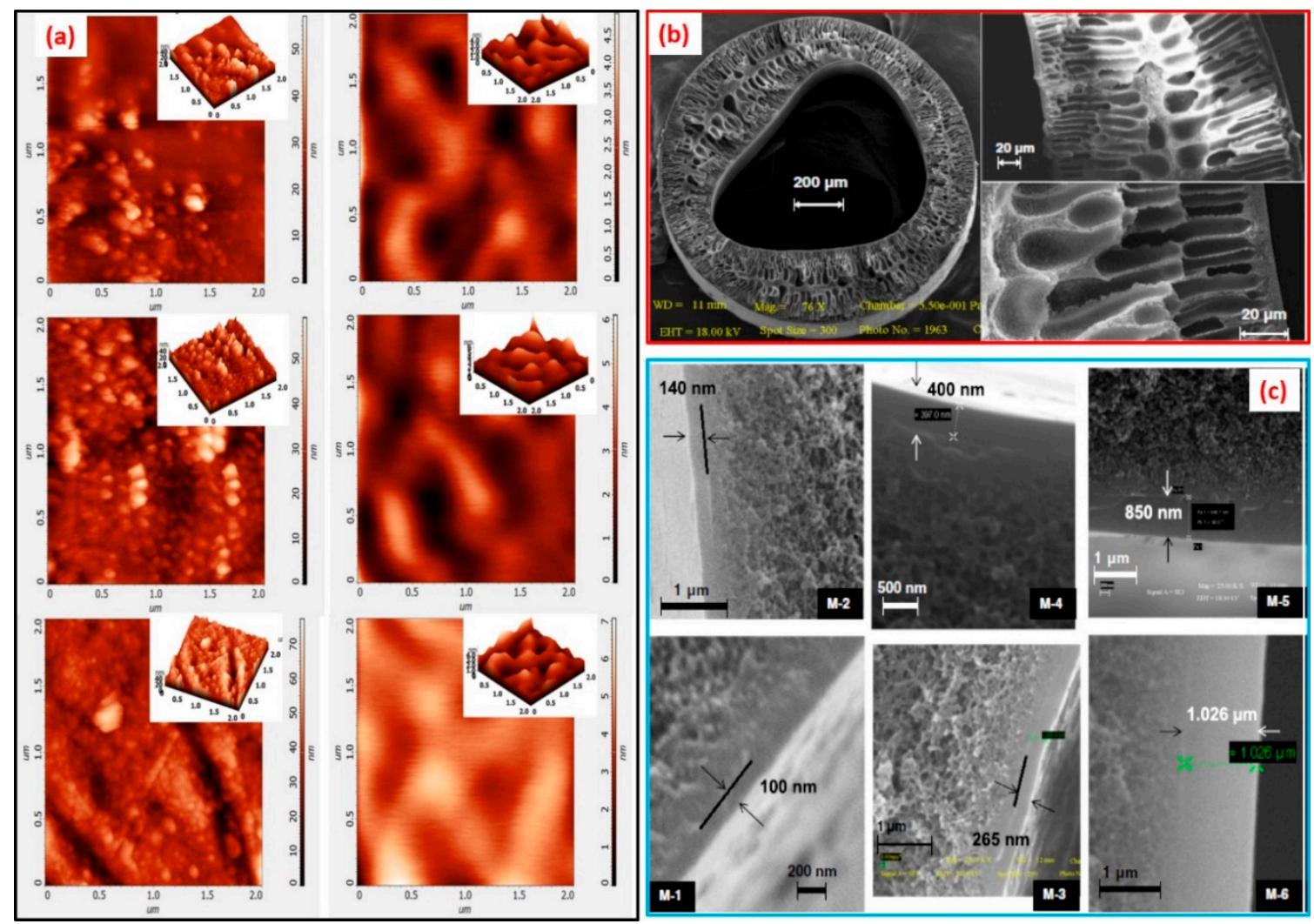

Figure 13. Cross-sectional SEM images of (a) hollow fiber support; (b) composite membranes; and (c) top surface AFM images of the composite membranes and (inset) 3D images of the respective samples. Reprinted with permission from [114]. Copyright 2015 Elsevier B.V.

In this regard, water tends to flow preferentially from the ridges to the valleys that effectively produce a shorter diffusion path length and thereby generating higher flux (Figure 15). Moreover, almost vertical orientation of GO sheets at the membrane surface is desired to achieve accelerated flux. However, while running the pervaporative separation, foulants may be trapped and accumulated in the valleys, resulting in clogging of the pathway despite accelerated flow from ridge to valley. For estimation of the possible incorporation of $\mathrm{SiO}_{2}$ in $\mathrm{PVA}-\mathrm{SiO}_{2}$-based composite membrane, Chaudhri et al. compared the thickness of the coated composite membranes from the respective SEM photomicrographs (Figure 13b,c) and by employing a gravimetric method based on Equation (1) [118]:

$$
t=\frac{W_{c}-W_{u}}{d \times A}
$$

Here, $t, W_{c} / W_{u}, d$, and $A$ are thickness, weights of the coated/uncoated fibers, density, and surface area of fiber, respectively. The $A$ is calculated from Equation (2), in which $r$ and $l$ are outer radius and length of the fiber, respectively:

$$
A=2 \pi r l
$$

The main objective behind evaluating thicknesses by both SEM and gravimetric analyses was to detect the incorporation of $\mathrm{SiO}_{2}$ in the top layer and hollow fiber portions. It was observed that the gravimetric equation-derived thickness was almost twice as compared to the SEM-derived thickness because of the huge difference between $W_{c}$ and $W_{u}$ as a result of incorporating a significant amount of $\mathrm{SiO}_{2}$ within $\mathrm{PVA}-\mathrm{SiO}_{2}$ film. In this regard, distribution of the incorporated $\mathrm{SiO}_{2}$ was also evaluated via EDX analyses (Figure 12h), which demonstrated a very large population of $\mathrm{Si}$ at the surface of the top layer, whereas the inner layer possessed lower population $\mathrm{Si}$, suggesting intrusion of $\mathrm{SiO}_{2}$ at the inner layer of the composite membrane. 

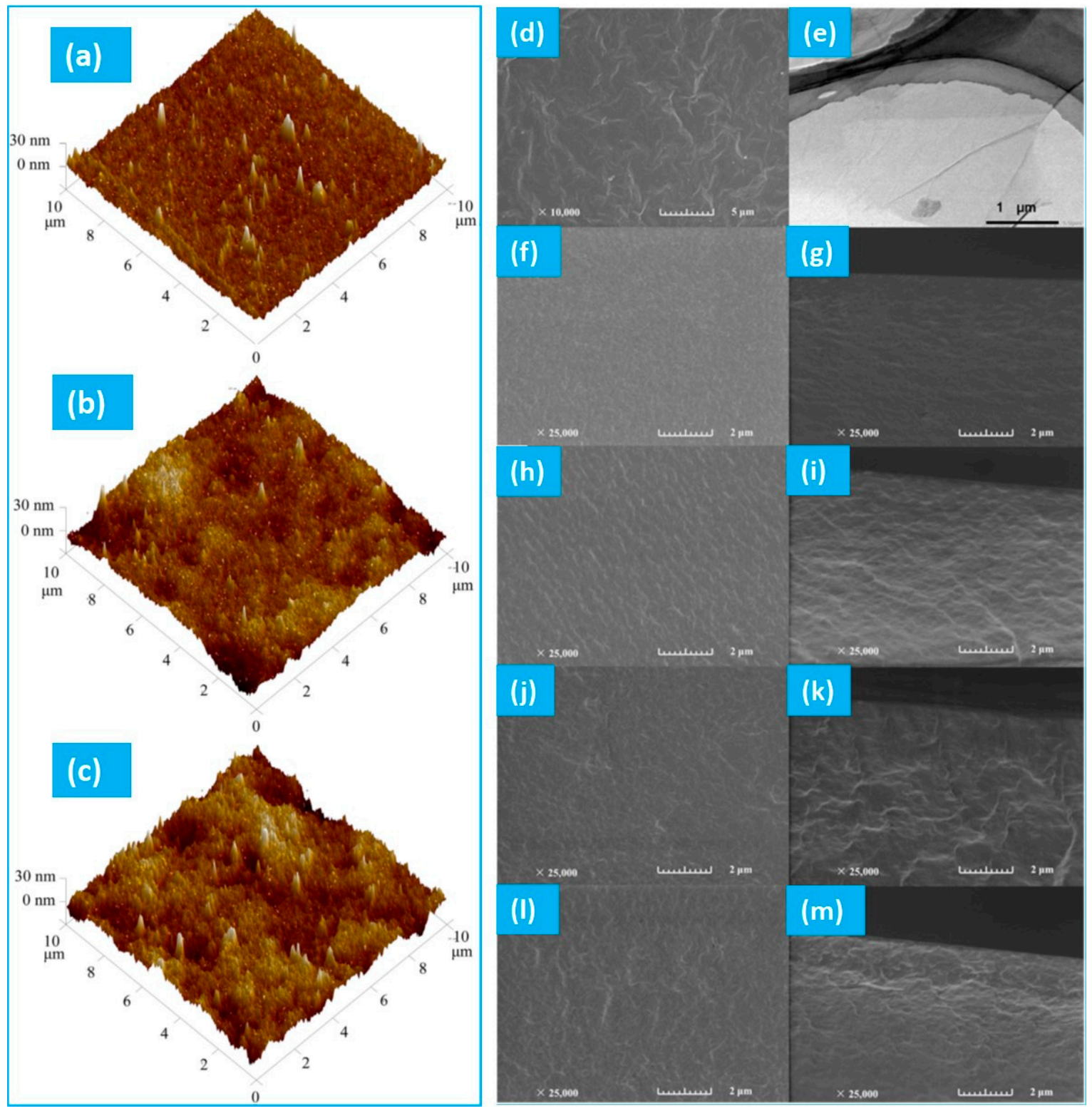

Figure 14. AFM images of (a) pristine CS membrane, (b) CS/GO-1, and (c) CS/GO-2 MMMs. (d) SEM and (e) TEM of GO and SEM images of the top surface and cross-section of (f,g) CS, (h,i) CS/GO-0.5, $(\mathbf{j}, \mathbf{k}) \mathrm{CS} / \mathrm{GO}-1.5$, and $(\mathbf{l}, \mathbf{m}) \mathrm{CS} / \mathrm{GO}-2$ membranes. Reprinted with permission from [136]. Copyright 2018 Elsevier B.V.

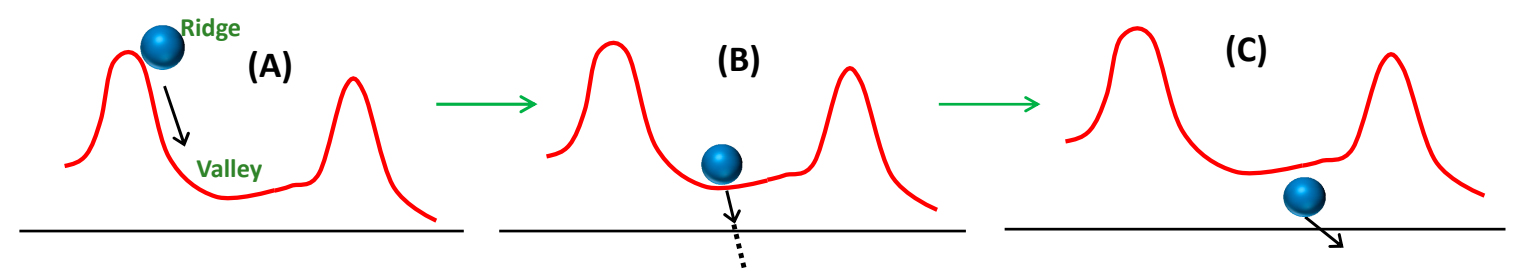

Figure 15. Accelerated water transport on rough membrane comprising of ridge and valley.

In GO-PAN composite membranes, the vacuum assisted filtration-based technique resulted in exfoliated distribution of GO particles in PAN membrane [50], suggesting formation of substantial interfacial area between PAN and GO. Indeed, agglomeration of GO particle could be avoided in GO-PAN composite membranes because of the sufficient homogenization of GO suspension during 
preparation of the composite membrane. In addition, a high-performance PV membrane should also be devoid of defects, such as cracks and pinholes [126].

The lateral pore structures contributed significantly in enhancing the water fluxes of the asymmetric GO-PI hollow fiber membranes. Additionally, the pore characteristics of such membranes influenced to achieve higher water flux and improved membrane selectivity than PI-based hollow fiber membranes containing frequent macropores. In this regard, though finger- and sponge-like pores were much denser in PI-based hollow fiber membrane than GO-PI hollow fiber membranes, the BET-specific surface area of GO-PI hollow fiber membranes were found to be much higher than PI-based hollow fiber membranes. Thus, the incorporated GO played a crucial role in forming porous membranes.

In this regard, the hydrophilic groups in GO accelerated the rate of solvent and non-solvent exchange during phase-inversion process [176]. Influence of pore characteristics and micro-defects can contribute significantly in the performance of PVA-PVDF composite membranes [123]. In this context, pore size and structure of PVDF can be altered depending on the PVA concentration in dipping solution. During the dip-coating process, PVA solution of low concentration and viscosity can penetrate easily into the pores of PVDF hollow membrane, leading to the insufficient thickness of the coating layer at the PVDF surface. On the other hand, highly concentrated and viscous PVA solution can produce the undesirably thicker coating layer and thus reduced flux. Thus, both of these aspects are unfavorable in fabricating a thin PVA selective layer equipped with desirable PV efficiency. Moreover, time-dependent deterioration of flux was observed, irrespective of the thickness of PVA layer. Such phenomenon was observed because of the superficial deposition of crystalline particulate matters of salt on the permeate side of the membrane [123], along with the hydrated salt ions occupying free volume within PVA matrix, blocking the passage of water molecules (Figure 16).

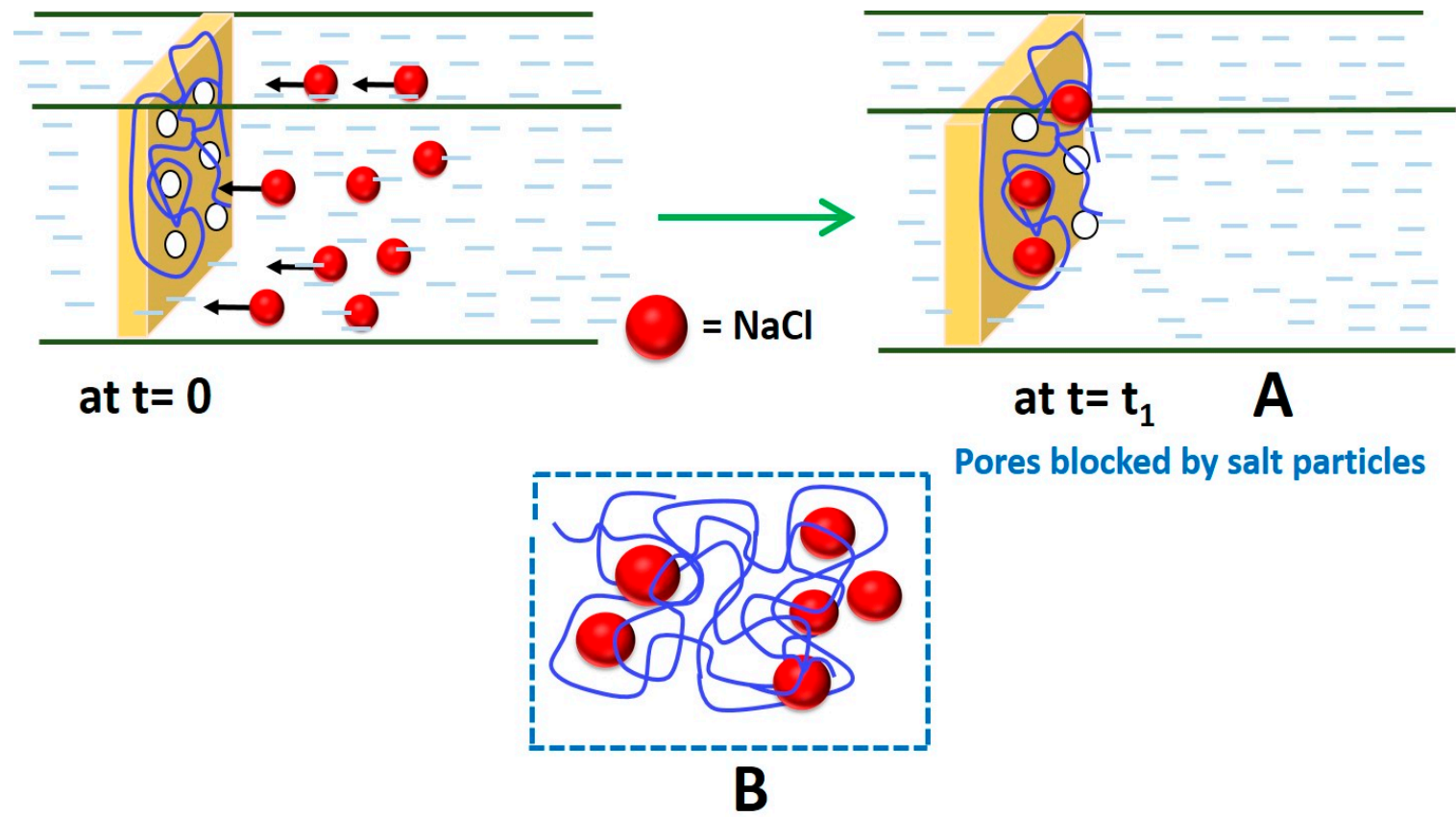

Figure 16. Time dependent deterioration of flux by (A) blocking of pores by crystalline deposition of salt and (B) occupation of free volume by hydrated salt species.

\subsubsection{FTIR Analyses}

FTIR analyses were carried out to identify the formation or destruction of bonds during synthesis of the membranes. By means of FTIR analyses, reactions and thereby intimate association among various components of the hybrid PVA-MA-silica membrane was realized because of the formation of newly generated peaks. The FTIR spectrum of the PVA-MA-silica membrane showed an ester-specific new peak at $1726 \mathrm{~cm}^{-1}$, as a result of grafting or crosslinking via esterification reaction between $\mathrm{O}-\mathrm{H}$ of 
PVA and -COOH of MA [46]. Another new peak at $950 \mathrm{~cm}^{-1}$ was attributed to Si-OH resulting from hydrolysis of TEOS and associated H-bonds between organic groups and silica. Moreover, significant rise in the peak intensity at $1080 \mathrm{~cm}^{-1}$ was associated with the formation of Si-O-Si via condensation reaction between hydrolyzed silanol-specific Si-OH and crosslinking between PVA and TEOS.

Chaudhri et al. also observed similar types of reactions during monitoring the time-dependent change in FTIR spectra during aging of TEOS treated PVA-SiO $\mathrm{P}_{2}$ film, to be used as the top layer of the polyvinylpyrolidone hollow fiber supported composite membrane [118]. Interestingly, with the increase in aging time from 24 to $72 \mathrm{~h}$, the peaks within $1000-1200 \mathrm{~cm}^{-1}$ were found to broaden because of the contribution of newly generated $\mathrm{C}-\mathrm{O}-\mathrm{H}$ bending and $\mathrm{Si}-\mathrm{O}-\mathrm{Si}$ and $\mathrm{Si}-\mathrm{O}-\mathrm{C}$ asym. str. Arrival of such vibrations can only be possible because of hydrolysis and self-condensation of $\mathrm{Si}-\mathrm{OH}$ or condensation of $\mathrm{Si}-\mathrm{OH}$ and $\mathrm{O}-\mathrm{H}$ of PVA. Indeed, the involvement of $\mathrm{O}-\mathrm{H}$ of PVA during crosslinking was also detected from the complete disappearance of PVA-specific peak at $1583 \mathrm{~cm}^{-1}$ assigned to $\mathrm{C}-\mathrm{O}$ of $\mathrm{C}-\mathrm{OH}$ of PVA. Moreover, the existence of $\mathrm{Si}-\mathrm{OH}$ in $\mathrm{PVA}^{-\mathrm{SiO}_{2}}$ was also substantiated from the prevalence of a broad shoulder at $970 \mathrm{~cm}^{-1}$, interrelated with the increased hydrophilicity of composite membrane. Indeed, such a reaction between $\mathrm{PVA}$ and $\mathrm{SiO}_{2}$ also resulted in the destruction of the crystallinity in the PVA-SiO 2 membrane, as reported earlier by Xie et al. [100].

For GO-PAN composite membranes, strong H-bonding among diversified functional groups of $\mathrm{GO}$, such as $\mathrm{C}-\mathrm{O}, \mathrm{C}=\mathrm{O}$, and $\mathrm{O}-\mathrm{C}=\mathrm{O}$ with $-\mathrm{COOH}$ and $-\mathrm{CONH}_{2}$ of PAN [177] was observed. Indeed, the existence of these oxidation-derived functional groups in GO, conforming to the Lerf-Klinowski Model (Figure 17) [140], was rationalized by FTIR, XPS, and Raman spectroscopy [50].

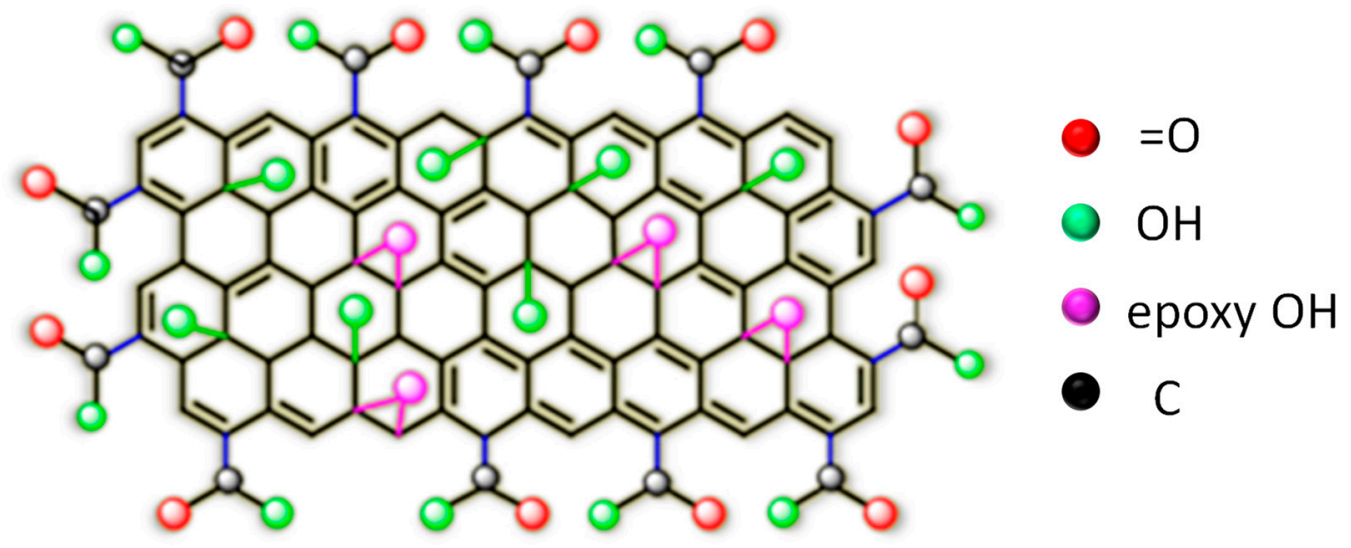

Figure 17. Lerf-Klinowski model of GO.

In another report, the reaction of O-H of GO with PI and thereby formation of ether linkage in GO-PI hollow fiber membranes was realized from FTIR analyses [126]. Similarly, crosslinking of $\mathrm{O}-\mathrm{H}$ of PVA with MA in composite PVA membranes supported on PVS-based hollow fibers was realized from the loss of PVA-specific free O-H and -COOH of MA [114]. Condensation of -COOH of PMDA crosslinker and O-H of PVA in preparing the PVA-PAN composite membrane was detected from the continuous loss of intensity for $\mathrm{O}-\mathrm{H}$ specific broad peak centered at $3320 \mathrm{~cm}^{-1}$ [178-183], along with the consequent gain in $\mathrm{C}=\mathrm{O}$ and $-\mathrm{C}-\mathrm{O}-\mathrm{C}-$ peaks of aromatic ester at 1750 and $1275 \mathrm{~cm}^{-1}$, respectively [127].

Similarly, for SSA crosslinked PVA film, the peaks at $1030 \mathrm{~cm}^{-1}$ and $1226 \mathrm{~cm}^{-1}$ represent asym and sym str. $\mathrm{S}=\mathrm{O}$ of the sulfonic acid group, respectively [122,184,185]. For GO hybridized CS membrane, reaction between primary $-\mathrm{NH}_{2}$ of $\mathrm{CS}$ with epoxy group of $\mathrm{GO}$ was identified from the increase in $\mathrm{N}-\mathrm{H}$ bending, along with the weakening of primary $-\mathrm{NH}_{2}$ peak at $1651 \mathrm{~cm}^{-1}[136,186-188]$. Though, the authors have not reported the change in FTIR peak corresponding to the epoxy group of GO as a result of reaction with primary $-\mathrm{NH}_{2}$, such reaction was confirmed from the increased intensity of C-N specific deconvoluted C1s spectra for the GO hybridized membrane. Moreover, by monitoring the change in N1s XPS spectra, the authors reported ionic interaction of $-\mathrm{NH}_{3}{ }^{+}$of $\mathrm{CS}$ with $-\mathrm{COO}^{-}$of 
GO moieties. Additionally, strong H-bonding interactions between GO and CS was also realized from the FTIR and XPS analyses.

\subsubsection{Thermal Properties}

Noticeable changes were observed in the characteristic transition peaks of DSC thermogram for PEBA block copolymer comprising of soft polyether and hard polyamide segments [121]. As a result of GNP addition in PEBA, absolute disappearance of polyether-specific peak at $58{ }^{\circ} \mathrm{C}$ was associated with the interaction of GNPs with polyether moieties, resulting in the enhanced thermal stability and reduced crystallinity of PEBA-GNP NCP membranes than the unfilled PEBA matrices.

The enhanced thermal stability was also noticed for hybrid PVA-MA-silica membranes as compared to the membranes devoid of MA crosslinking at high temperature, substantiating the MA-assisted crosslinking in hybrid PVA-MA-silica membranes. MA- and silica-mediated crosslinking dependent improvement in thermal stability was also exemplified from the continuous rise of the characteristic $\mathrm{T}_{\mathrm{g}}$ of PVA from 84 to 94 and $103^{\circ} \mathrm{C}$ for PVA-silica and PVA-MA-silica membranes, respectively [46]. With the rise in MA content, similar increase in $\mathrm{T}_{\mathrm{g}}$ from 93 to $136^{\circ} \mathrm{C}$ was also observed in composite PVA membranes supported on PVS-based hollow fibers because of increased crosslinking between $\mathrm{O}-\mathrm{H}$ of PVA and -COOH of MA [114]. Such crosslinking-driven loss of crystallinity in composite membranes was also realized from the considerable decrease in endothermic melting peaks at $220-340{ }^{\circ} \mathrm{C}$ of the polymer.

Crosslinking and associated improvement in thermal stability of $\mathrm{PVA}_{-} \mathrm{SiO}_{2}$ over PVA was realized while comparing the respective TGA plots [118], along with the appreciable enhancement in the melting point of $\mathrm{PVA}^{-\mathrm{SiO}_{2}}$ at $236{ }^{\circ} \mathrm{C}$ as compared to pure PVA at $217^{\circ} \mathrm{C}$. In an another study, the crosslinking of PVA by GA was realized from the comparative TGA plots showing higher thermal stability for GA crosslinked PVA membrane over untreated PVA [80]. Indeed, crosslinking was substantiated from the disappearance of the characteristic endothermic peak of pure PVA at $225^{\circ} \mathrm{C}[189,190]$.

In this regard, crosslinking of PVA by PMDA was realized from the enhanced thermal stability of PMDA crosslinked PVA over pure PVA within $120-250{ }^{\circ} \mathrm{C}$, suggesting crosslinking-originated retarded decomposition of PVA side chains in PMDA crosslinked PVA [127,191]. Invariably, better thermal stability in lower temperature range was observed for SSA crosslinked PVA over uncrosslinked PVA [122].

The poor thermal stability of SSA crosslinked PVA at high temperature region was attributed to the de-sulfonation and dissociation of ester linkages [192]. Moreover, higher crosslinking resulted in the enhancement of $T_{g}$ as well as the disappearance of melting temperature in SSA crosslinked PVA, which indicated the restricted formation of crystalline structure in PVA polymer together with the increased polymer chain rigidity [193]. As a result of H-bonding and other covalent/non-covalent interactions between individual components [194,195], such restricted movement of the polymer chains was noticed in the GO hybridized CS membrane, which was reflected from the increased $T_{g}$ of the GO hybridized CS over the mere CS membrane [136].

\subsubsection{Mechanical Properties}

Due to the reaction between $\mathrm{O}-\mathrm{H}$ of GO and PI, newly formed ethereal crosslinks were responsible for the enhanced tensile modulus of GO-PI hollow fiber membranes over PI hollow fiber membranes [126]. However, the TS and EAB of the GO-PI hollow fiber membrane were less than the PI hollow fiber membranes, since the mobility of polymer chains was restricted because of the formation of crosslinks [196,197]. For GO-hybridized CS membrane, appreciable increase in both TS and EAB was observed in $0.5 \mathrm{wt} \%$ GO-loaded CS membrane [136]. However, with the further increase in GO content, TS was found to deteriorate because of the formation of GO aggregates within the GO-loaded CS membrane, leading to the poor interfacial interactions. Such enhancement of TS and EAB was ascribed to the increased CD of the GO-hybridized CS membrane because of the covalent 
interaction between GO and CS moieties [198]. Wang et al. reported the similar trend in TS of cellulose triacetate-GO membrane suitable for the FO process [199].

\subsubsection{Swelling}

Swelling study of the membranes can be a potent way to identify and substantiate the stability of novel crosslinks in polymeric membranes, since the SR is inversely proportional to CD. SR deteriorated in the following order: PVA > PVA-silica > PVA-MA-silica membranes, suggesting the increase in crosslinking in PVA-MA-silica membranes [46]. Crosslinking-mediated reduction of hydrophilic character was manifested in the decreased SR of PMDA crosslinked PVA membranes than un-crosslinked PVA. Similar observations were registered for MWCNT-PVA membranes when proportion of MWCNT in PVA matrix was increased from 0.3 to $0.5 \mathrm{wt} \%$ [100]. As per Yilman et al., such lowering in SR was ascribed to the enriched hydrophobicity of MWCNT-PVA membranes containing hydrophobic aggregates carrying higher amounts of MWCNTs. Interestingly, with the increase in MWCNT proportion of PVA matrix from 0.1 to $0.3 \mathrm{wt} \%$, substantial increase in SR was observed because of the enhancement in the amorphous region within the polymers via destruction of crystalline structure in-presence of MWCNT, also realized from DSC analyses. Panahian et al. reported similar kind of increasing tendency in SR for multilayer polymeric membranes containing modified-MWCNTs [200].

\subsubsection{Hydrophilicity}

Enhanced hydrophilicity of PEBA-GNP NCP membranes over unfilled PEBA membranes was realized from the lowering in contact angle for the NCP membrane as compared to the unfilled membrane [121]. Such improved hydrophilicity for increasingly GO-loaded GO-CS hybrid membranes was attributed to the presence of ionic groups (i.e., $-\mathrm{COO}^{-}$and $-\mathrm{NH}_{3}{ }^{+}$), together with the superficial roughness created by the GO flakes and aggregates $[136,175]$. Similarly, with the increased addition of Zeolite 3A, elevated hydrophilicity of the composite membrane was observed, resulting in the improved water flux and salt retention [120]. With the increase in thickness of PVA composite membranes, the contact angle was noted to decrease, suggesting continuously enhanced hydrophilicity for the relatively thicker membrane. The hydrophobicity followed the order: PVA < PVA-silica < PVA-MA-silica membranes, as the hydrophilic $\mathrm{O}-\mathrm{H}$ and $-\mathrm{COOH}$ involved largely in the production of lesser hydrophilic ester- and Si-O-Si-based crosslinks [46]. Similar results were obtained when PVA was crosslinked with either GA [80] or PMDA [127], leading to the consumption of some hydrophilic functional groups. Accordingly, with the increased crosslinking, reduced hydrophilicity was observed for PVA composite membranes supported on PVS-based hollow fibers and the PVA-PAN composite membranes [88,122,127]. Indeed, CD was determined by Flory-Rehner equation (Equation (3)):

$$
V_{c}=-\left[\ln \left(1-\phi_{p}\right)+\phi_{p}+\chi \phi_{p}^{2}\right] /\left[V_{s}\left(\phi_{p}^{1 / 3}-0.5 \phi_{p}\right)\right]
$$

Here, $\chi, \phi_{p}$, and $V_{s}$ are the Flory-Huggins solvent interaction parameter (0.494) [201], volume fraction of the swollen polymer, and molar volume of the swelling agent (i.e., water). Initially, the polymer film was immersed in hot water at $80{ }^{\circ} \mathrm{C}$ for few hours until a constant weight of swollen polymer film was obtained. Thereafter, from $V_{c}$, the average molecular weight between crosslinks (i.e., $M_{\mathcal{C}}$ ) was calculated with the help of Equation (4):

$$
V_{c}=\frac{d}{M_{c}}
$$

Here, $d$ is density of polymer. In this context, the density of amorphous PVA (i.e., $1.269 \mathrm{~g} \mathrm{~cm}^{-3}$ ) was taken into consideration, as the XRD of crosslinked PVA film showed amorphous behavior. 


\subsection{Desalination Performance and Mechanisms}

\subsubsection{Membrane Structure}

Theoretically, permeability and selectivity of membranes during PV are governed by the solubility and diffusivity of components of the membrane. In fact, water permeability of a membrane is governed by the hydrophilicity and availability of free volume within the membrane. It is the difference of diffusion rate between salt and water other than their difference in solubility in the membrane that essentially contributes to the preferential permeation of water in the membranes (Table 3). Indeed, solubility of $\mathrm{NaCl}$ in the membranes is very close to that of water, while the diffusivity of $\mathrm{NaCl}$ in the membrane is half that of water, which contributes to the high $\mathrm{H}_{2} \mathrm{O} / \mathrm{NaCl}$ selectivity of the membranes. Thus, high diffusivity of water over salt is ascribed to the inherent characteristics of dense hydrophilic GO hybridized CS membrane, as the diffusivity of water and salt in membrane is dependent on the property and microstructure of membrane materials [202].

Similarly, all the GNP-loaded membranes demonstrated improved flux and rejection than unfilled PEBA membranes. Such increment in flux should be attributed to the increasing hydrophilicity of nanohybrid membrane during addition of GNPs [121]. Increased flux and hydrophilicity of GNP-filled nanohybrid membranes were attributed to the homogeneously dispersed graphene components acting as water-selective channels [203,204]. In fact, with the increase in GNP content in PEBA from 0 to $3 \mathrm{wt} \%$, total salt rejection was found to enhance from 99.12 to $99.92 \%$ at $65{ }^{\circ} \mathrm{C}$. Such improved salt rejection was related to the lengthened tortuous pathway and simultaneously decreased free volume within the GNP-filled PEBA matrix. However, flux was noted to become significantly deteriorated when GNP content was further increased in PEBA, as GNP aggregations affected the passage of water molecules by blocking the pores. In case of GNP-filled polymer membranes, pores are absent in GNP moieties and, hence, GNP is impermeable to molecules or ions. However, if nano-pores can be created inside GNP filled matrix, the matrix can allow the selective passage of the ions. Otherwise, in the absence of nano-pores, GNPs can merely act as fillers, which behave as barriers against the uncontrolled ion passage by extension of the tortuous pathway through the membrane.

NaX NPs containing PEBA-based hybrid composites demonstrated encouraging rejection of $>99 \%$, because of the disruption of polymer chain packing in PEBA and associated lowering in free volume radius [119]. Moreover, enhanced salt rejection was observed in PVA-MA-silica membranes over PVA-silica membranes, as relatively crosslinked and compact nature of PVA-MA-silica membranes prevented the passage of salts [100]. Accordingly, as the silica content was increased further, salt rejection increased because of the consequent increase in the degree of crosslinking. Despite the increase in hydrophobicity of PVA-MA-silica membranes over PVA-silica membrane, water flux increased in PVA-MA-silica membranes as compared to PVA-silica membrane. However, both flux and salt rejection were noted to increase for PVA-MA-silica membranes containing $10 \% \mathrm{SiO}_{2}$ [46]. Such combined improvement in both flux and salt rejection can be ascribed to the disruption of polymer chain packing by the incorporated silica particles in nano-scale and associated enhancement in free volume. Consequently, diffusion coefficient of the PVA-MA-silica membrane bearing $10 \mathrm{wt} \% \mathrm{SiO}_{2}$ was noted to be elevated because of the increasingly amorphous segments of PVA-MA-silica membrane facilitated faster diffusion of water (Figure 18a). However, water flux was noted to deteriorate once the $\mathrm{SiO}_{2}$ content was increased beyond $10 \mathrm{wt} \%$. Gradually, the elevated hydrophobicity and the compact nature might be the major contributing factors behind such reduced water flux. 


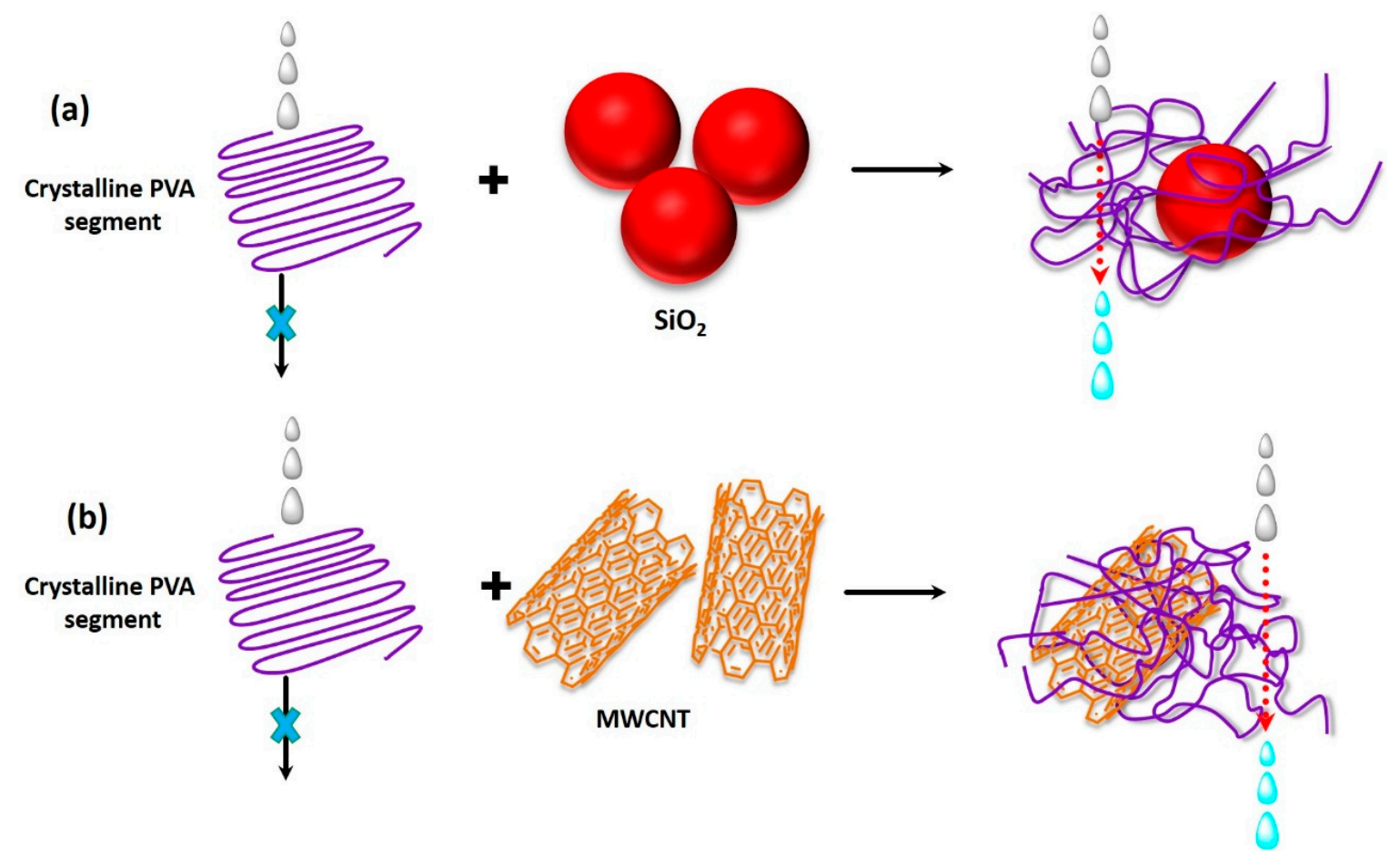

Figure 18. Disruption of polymer chain packing facilitates increased flux in NCP membrane containing (a) $\mathrm{SiO}_{2}$ and (b) MWCNT.

A similar kind of observation was also noted for MWCNT-PVA and Zeolite 3A-PEBA composites [120], in which the slight reduction in highly loaded composites could be explained by agglomeration of fillers. For instance, water flux was the maximum for MWCNT-PVA composite bearing $0.3 \mathrm{wt} \%$ filler, suggesting the maximum availability of voids because of the creation of such amorphous region that facilitated easier passage of water molecules (Figure 18b) [205,206]. Moreover, water molecules can pass through the hole of MWCNT with less resistance as compared to the PVA matrix [125].

In addition, similar to PVA-MA-silica membrane containing intermediate level of $\mathrm{SiO}_{2}$ (i.e., $10 \mathrm{wt} \%$ ), MWCNT-PVA composite containing $0.3 \mathrm{wt} \%$ filler showed better salt rejection than the composites containing 0.1 and $0.5 \mathrm{wt} \%$ MWCNTs. In fact, higher aggregation in MWCNT-PVA composite possessing $0.5 \mathrm{wt} \%$ filler was the major reason behind such inferior salt rejection. Indeed, deteriorated flux was observed for the PVA composite membrane prepared with the increasing amount of MA [114] or PMDA [127] as crosslinker, which was possibly because of the reduced hydrophilicity as a result of consumption of $\mathrm{O}-\mathrm{H}$ of PVA, along with the relatively compact structure and thus, lesser availability of free volume in the crosslinked structure. Indeed, such a crosslinked structure might contribute significantly in the enhanced salt rejection up to $99.9 \%$ for the feed saline of 50,000 ppm [114].

In case of PMDA crosslinked PAN-PVA composite membranes, crosslinking should be desired at the optimum level to ensure the minimum availability of $-\mathrm{COOH}$, which in-turn influence the facilitation of the water transport through the membrane [127]. In this context, the highest performance for PAN-PVA composite membrane could be achieved when crosslinking was conducted at $100{ }^{\circ} \mathrm{C}$. However, beyond $100^{\circ} \mathrm{C}$, water flux deteriorated excessively whereas salt rejection performance was found to be $<99 \%$ when crosslinking was conducted below $100{ }^{\circ} \mathrm{C}$, since crosslinking could not be completed below $100{ }^{\circ} \mathrm{C}$.

For SPTA crosslinked PAN-PVA composite membranes, $-\mathrm{SO}_{3} \mathrm{H}$ contributed significantly in maintaining water flux, despite increased crosslinking [128]. Clearly, a higher content of SPTA crosslinker is beneficial to water transport. Therefore, permeation of water through S-PVA layer was a combination of two mechanisms, of which the first mechanism is based on solution-diffusion, 
wherein water dissolves in the upper surface of SPVA layer, diffuses through the free volumes in the S-PVA polymer, and desorbs to the downstream atmosphere (Figure 19). The second mechanism is the $-\mathrm{SO}_{3} \mathrm{H}$-assisted transportation, by which water molecules are adsorbed to $-\mathrm{SO}_{3} \mathrm{H}$ of the membrane surface, followed by jumping to the nearby $-\mathrm{SO}_{3} \mathrm{H}$ of the bulk, until reaching the other side of the S-PVA layer, and finally desorption at the permeate side $[207,208]$. In fact, higher SPTA content in S-PVA films enhances the interaction probability of water molecules with $-\mathrm{SO}_{3} \mathrm{H}$, suggesting rapid binding of more carriers with the permeate on the membrane feed side. Such passage of permeate reduced the mass transport resistance in S-PVA films, transforming the convex water concentration profiles into the rectilinear shapes in the permeate direction [209].
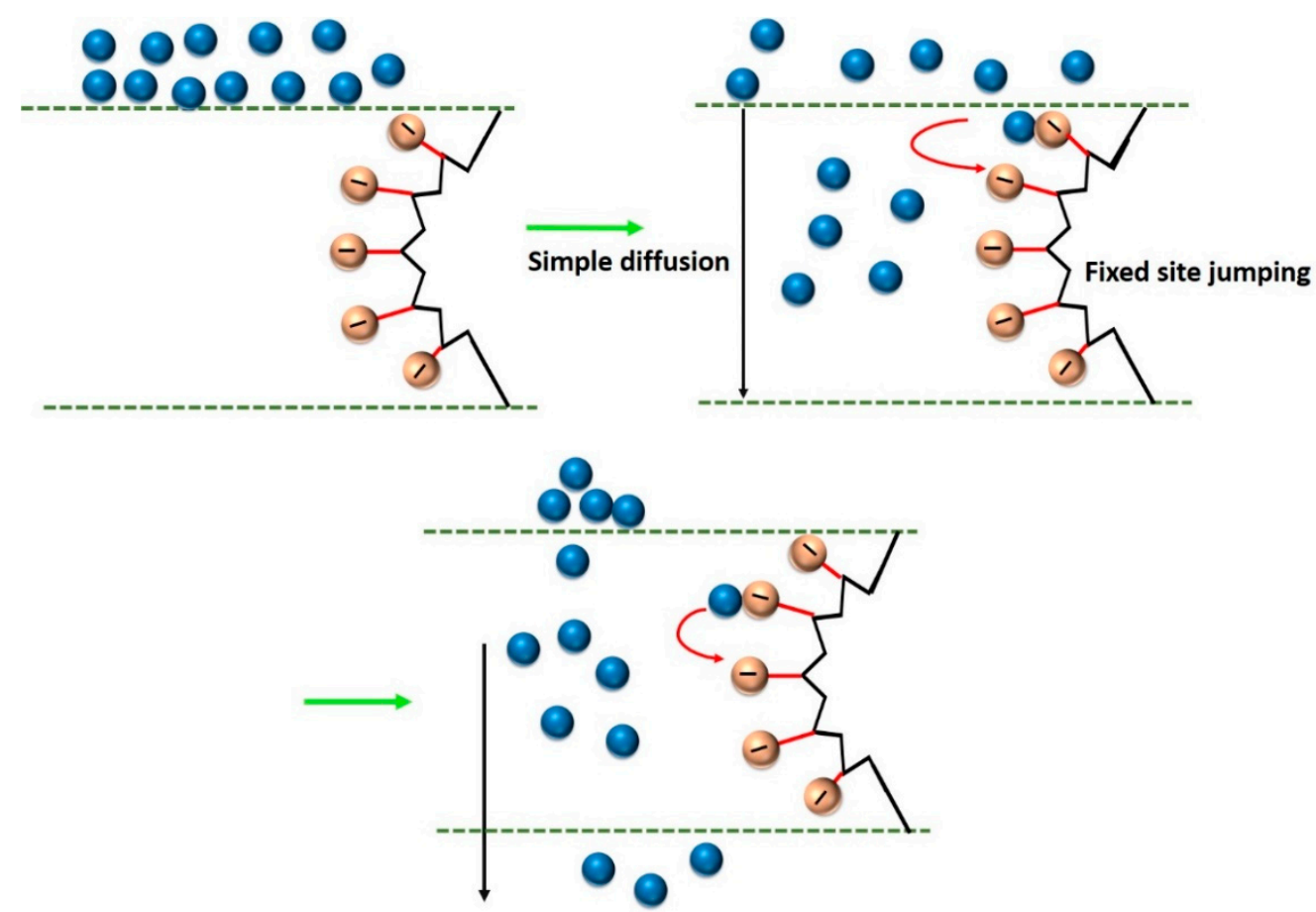

Figure 19. Mass transport of water molecules through an SPTA crosslinked PVA layer by simple diffusion and fixed site jumping.

In the case of the Zeolite 3A-PEBA membrane, the cage size is an important parameter for allowing higher rejection value. Thus, excellent salt rejections of $>99.67$ were achieved for all the Zeolite 3A-PEBA membranes, as most of the contaminating ions have larger molecular diameter than the cage size of zeolite or restricted free volume of the polymer [81,120]. Moreover, active deposition of crystalline particulate matter of inorganic salts and organic foulants, such as humic acid, can actuate the time dependent deterioration of flux through PV membrane, as the deposited layer can block the passage of water via occupying hydrated salts in the free volume of PVA network [164].

In this context, because of larger molecular size, organic foulants possess lesser tendency to penetrate into the bulk of membrane. However, they reside at the surface as a layer susceptible to microbial degradation. Moreover, it was noticed that foulants might combine with $\mathrm{Ca}^{2+}$ to produce insoluble Ca salts, which efficiently prevents water transport because of blocking the pores. Membranes equipped with anti-foulant properties can easily be cleaned by water solution and, thus, the fouling layer was strategically not allowed to penetrate deeply or associated with the membrane with stronger bonding force. It is well known that the PV performance not only depends on the membrane properties, but also on the operational conditions, such as feed concentration, temperature, permeate pressure, and feed flow rate [210]. 
Table 3. Performances of polymeric membranes in pervaporative desalination.

\begin{tabular}{|c|c|c|c|c|c|c|c|c|c|}
\hline $\begin{array}{l}\text { Composite/NCP } \\
\text { Membranes }\end{array}$ & Thickness $(\mu \mathrm{m})$ & $\begin{array}{l}\text { Feed } \\
\text { Temperature }\left({ }^{\circ} \mathrm{C}\right)\end{array}$ & 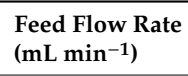 & $\begin{array}{l}\text { Feed Concentration } \\
(\mathrm{ppm})\end{array}$ & $\begin{array}{l}\text { Activation Energy } \\
\left(\mathrm{kJ} \mathrm{mol}^{-1}\right)\end{array}$ & $\begin{array}{l}\text { Permeate } \\
\text { Pressure }\end{array}$ & Flux $\left(\mathrm{kg} \mathrm{m}^{-2} \mathrm{~h}^{-1}\right)$ & Salt Rejection (\%) & Ref \\
\hline $\begin{array}{l}\mathrm{PVA}^{\mathrm{a}} / 20 \mathrm{MA} \\
\mathrm{b} / 10 \mathrm{Silica}\end{array}$ & 5 & 22 & - & - & - & 0.80 & 5.51 & $>95.50$ & [139] \\
\hline $\begin{array}{l}\text { PVA a/20MA } \\
\text { b/25Silica }\end{array}$ & 5 & 22 & - & - & - & 0.80 & $>3.65$ & $>95.50$ & [139] \\
\hline $\begin{array}{l}\text { PVA a/5MA } \\
\text { b/10Silica }\end{array}$ & $20 \pm 1$ & $22-65$ & 30 & $2000-50,000 \mathrm{NaCl}$ & $23.80-20.10$ & 0.80 & $2.50-11.70$ & $99.90(\max )$ & [100] \\
\hline $\mathrm{GO}^{\mathrm{c}} / \mathrm{PAN}^{\mathrm{d}}$ & - & 30 & - & $2000 / 35,000 / 50,000 / 100,000$ & 22.19 & - & $16.84 / 14.31 / 13.56 / 11.23$ & $>99.80$ & [50] \\
\hline $\mathrm{GO}^{\mathrm{c}} / \mathrm{PAN}^{\mathrm{d}}$ & $0.003-1.4$ & 90 & - & 35,000 & 22.19 & - & 65.10 & $>99.80$ & [50] \\
\hline PEBA $^{\mathrm{e}}$ & $120 \pm 5$ & 65 & - & - & - & 0.50 & - & 99.12 & [121] \\
\hline 3 GNPs $^{\mathrm{f}} / \mathrm{PEBA}^{\mathrm{e}}$ & $72 / 120 \pm 5 / 181$ & 65 & - & - & - & 0.50 & $5.12 / 3.61 / 2.73$ & $>99.89$ & [121] \\
\hline $3 \mathrm{GNPs}^{\mathrm{f}} / \mathrm{PEBA}^{\mathrm{e}}$ & $120 \pm 5$ & 35 & - & - & - & 0.50 & 2.58 & 99.94 & [121] \\
\hline MWCNT-PVA $g$ & 100 & 40 & - & $\begin{array}{l}\mathrm{NaCl}(1000 / 1500 / 2000)+ \\
\mathrm{MgCl}_{2}(200)+\mathrm{KCl}(200)\end{array}$ & - & - & - & $>92.00$ & [125] \\
\hline $\begin{array}{l}\mathrm{GO}^{\mathrm{c}} / \mathrm{PI}^{\mathrm{h}} \text { hollow } \\
\text { fiber }\end{array}$ & 1000 & 45 & - & $\begin{array}{l}35,000 \text { sea water }\left[\mathrm{Na}^{+}\right. \\
(2067) \mathrm{K}^{+}(323) \mathrm{Mg}^{2+}(872) \\
\mathrm{Ca}^{2+}(247), \mathrm{F}^{-}(188), \mathrm{Cl}^{-} \\
\left.(3132), \mathrm{PO}_{3}{ }^{-}(1025)\right]\end{array}$ & 18.76 & - & 6.40 & $\begin{array}{l}>99.80\left[\mathrm{Na}^{+}(99.90)\right. \\
\mathrm{K}^{+}(99.80) \\
\mathrm{Mg}^{2+}(99.90) \\
\mathrm{Ca}^{2+}(99.90), \mathrm{F}^{-} \\
(99.80), \mathrm{Cl}^{-}(99.90) \\
\left.\mathrm{PO}_{3}^{-}(99.80)\right]\end{array}$ & [126] \\
\hline $\begin{array}{l}\mathrm{GO}^{\mathrm{c}} / \mathrm{PI}^{\mathrm{h}} \text { hollow } \\
\text { fiber }\end{array}$ & 1000 & 60 & - & Do & Do & - & 8.10 & Do & [126] \\
\hline $\begin{array}{l}\mathrm{GO}^{\mathrm{c}} / \mathrm{PI}^{\mathrm{h}} \text { hollow } \\
\text { fiber }\end{array}$ & 1000 & 75 & - & 20,000/35,000/100,000 & Do & - & $17.50 / 11.50 / 4.20$ & Do & [126] \\
\hline $\begin{array}{l}\mathrm{GO}^{\mathrm{c}} / \mathrm{PI}^{\mathrm{h}} \text { hollow } \\
\text { fiber }\end{array}$ & 1000 & 90 & - & $\begin{array}{l}35,000 \text { sea water }\left[\mathrm{Na}^{+}\right. \\
(2067) \mathrm{K}^{+}(323) \mathrm{Mg}^{2+}(872) \\
\mathrm{Ca}^{2+}(247), \mathrm{F}^{-}(188), \mathrm{Cl}^{-} \\
\left.(3132), \mathrm{PO}_{3}{ }^{-}(1025)\right]\end{array}$ & Do & - & 15.60 & Do & [126] \\
\hline $\mathrm{PI}^{\mathrm{h}}$ & 1000 & 75 & - & Do & - & - & 1.90 & - & [126] \\
\hline $\mathrm{PEBA}^{\mathrm{e}} / \mathrm{PAN}^{\mathrm{d}} / \mathrm{PE}^{\mathrm{i}}$ & - & $40 / 50 / 60$ & - & $760 \mathrm{NaCl}$ & - & 4.00 & $>3.00 / 4.93 / 7.63$ & $>93.00$ & [119] \\
\hline $\mathrm{PEBA}^{\mathrm{e}} / \mathrm{PSF}^{\mathrm{j}} / \mathrm{PE}^{\mathrm{i}}$ & - & 50 & - & Do & - & Do & 1.24 & $>93.00$ & [119] \\
\hline $\begin{array}{l}\mathrm{PEBA}_{\mathrm{j} / \mathrm{PE}^{\mathrm{i}}}^{\mathrm{e}}+\mathrm{NaX} / \mathrm{PSF} \\
\end{array}$ & - & 50 & - & Do & - & Do & 1.30 & $>93.00$ & [119] \\
\hline
\end{tabular}


Table 3. Cont.

\begin{tabular}{|c|c|c|c|c|c|c|c|c|c|}
\hline $\begin{array}{l}\text { Composite/NCP } \\
\text { Membranes }\end{array}$ & Thickness $(\mu \mathrm{m})$ & $\begin{array}{l}\text { Feed } \\
\text { Temperature }\left({ }^{\circ} \mathrm{C}\right)\end{array}$ & 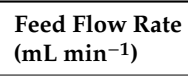 & $\begin{array}{l}\text { Feed Concentration } \\
\text { (ppm) }\end{array}$ & $\begin{array}{l}\text { Activation Energy } \\
\left(\mathrm{kJ} \mathrm{mol}^{-1}\right)\end{array}$ & $\begin{array}{l}\text { Permeate } \\
\text { Pressure }\end{array}$ & Flux $\left(\mathrm{kg} \mathrm{m}^{-2} \mathrm{~h}^{-1}\right)$ & Salt Rejection (\%) & Ref \\
\hline $\begin{array}{l}\mathrm{PVA}^{\mathrm{a}}\left(\mathrm{GA}^{\mathrm{k}}\right. \\
\text { crosslinked }) / \mathrm{PAN}^{\mathrm{d} / \mathrm{PET}^{1}}\end{array}$ & - & 25 & - & $5000 / 35,000 / 50,000$ & - & 0.10 & $8.53 / 7.36 / 5.81$ & 99.90/99.80/99.80 & {$[80]$} \\
\hline $\begin{array}{l}\text { SPTA }{ }^{\mathrm{m}} \text { crosslinked } \\
\text { PVA }^{\mathrm{a}} / \mathrm{PAN}^{\mathrm{d}}\end{array}$ & $\begin{array}{l}0.8 \text { (thickness of SPTA }{ }^{\mathrm{m}} \\
\text { crosslinked PVA }^{\text {a) }}\end{array}$ & 70 & - & $35,000 \mathrm{NaCl}$ & - & 0.10 & $49.30 \pm 1.10$ & 99.80 & [128] \\
\hline $\begin{array}{l}\text { SPTA }{ }^{m} \text { crosslinked } \\
\text { PVA }^{\text {a }} / \text { PAN }^{d}\end{array}$ & $\begin{array}{l}\text { 0.8/1.06/1.84/2.56/4.48/4.86/ } \\
17.2 / 33 / 46.3 / 76 \text { (thickness } \\
\text { of SPTA }^{\mathrm{m}}{ }^{\text {crosslinked }} \\
\text { PVA }^{\text {a) }} \text { ) }\end{array}$ & 30 & - & $35,000 \mathrm{NaCl}$ & - & 0.10 & $\begin{array}{l}\text { 14.11/11.23/10.08/9.50/9.42/ } \\
8.64 / 8.35 / 6.76 / 5.18 / 3.74\end{array}$ & $99.80 \pm 0.10$ & [128] \\
\hline $\begin{array}{l}\text { SPTA }{ }^{m} \text { crosslinked } \\
\text { PVA }^{a} / \text { PAN }^{d}\end{array}$ & 0.8 & 30 & - & $100,000 \mathrm{NaCl}$ & - & 0.10 & $7.80 \pm 0.30$ & & [128] \\
\hline $\begin{array}{l}\text { 20zeolite 3A/PEBA } \\
\mathrm{e}\end{array}$ & 100 & 40 & - & $\begin{array}{l}10,000 / 30,000 / 100,000 \\
\mathrm{NaCl}\end{array}$ & - & - & $3.30 / 3.10 / 1.98$ & 99.63 & [120] \\
\hline $\begin{array}{l}\text { 20zeolite 3A/PEBA } \\
\mathrm{e}\end{array}$ & 100 & 60 & - & $30,000 \mathrm{NaCl}$ & - & - & 4.33 & 99.16 & [120] \\
\hline PEBA $^{\mathrm{e}}$ & 100 & 40 & - & $30,000 \mathrm{NaCl}$ & - & - & 2.07 & $>99.50$ & [120] \\
\hline $\mathrm{GO}^{c} / \mathrm{CS}^{\mathrm{n}}$ & - & 81 & 1000 & $50,000 / 100,000 \mathrm{NaCl}$ & $\begin{array}{l}31.28 \pm 1.09 / 32.95 \pm \\
2.37\end{array}$ & 0.80 & $30.00 / 27.60$ & 99.99 & [136] \\
\hline $\mathrm{GO}^{\mathrm{c}} / \mathrm{CS}^{\mathrm{n}}$ & - & 75 & 1000 & $50,000 \mathrm{NaCl}$ & Do & 6.00 & 25.80 & 99.99 & [136] \\
\hline $\mathrm{GO}^{c} / \mathrm{CS}^{\mathrm{n}}$ & - & 60 & 1000 & $35,000 / 100,000 \mathrm{NaCl}$ & Do & 6.00 & $17.70 / 16.20$ & 99.99 & [136] \\
\hline $\mathrm{CS}^{\mathrm{n}}$ & - & 81 & 1000 & $50,000 / 100,000 \mathrm{NaCl}$ & $\begin{array}{l}37.94 \pm 1.19 / 42.90 \pm \\
1.93\end{array}$ & 6.00 & - & - & [136] \\
\hline $\begin{array}{l}\text { SSA }^{\circ} \text { crosslinked } \\
\text { PVA }^{a} / \text { PAN }^{d}\end{array}$ & $\begin{array}{l}4.9 \text { SSA }^{\mathrm{P}} \text { crosslinked } \\
\text { PVA }^{\mathrm{a}} \text { layer) }\end{array}$ & 70 & - & 35,000 & - & 0.10 & 27.90 & 99.80 & [122] \\
\hline $\begin{array}{l}\text { SSA }^{o} \text { crosslinked } \\
\text { PVA }^{a} / \text { PAN }^{d}\end{array}$ & $\begin{array}{l}\text { 4.9/18.4 (SSA }{ }^{\mathrm{P}} \\
\text { crosslinked PVA a layer) }\end{array}$ & 30 & - & 35,000 & - & 0.10 & $7.90 / 6.40$ & 99.80 & [122] \\
\hline $\begin{array}{l}\text { SSA }^{\circ} \text { crosslinked } \\
\text { PVA }^{a} / \text { PAN } \\
\end{array}$ & $\begin{array}{l}4.9 \text { SSA }^{\mathrm{P}} \text { crosslinked } \\
\text { PVA }^{\mathrm{a}} \text { layer) }\end{array}$ & 30 & - & 100,000 & - & 0.10 & 4.50 & - & [122] \\
\hline $\begin{array}{l}\text { 20PMDA } \mathrm{p} \\
\text { crosslinked PVA }^{\text {a } / \text { PAN }}{ }^{\mathrm{d}}\end{array}$ & $\begin{array}{l}2\left(\text { PMDA }^{\mathrm{P}} \text { crosslinked }\right. \\
\text { PVA }^{\mathrm{a}} \text { layer) }\end{array}$ & 70 & - & 35,000 & 23.60 & 0.10 & 32.26 & 99.98 & [127] \\
\hline
\end{tabular}


Table 3. Cont.

\begin{tabular}{|c|c|c|c|c|c|c|c|c|c|}
\hline $\begin{array}{l}\text { Composite/NCP } \\
\text { Membranes }\end{array}$ & Thickness $(\mu \mathrm{m})$ & $\begin{array}{l}\text { Feed } \\
\text { Temperature }\left({ }^{\circ} \mathrm{C}\right)\end{array}$ & $\begin{array}{l}\text { Feed Flow Rate } \\
\left(\mathrm{mL} \mathrm{min}^{-1}\right)\end{array}$ & $\begin{array}{l}\text { Feed Concentration } \\
(\mathrm{ppm})\end{array}$ & $\begin{array}{l}\text { Activation Energy } \\
\left(\mathrm{kJ} \mathrm{mol}^{-1}\right)\end{array}$ & $\begin{array}{l}\text { Permeate } \\
\text { Pressure }\end{array}$ & Flux $\left(\mathrm{kg} \mathrm{m}^{-2} \mathrm{~h}^{-1}\right)$ & Salt Rejection (\%) & Ref \\
\hline $\begin{array}{l}\text { 5PMDA }{ }^{\mathrm{P}} \\
\text { crosslinked PVA }^{\text {a/PAN }}{ }^{\mathrm{d}}\end{array}$ & 2 (do) & 50 & - & 35,000 & - & 0.10 & 9.88 & 99.96 & [127] \\
\hline $\begin{array}{l}\text { 10PMDA }{ }^{\mathrm{P}} \\
\text { crosslinked PVA }^{\text {a/PAN }}{ }^{\mathrm{d}}\end{array}$ & 2 (do) & 50 & - & 35,000 & - & 0.10 & 12.32 & 99.98 & [127] \\
\hline $\begin{array}{l}\text { 20PMDA } \mathrm{p} \\
\text { crosslinked PVA }^{\text {a/PAN }}{ }^{\mathrm{d}}\end{array}$ & 2 (do) & 50 & - & 35,000 & - & 0.10 & 16.47 & 99.98 & [127] \\
\hline $\begin{array}{l}\text { 30PMDA }{ }^{\mathrm{p}} \\
\text { crosslinked PVA }^{\text {a/PAN }}{ }^{\mathrm{d}}\end{array}$ & 2 (do) & 50 & - & 35,000 & - & 0.10 & 16.02 & 99.98 & [127] \\
\hline $\begin{array}{l}\mathrm{PVA}^{\mathrm{a}}-\mathrm{SiO}_{2} / \mathrm{PVSF} \mathrm{PV}^{\mathrm{N}} \\
\text { hollow fiber }\end{array}$ & $0.22 \pm 0.03$ & 60 & - & $2000 / 30,000 / 50,000$ & $-/ 14.44 / 14.74$ & - & $\begin{array}{l}20.60 \pm 0.45 / 10.40 \pm \\
0.22 / 8.80 \pm 0.20\end{array}$ & 99.90 & [118] \\
\hline $\begin{array}{l}\mathrm{PVA}^{\mathrm{a}}-\mathrm{SiO}_{2} / \mathrm{PVSF} \mathrm{q} \\
\text { hollow fiber }\end{array}$ & $0.30 \pm 0.03$ & 60 & - & Do & $-/ 15.05 / 16.47$ & - & $\begin{array}{l}19.80 \pm 0.40 / 9.70 \pm \\
0.24 / 7.90 \pm 0.18\end{array}$ & 99.90 & [118] \\
\hline $\begin{array}{l}\mathrm{PVA}^{\mathrm{a}}-\mathrm{SiO}_{2} / \mathrm{PVSF} \mathrm{PV}^{\mathrm{N}} \\
\text { hollow fiber }\end{array}$ & $0.60 \pm 0.05$ & 60 & - & Do & $-/ 16.63 / 20.05$ & - & $\begin{array}{l}17.20 \pm 0.40 / 8.10 \pm 0.22 / 6.70 \\
\pm 0.17\end{array}$ & 99.90 & [118] \\
\hline $\begin{array}{l}\mathrm{PVA}^{\mathrm{a}}-\mathrm{SiO}_{2} / \mathrm{PVSFq} \\
\text { hollow fiber }\end{array}$ & $0.85 \pm 0.07$ & 60 & - & Do & $-/ 18.52 / 23.49$ & - & $\begin{array}{l}15.30 \pm 0.33 / 7.00 \pm 0.23 / 5.90 \\
\pm 0.18\end{array}$ & 99.90 & [118] \\
\hline $\begin{array}{l}\mathrm{PVA}^{\mathrm{a}}-\mathrm{SiO}_{2} / \mathrm{PVSF} \mathrm{PV}^{\mathrm{N}} \\
\text { hollow fiber }\end{array}$ & $1.13 \pm 0.11$ & 60 & - & Do & $-/ 22.01 / 24.48$ & - & $\begin{array}{l}11.90 \pm 0.29 / 5.80 \pm 0.25 / 4.70 \\
\pm 0.26\end{array}$ & 99.90 & [118] \\
\hline $\begin{array}{l}\mathrm{MA}^{\mathrm{b}} \text { crosslinked } \\
\text { PVA }{ }^{\mathrm{a}} / \text { PVSF } \mathrm{q} \\
\text { hollow fiber }\end{array}$ & 0.10 & 71 & - & $30,000 / 40,000 / 50,000$ & $25.80 / 25.40 / 25.39$ & - & $4.60-7.40 /-/-$ & 99.90 & [114] \\
\hline $\begin{array}{l}\text { MA }^{\mathrm{b}} \text { crosslinked } \\
\text { PVA }^{\mathrm{a}} / \mathrm{PVSF} \mathrm{q} \\
\text { hollow fiber }\end{array}$ & 0.14 & 71 & - & Do & $25.80 / 25.06 / 25.06$ & - & Do & 99.90 & [114] \\
\hline $\begin{array}{l}\text { MA }^{\mathrm{b}} \text { crosslinked } \\
\text { PVA a/PVSF } \mathrm{q} \\
\text { hollow fiber }\end{array}$ & 0.27 & 71 & - & Do & $24.51 / 24.60 / 24.41$ & - & Do & 99.90 & [114] \\
\hline $\begin{array}{l}\text { MA }^{\mathrm{b}} \text { crosslinked } \\
\text { PVA a/PVSF } \mathrm{q} \\
\text { hollow fiber }\end{array}$ & 0.40 & 71 & - & Do & $23.72 / 24.38 / 24.06$ & - & Do & 99.90 & [114] \\
\hline
\end{tabular}


Table 3. Cont.

\begin{tabular}{|c|c|c|c|c|c|c|c|c|c|}
\hline $\begin{array}{l}\text { Composite/NCP } \\
\text { Membranes }\end{array}$ & Thickness $(\mu \mathrm{m})$ & $\begin{array}{l}\text { Feed } \\
\text { Temperature }\left({ }^{\circ} \mathrm{C}\right)\end{array}$ & $\begin{array}{l}\text { Feed Flow Rate } \\
\left(\mathrm{mL} \mathrm{min}^{-1}\right)\end{array}$ & $\begin{array}{l}\text { Feed Concentration } \\
(\mathrm{ppm})\end{array}$ & $\begin{array}{l}\text { Activation Energy } \\
\left(\mathrm{kJ} \mathrm{mol}^{-1}\right)\end{array}$ & $\begin{array}{l}\text { Permeate } \\
\text { Pressure }\end{array}$ & Flux $\left(\mathrm{kg} \mathrm{m}^{-2} \mathrm{~h}^{-1}\right)$ & Salt Rejection (\%) & Ref \\
\hline $\begin{array}{l}\text { MA }^{\mathrm{b}} \text { crosslinked } \\
\text { PVA }^{\text {a }} / \mathrm{PVSF}^{\mathrm{q}} \\
\text { hollow fiber }\end{array}$ & 0.85 & 71 & - & Do & 23.80/23.62/23.51 & - & Do & 99.90 & [114] \\
\hline $\begin{array}{l}\text { MA }^{\mathrm{b}} \text { crosslinked } \\
\text { PVA a }{ }^{\mathrm{a} V S F} \mathrm{q} \\
\text { hollow fiber }\end{array}$ & 1.03 & 71 & - & Do & 23.46/23.10/23.07 & - & Do & 99.90 & [114] \\
\hline $\begin{array}{l}\text { nonporous films of } \\
\text { hydrated cellulose }\end{array}$ & - & - & - & - & - & 0.02 & $0.91-1.90$ & 100.00 & [142] \\
\hline $\begin{array}{l}\mathrm{CA}^{\mathrm{r}} \text { powder based } \\
\text { membranes }\end{array}$ & $20-25$ & $50-80$ & - & $\begin{array}{l}40,000,48,000,50,000, \\
\text { and } 140,000 \mathrm{NaCl}\end{array}$ & $\begin{array}{l}21.71,19.83,15.94, \\
\text { and } 20.21\end{array}$ & - & $5.97-10.00$ & 99.70 & [130] \\
\hline cellulose triacetate & 10 & 50 & - & 100,000 & - & air sweep & 2.30 & 99.00 & [101] \\
\hline $\begin{array}{l}\text { quaternized } \mathrm{PE}{ }^{\mathrm{i}} \text {, } \\
\text { anion exchanger }\end{array}$ & - & $45-65$ & - & $0-176,000$ & - & & $1.50-3.00$ & & [42] \\
\hline polyether amide & 40 & $68-70$ & solar heating & 32,000 & - & cooler tunnel & 0.56 & 99.99 & [43] \\
\hline $\begin{array}{l}\text { deacetylated } \\
\text { cellulose acetate }\end{array}$ & 22 & 70 & - & 120,000 & - & air sweep & 4.11 & 99.90 & [211] \\
\hline cotton cellulose & 30 & 40 & - & 40,000 & - & vacuum; 0.02 & $4.55-6.70$ & 100.00 & [131] \\
\hline polyester & 750 & 20 & 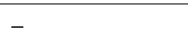 & 35,000 & - & sand heating & $7.10 \times 10^{-3}$ & 99.84 & [102] \\
\hline
\end{tabular}

${ }^{a}$ Polyvinyl alcohol, ${ }^{\mathrm{b}}$ maleic acid, ${ }^{\mathrm{c}}$ graphene oxide, ${ }^{\mathrm{d}}$ polyacrylonitrile, ${ }^{\mathrm{e}}$ polyether block amide, ${ }^{\mathrm{f}}$ graphene nanoplates, ${ }^{\mathrm{g}}$ multi-walled carbon nanotubes loaded polyvinyl alcohol membranes, ${ }^{\mathrm{h}}$ polyimide, ${ }^{\mathrm{i}}$ polyester, ${ }^{\mathrm{j}}$ polysulfone, ${ }^{\mathrm{k}}$ glutaraldehyde, ${ }^{l}$ polyethylene terephthalate, ${ }^{\mathrm{m}} 4$-sulfophthalic acid, ${ }^{\mathrm{n}}$ chitosan, ${ }^{\mathrm{o}}$ sulfosuccinic acid, ${ }^{\mathrm{p}}$ pyromellitic dianhydride, ${ }^{\mathrm{q}}$ polyvinylsulfone, and ${ }^{\mathrm{r}}$ cellulose acetate. 


\subsubsection{Feed Concentration}

The feed concentration is believed to affect directly the sorption of its components at the interface between feed and membrane surface [210-212]. With the increase in salt concentration, reduction in the vapor pressure of water occurs, accompanied by the slight reduction in membrane swelling. Therefore, permeate flux is reduced (Figure 20) [213]. In general, the effect of salt concentration on water flux is dependent on feed temperature. In fact, salt concentration has a negligible influence on water flux at room temperature $[100,119]$. However, with the increase in feed temperature, water flux was noted to decrease with the increase in salt concentration $[50,100,126,127,136]$. Such an adverse effect of increased $\mathrm{NaCl}$ concentration on the reduced water flux was observed for pervaporative desalination by the MWCNT-PVA membrane at $40^{\circ} \mathrm{C}$ [125] and the PEBA-Zeolite 3A membranes [120]. The gradual reduction in the water of feed solution with higher $\mathrm{NaCl}$ concentration affect $\mathrm{PV}$ significantly, since the driving force for the pervaporative separation is primarily the difference in the partial pressures of the components on the two sides of the membrane. Importantly, vapor pressure is exponentially related to the temperature and, thus, lowering of the water concentration imposes a pronounced effect on the concentration of water at the membrane surface that ultimately reduces the difference between the partial pressures of the water on either sides of the membrane, hampering the diffusivity and flux at the higher temperature. However, a substantial effect of increased salt concentration of the feed solution in reducing the water flux was observed for PV-based separation by the GO-PAN membrane even at $30{ }^{\circ} \mathrm{C}$ [50]. With the increase in feed concentration in the pseudo-liquid type aqueous salt solution, increased relative population of bulky hydrated ions and accordingly decreased concentration of free water molecules at the adjacent region of membrane surface was responsible for the lowering of water flux through membrane. Similar flux declines with the increased feed concentration were reported in seawater desalination through PV [113,214] and MD [215-217] processes. Indeed, the decrease in flux for more concentrated feed can be explained by the reduction in water VP. Such reduction in VP of saline water can be interpreted from Equation (5) showing the relation between VP of saline water $(P)$ and pure water $\left(P_{0}\right)$ :

$$
\log \left(\frac{P}{P_{0}}\right)=h S+j S^{2}
$$

Here, $S$ and $h / j$ represent salinity (i.e., the amount of salt in water) and constants, respectively.

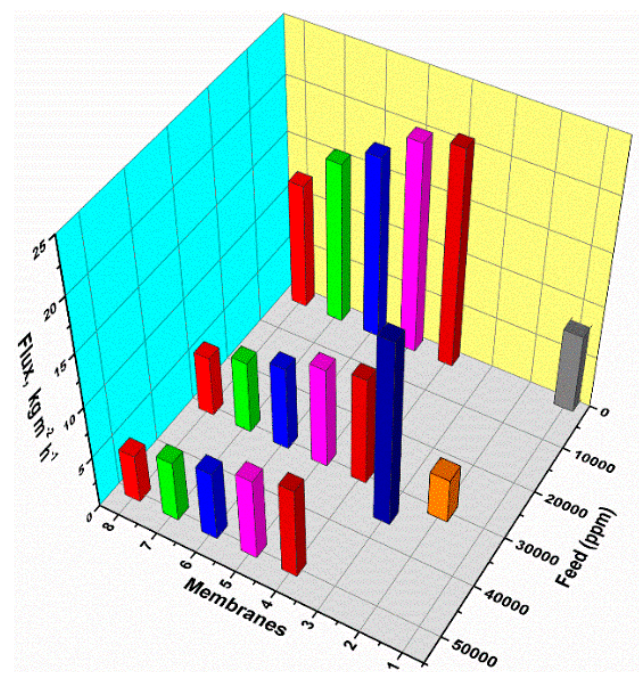

Figure 20. Variation of flux as the function of feed concentrations of different membranes (1: PEBA/PAN/PE, 2: 20zeolite 3A/PEBA, 3: GO/CS, 4: $\mathrm{PVA}-\mathrm{SiO}_{2} / \mathrm{PVSF}$ hollow fiber (thickness: $0.22 \pm 0.03 \mu \mathrm{m}$ ), 5: PVA-SiO $2 / \mathrm{PVSF}$ hollow fiber (thickness: $0.30 \pm 0.03 \mu \mathrm{m}$ ), 6: PVA-SiO $/ \mathrm{PVSF}$ hollow fiber (thickness: $0.60 \pm 0.05 \mu \mathrm{m}$ ), 7: PVA-SiO $2 / \mathrm{PVSF}$ hollow fiber (thickness: $0.85 \pm 0.07 \mu \mathrm{m}$ ), and 8: PVA-SiO $2 / \mathrm{PVSF}$ hollow fiber (thickness: $1.13 \pm 0.11 \mu \mathrm{m}$ ) at $60{ }^{\circ} \mathrm{C}$. 


\subsubsection{Feed Flow Rate}

Xie et al. evaluated the impact of feed flow rate on water flux, while keeping all the other parameters unaltered [100]. According to their observation, the feed flow rate showed little or negligible effect on water flux through hybrid PVA-MA-silica membrane. In this context, the feed flow rate was varied while maintaining the Reynolds numbers within 21-105 to ensure laminar flow of the feeding mixture. In general, an increase in feed flow rate reduces concentration polarization and increases flux because of the reduction of transport resistance in liquid boundary layer [210]. On the contrary, such an observation made by Xie et al. indicated that mass transfer from the feed to the membrane was not a rate-limiting step and, thus, the rate of PV was not affected by the feed flow rate. However, it was not reported that what will happen to the rate of PV if the feed flow rate is increased to the turbulent flow region so that the Reynolds number exceeds beyond 4100.

\subsubsection{Effect of Permeate Pressure}

Theoretically, the maximum flux is achieved when the permeate pressure reaches absolute zero. In doing so, a reasonable cost factor is involved for maintaining high vacuum. In general, the water flux decreases when the permeate pressure is increased because of the consequent decrease in the driving force, necessary for mass transport [119]. As per the observation made by Xie et al. [100], once the permeate pressure exceeded 15 Torr, the driving force for water vaporization approached near zero, leading to the negligible net evaporation and, consequently, to the low mass transport of water. Such a phenomenon is closely related to the fact that the saturation VP of water is about $2.27 \mathrm{kPa}$. Thus, as the permeate pressure was increased beyond $2 \mathrm{kPa}$, almost a $90 \%$ drop in the diffusion coefficient was observed, indicating a tremendous reduction in the diffusion of water through the membrane [100].

\subsubsection{Temperature}

Increasing flux with temperature is the prevalent observation for PV separation studies [218,219]. As VP is exponentially related to temperature $[100,220]$, increased temperature up to a certain level resulted in the enhanced flux, which is again because of the increased driving force between the sides of the membrane created by the increasing VP in the feed side $[119,121,126]$. Such an observation can be interpreted by the Antoine equation (Equation (6)), which expresses an exponential relation between VP (i.e., $P$ ) and temperature (i.e., $T$ ) of water [221]:

$$
\log \frac{P}{P_{0}}=A-\frac{B}{T+C}
$$

Here, $A, B$, and $C$ are the constants.

Furthermore, with the increase in operational temperature, exacerbated thermal motion of water molecules in solutions can accelerate the diffusion of water through the membrane. In addition, the mobility of the polymer chains in a membrane increased with the feed temperature, leading to the increased free volume in the membranes. According to the free volume theory [222], such a temperature-dependent increase in free-volume can be ascribed to the enhanced frequency and amplitude of the polymer chains in amorphous regions, creating momentary free volumes in excess at higher temperatures $[119,223]$. Consequently, greater free space is available for water molecules to diffuse easily through the membrane. Thus, with increasing temperature, flux was noted to increase exponentially for all the membranes at all the feed concentrations [114,118]. However, such enhanced free volume at higher temperatures is responsible for the deterioration in the salt rejection capability, as enhanced thermal motion of polymer chain segments allowed salt-ions to pass through the membrane [118]. 


\subsubsection{Thickness of Membrane}

With the increase in membrane thickness, resistance across membrane increases $[46,218,224,225]$. Accordingly, water flux was found to decrease from 5.12 to $2.73 \mathrm{~kg} \mathrm{~m}^{-2} \mathrm{~h}^{-1}$ when the PEBA-NCP membrane thickness was altered from 72 to $181 \mu \mathrm{m}$ [121]. A similar decrease in flux with the enhancement in membrane thickness was observed by Xie et al. [46]. However, the thickness variation did not remarkably affect the extent of salt rejections.

In this context, water permeabilities through S-PVA-PAN composite membranes were found to reduce drastically with the increase in thickness of S-PVA layer from 76 to $1.06 \mu \mathrm{m}$ [128] because of the significantly lower water diffusivity at the dry portions of the membrane, closer to the permeate side. Interestingly, in dry regions, water flux is the function of diffusivity, which was reduced slightly because of the higher membrane thickness [135,209,226].

According to Liang et al. [50], thicker deposition of GO increased the thickness of GO-PAN composite membrane, which affected water flux and membrane efficiency [227]. Therefore, in order to fabricate high-efficiency PV membranes, the minimum thickness of the GO layer should be preferable, along with the maintenance of the required structural integrity. It appeared that the increased thickness of the GO layer should compel the diffusing water molecules to travel through a substantially longer tortuous pathway, constituting of the nano-capillaries between well-stacked GO sheets [228-230], resulting in the significant lowering of mass transport through the relatively thicker GO-PAN composite membrane.

A similar influence of increasing thickness was observed in the case of composite PVA membranes [88]. In fact, composite membranes based on dilute PVA solution-coated PVS hollow fiber exhibited higher flux (up to $7.4 \mathrm{~L} \mathrm{~m}^{-2} \mathrm{~h}^{-1}$ ) as compared to those membranes prepared using less dilute-solution-coating, relatively concentrated PVA solution produced the membranes of higher thickness offering higher resistance against the mass transport [227].

On contrary, the increased flux was resulted using thin membrane obtained from less dilute solution coating [118]. In the case of composite membranes, the non-linear variation between membrane thickness and flux was ascribed to the cumulative effect shown by layer thicknesses of top and support layers. These two layers were composed of different materials carrying different porosities and structures. Moreover, steep decline of flux was resulted in the case of increasingly dense support structure, along with the increase in the top membrane layer thickness [231].

\subsubsection{Electrical Resistance of Membranes}

It is well established that the PV mechanism is mostly interpreted by the solution-diffusion model, constituting three steps: firstly adsorption and dissolution of feed molecules on the membrane surface, followed by diffusion of dissolved species through the membrane, and finally, desorption of the diffused species at the permeate side [50]. In addition to the usual solution-diffusion model, water passage or salt rejection in the PV desalination system is directly related to the size exclusion and/or charge exclusion phenomena (Figure 21) [81,218]. Electrical resistance of the membrane is an important parameter, which helps evaluate the charge characteristics of the membrane involved in separating charged species in PV desalination system. Thus, PV desalination can be subdivided into two major periods, of which in the first period, water passage and diffusion through the uncharged membrane is related to the size exclusion process, because the size of the molecules is the sole deciding factor to separate the unwanted species from water. Later, during the subsequent period, once the surface of the membrane becomes charged by the ions in seawater, an electrostatic interaction starts to prevail between the membrane surface and seawater. Consequently, water passage and diffusion through the membrane is jointly controlled by both charge exclusion and size exclusion mechanisms (Figure 21). Accordingly, when an uncharged membrane becomes charged during the last period of PV desalination, the electrical resistance of the membrane should be altered. 
(a)

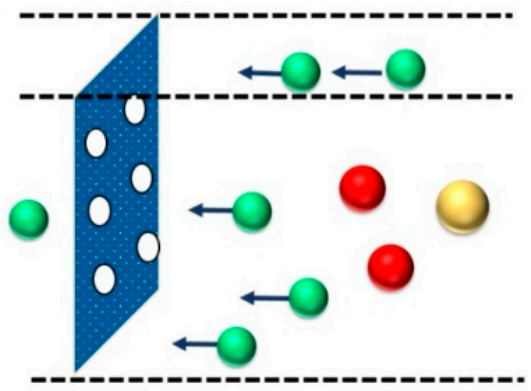

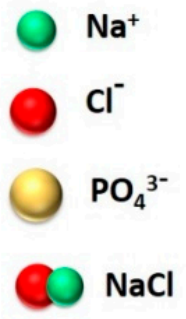

(b)

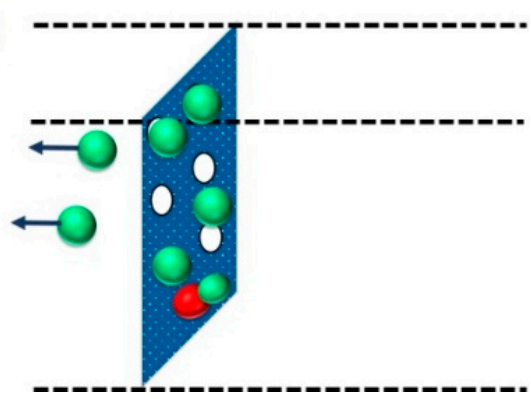

Figure 21. Two-stage separation of membrane comprising (a) size exclusion and (b) both size and charge exclusion.

In the case of the PEBA-GNP composite membrane, the electrical resistance of PEBA membrane was noted to decrease after desalination. Accordingly, the conductivity and the charge load on membrane increased during desalination, as the hydrated ions penetrate and reside in the feed side of the membrane structure. Thus, this increasingly charged membrane repels the existing ions in the feed side of the membrane, and hence, the incoming ions experience repulsive force towards the feed side according to the 'charge exclusion' theory. Moreover, during addition of GNP moieties, the initial electrical conductivity of the uncharged membrane increased, if GNP moieties are devoid of forming agglomerates inside the membrane [121]. Such increased conductivity helps improve the performance of PV desalination via enhancing the charge exclusion ability of the membrane, in addition to the enhanced size exclusion ability through extending the tortuous pathway through the GNP-loaded membrane.

For the PVA-coated composite membrane, the purity of the produced water was evaluated by measuring the conductivity [114]. Chaudhri et al. observed the lowest conductance of $\sim 20 \mu \mathrm{S} \mathrm{cm}{ }^{-1}$ when a membrane of $1000 \mathrm{~nm}$ top-layer-thickness was used to purify feed water containing 30,000 ppm $\mathrm{NaCl}$. However, with the reduction of thickness, the conductance value of the produced water was noted to increase because of diffusion and percolation of some solvated $\mathrm{NaCl}$ through the swollen membranes.

\section{Inorganic Membranes for Pervaporative Desalination}

Recently, polymeric membranes have found extensive applications for membrane-based desalination and wastewater treatment because of sustainability, selectivity, and high performance potential. Use of polymeric membranes in desalination and wastewater treatment depends on the optimization of the two opposite terms, i.e., permeability and selectivity, along with membrane fouling and scaling. Poor sustainability restricts the use of the polymeric membranes as water purifier and thus, substantial attention was introduced for the development of thermomechanically stable and sustainable MMMs and thin film NCPs [232]. In fact, composite membranes comprising of the blended properties of both polymeric matrix and inorganic fillers are gaining high insight for membrane-based desalination techniques.

As compared to the organic membranes, inorganic membranes usually possess superior structural stability, i.e., no swelling and compaction, even in harsh chemical environments and high temperatures [233-235]. In addition, desalination of wastewater containing radioactive substances and highly concentrated organic effluents, oil, and grease can effectively be carried out using inorganic membranes instead of the polymeric membranes, which suffer from severe fouling and poor sustainability [236-239]. Additionally, inorganic membranes are lesser susceptible towards bacterial attack as compared to the most of the polymeric membranes [240]. Moreover, inorganic membranes are beneficial for brackish water treatment, seawater pre-treatment, and high temperature desalination, wherein the high rejection (i.e., >99\%) is not an essential task [241]. Therefore, development of inorganic membranes possessing extraordinary physicochemical properties, high tunability, and recyclability/reusability are gaining high insight. The selective transportation of constituents 
through inorganic membranes are principally guided by the pore size of the membranes. In this context, inorganic membranes can broadly be classified into two categories, such as ceramic- and carbon-based membranes. Oxides, such as alumina, silica, titania, and mixtures of these components are the most commonly used ceramic membranes [242]. Of these, amorphous silica contains extremely small pores and an asymmetric structure, wherein the microporous silica prevails onto a support containing several $\alpha$-and $\gamma$-alumina layers $[243,244]$. Most of the reported silica membranes possess either flat plate or tubular geometry. The flat plate geometry usually possess small surface area of $\sim 10^{-2} \mathrm{~m}^{2}$ because of the limitations of dip-coating technique. However, because of larger surface area, tubular-shaped silica membranes are better suitable for pervaporative desalination [235]. Instead of such advantages, the tubular-shaped membranes possess certain disadvantages, such as expensive and low surface area-to-volume ratio (i.e., $<500 \mathrm{~m}^{2} \mathrm{~m}^{-3}$ ).

Ceramic membranes, another extensively used inorganic membrane, is composed of a macroporous support layer and a meso-/micro-porous active layer. Initially, high cost of synthesis and complex instrumentation limited the industrial use of inorganic membranes for pervaporative desalination [245]. In past days, inorganic membranes were merely used to work under highly contaminated feed environment and at high temperature, wherein the polymeric membranes did not work properly. However, the discovery of low-cost ceramic membranes containing clays and organic pore formers has reinvigorated the frequent use of ceramic-based inorganic membranes in the commercial scale [246-249]. In fact, in the modern era, syntheses of new inorganic-based composite membranes, such as MOF, $\mathrm{CNT}$, and graphene and its derivatives, have gained a high impact for the pervaporative desalination of wastewater. These membranes have imparted the high permeability, selectivity, and salt rejection. Therefore, these new membranes are anticipated to ameliorate some existing issues found in the contemporarily used materials and accomplish the practically efficient, high productivity, and energy saving wastewater treatment processes.

\subsection{Various Inorganic Membranes Used}

Korngold et al. optimized the effects of membrane properties (i.e., thickness and charge density) and experimental conditions (i.e., temperature, feed water salinity, and sweep gas velocity) on water flux during pervaporative desalination of a nonporous proton exchange membrane [42]. Interestingly, the water flux was found to increase with the rise in velocity of sweeping gas to attain a plateau at the sweeping gas velocity of $2 \mathrm{~m} \mathrm{~s}^{-1}$, attributed to the hydraulic resistance, which was imposed by the hollow fiber membrane. Alternatively, the passage of water through the membrane depends on the transport of the liquid within the membrane and is independent of air velocity. The permeate flux increased with the decrease in membrane thickness and the increase in water temperature. However, permeate flux reduced with the enhancement of feed $\mathrm{NaCl}$ concentration from 0 to $3 \mathrm{M}$. In most of the cases, the salt rejection efficiencies through different membranes in pervaporative desalination have been reported to be $\sim 99 \%$. However, because of the permeation of both solutes and water through hydrophilic inorganic membranes, desalination efficiency reduces substantially $[43,137,250]$. The performance of various inorganic membranes are discussed in Table 4.

The permeation of salts through hydrophilic nonporous membranes occurs through different possible mechanisms [251-253], of which the most common mechanism includes the adsorption of salt molecules into membranes, followed by smooth passage through the polymer matrix by diffusion. In fact, the salt permeation was found to be significantly affected by several important membrane-based factors, such as the temperature, the free-volume space within the membrane, the hydrodynamic radius of the dissolved substances, the closeness of solubility parameters between membrane and component, and the possible electrostatic interactions between membrane and substance. According to Ju et al. [254], water selectivity of the membrane decreases with the increase in permeability. 
Table 4. Performances of composite/NCP inorganic membranes in pervaporative desalination.

\begin{tabular}{|c|c|c|c|c|c|c|c|c|}
\hline $\begin{array}{l}\text { Composite/ NCP } \\
\text { Inorganic Membranes }\end{array}$ & $\begin{array}{l}\text { Temperature } \\
\left({ }^{\circ} \mathrm{C}\right)\end{array}$ & $\begin{array}{l}\text { Conditions in Feed } \\
\text { Side }\end{array}$ & $\begin{array}{l}\text { Feed Concentration } \\
\left(\mathrm{g} \mathrm{L}^{-1}\right)\end{array}$ & $\begin{array}{l}\text { Conditions in } \\
\text { Permeate Side }\end{array}$ & $\begin{array}{l}\text { Membrane } \\
\text { Thickness }(\mu \mathrm{m})\end{array}$ & Flux $\left(\mathrm{kg} \mathrm{m}^{-2} \mathrm{~h}^{-1}\right)$ & Rejection (\%) & Ref. \\
\hline NaA zeolite membrane & 69 & - & - & - & - & 1.90 & - & [81] \\
\hline $\begin{array}{l}\mathrm{PVA}^{\mathrm{a}} / \mathrm{MA}^{\mathrm{b}} / \text { silica } \\
\text { hybrid membrane }\end{array}$ & 22 & - & - & - & - & 6.93 & - & [46] \\
\hline 2D MXene ${ }^{c}$ & 65 & - & 35.00 & - & 0.06 & 4.74 & 99.50 & [133] \\
\hline $\mathrm{GO}^{\mathrm{d}} / \mathrm{PAN}^{\mathrm{e}}$ & 90 & - & 100.00 & - & $0.03-1.40$ & 3.62 & 99.80 & [50] \\
\hline $\mathrm{GO}^{\mathrm{d}} / \mathrm{PVA}^{\mathrm{a}} / \mathrm{PVDF}^{\mathrm{f}}$ & 65 & $\begin{array}{l}\text { cross-flow velocity }= \\
0.625 \mathrm{~ms}^{-1}\end{array}$ & 100.00 & $\begin{array}{l}\text { vacuum pressure } \\
\sim 24,000 \mathrm{~Pa}\end{array}$ & 100.00 & 1.56 & 99.99 & [134] \\
\hline LiCl-S-PVA ${ }^{g}$ & 70 & flow rate $=0.2 \mathrm{~ms}^{-1}$ & 35.00 & pressure $=100 \mathrm{~Pa}$ & 33.10 & 60.80 & 99.80 & [135] \\
\hline pristine PVA $^{\mathrm{a}}$ & $20 / 30 / 40$ & atmospheric pressure & 35.00 & $3000 \mathrm{~Pa}$ & - & $1.49 / 1.63 / 1.98$ & $100.00 / 95.80 / 95.00$ & [255] \\
\hline zeolite 3A-loaded PVA & $20 / 30 / 40$ & atmospheric pressure & 35.00 & $3000 \mathrm{~Pa}$ & - & $1.82 / 2.36 / 2.57$ & $100.00 / 96.10 / 96.00$ & [255] \\
\hline $\mathrm{PVA}^{\mathrm{a}} / \mathrm{PAN}^{\mathrm{e}}$ & 20 & - & 5.00 & vacuum & 0.62 & 9.04 & 99.50 & [80] \\
\hline NaA zeolite membrane & 69 & - & Seawater & vacuum & - & 1.90 & 99.90 & [81] \\
\hline $\mathrm{NaA}$ zeolite membrane & 77 & - & 29.00 & vacuum & - & 4.40 & 99.90 & [81] \\
\hline LTA $^{\mathrm{h}}$ and MFI zeolite & 25 & - & 0.13 & vacuum & 15.00 & 0.20 & 99.40 & [111] \\
\hline NaA zeolite & 20 & - & 0.10 & vacuum & 10.00 & 1.43 & 99.83 & [108] \\
\hline clinoptilolite-phosphate & 95 & - & 1.40 & vacuum & - & 15.00 & 95.00 & [107] \\
\hline $\begin{array}{l}\text { silica from TEOS }{ }^{i} \text { and } \\
\text { MTES } j\end{array}$ & 25 & $700 \mathrm{kPa}$ & 3.00 & vacuum & - & 4.70 & 93.00 & [256] \\
\hline $\begin{array}{l}\text { silica from } \operatorname{TEOS}^{i} \text { and } \\
\text { MTES }^{j}\end{array}$ & 25 & $700 \mathrm{kPa}$ & 3.00 & vacuum & - & 2.20 & 99.90 & [256] \\
\hline CTS $^{k}$ & 20 & - & 3.00 & vacuum & - & 3.20 & 97.00 & [109] \\
\hline $\mathrm{CTAB}^{1}{ }^{1}$-silica & 25 & - & 40.00 & vacuum & 0.21 & 2.60 & 99.90 & [115] \\
\hline templated silica & 20 & - & 35.00 & vacuum & 0.50 & 3.70 & 98.50 & [112] \\
\hline nickel oxide silica & 25 & - & 3.00 & vacuum & - & 7.00 & 99.90 & [257] \\
\hline
\end{tabular}

${ }^{\mathrm{a}}$ polyvinyl alcohol, ${ }^{\mathrm{b}}$ maleic acid, ${ }^{\mathrm{c}} \mathrm{Ti}_{3} \mathrm{C}_{2} \mathrm{~T}_{\mathrm{x}}$ membranes, ${ }^{\mathrm{d}}$ graphene oxide, ${ }^{\mathrm{e}}$ polyacrylonitrile, ${ }^{\mathrm{f}}$ polyvinylidene difluoride, ${ }^{\mathrm{g}}$ 4-sulfonylphthalic acid cross-linked poly(vinyl alcohol),

$\mathrm{h}$ linde type $\mathrm{A},{ }^{\mathrm{i}}$ tetraethyl ortho silicate, ${ }^{\mathrm{j}}$ methyl tri-ethoxy silane, ${ }^{\mathrm{k}}$ carbon template silica, and ${ }^{1}$ cetyltrimethyl ammonium bromide. 


\subsubsection{Ceramic Membranes}

Recently, the use of ceramic membranes in UF, NF, RO, GS, and PV is gaining high insight [258-261]. The foremost application fields of ceramic membranes include food, biotechnology, water purification, and pharmaceutical industries. In pervaporative desalination, use of ceramic membranes possess several advantages over polymeric membranes, such as thermo-mechanical resistance, chemical stability, sustainability, non-swelling, and simple cleaning. Commercially viable ceramic membranes are synthesized from metal oxides, such as alumina, silica, zirconia, and titania. Because of the prevalence of $\mathrm{O}-\mathrm{H}$ groups, such hydrophilic ceramic membranes can easily bind with water molecules [258-261]. Therefore, the incorporation of hydrophobicity into the predominantly hydrophilic ceramic membranes via grafting of hydrophobic molecules and chemical modifications is recently gaining high insight [262-270]. Alami-Younssi et al. [262] and Jou et al. [263], grafted $\gamma$-alumina and polyvinyl acetate into ceramics for chemical modification. Again, Pickard et al. [264], investigated the impregnation of two fluorinated silanes, $\mathrm{C}_{6} \mathrm{~F}_{13} \mathrm{C}_{2} \mathrm{H}_{4} \mathrm{Si}(\mathrm{OMe})_{4}$ and $\mathrm{C}_{8} \mathrm{~F}_{17} \mathrm{C}_{2} \mathrm{H}_{4} \mathrm{Si}(\mathrm{OEt})_{3}$ into the ceramic membranes. Additionally, Caro et al. [265], reported the chemical treatment of commercial ceramic filters to achieve both pore narrowing and hydrophilic/hydrophobic functionalization. The $\gamma-\mathrm{Al}_{2} \mathrm{O}_{3}$-based top layer of the asymmetric ceramic filter was functionalized by in situ hydrolysis of tetraethylorthosilicate to introduce $\mathrm{Si}-\mathrm{OH}$-rich hydrophilic nanoporous $\mathrm{SiO}_{\mathrm{x}}$ top layer, followed by silylation of the $\gamma-\mathrm{Al}_{2} \mathrm{O}_{3}$ layer, to attain organophilic functionalization (Figure 22), and finally, reaction of the $\gamma-\mathrm{Al}_{2} \mathrm{O}_{3}$ layer with alkyl/aryl phosphonic acids to incorporate hydrophobic behavior. In this context, the use of FAS for the introduction of hydrophobic character via reaction between $\mathrm{O}-\mathrm{H}$ of the ceramics and ethoxy groups (O-Et) of organosilane compounds [262,264,270-272]. The as-prepared hydrophobic layer of organosilane compounds onto ceramic surface caused the hydrophobic character of such membranes [264,268,273] (Figure 23).

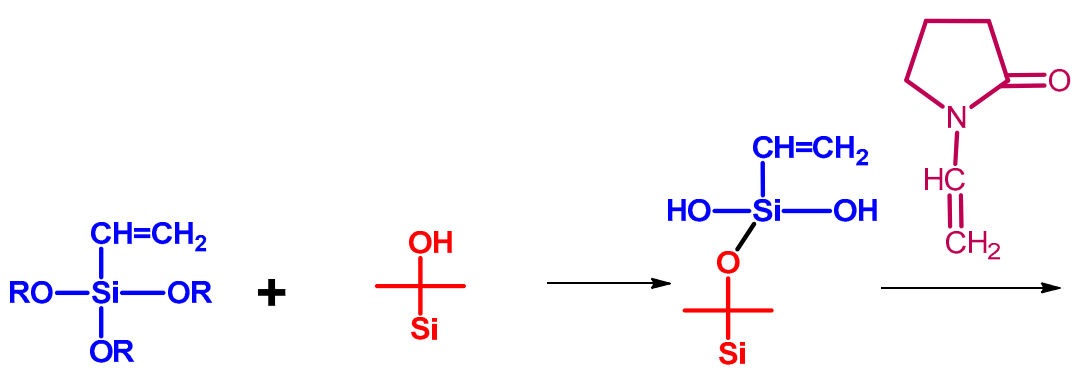

(A)

(B)

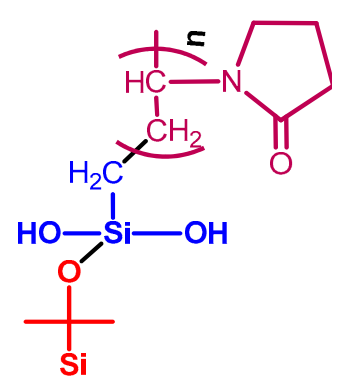

(C)

Figure 22. Schematic diagram of the surface modification procedure: (A) Surface silylation, (B) graft polymerization, and $(\mathbf{C})$ resultant covalently-bonded PVP chain.

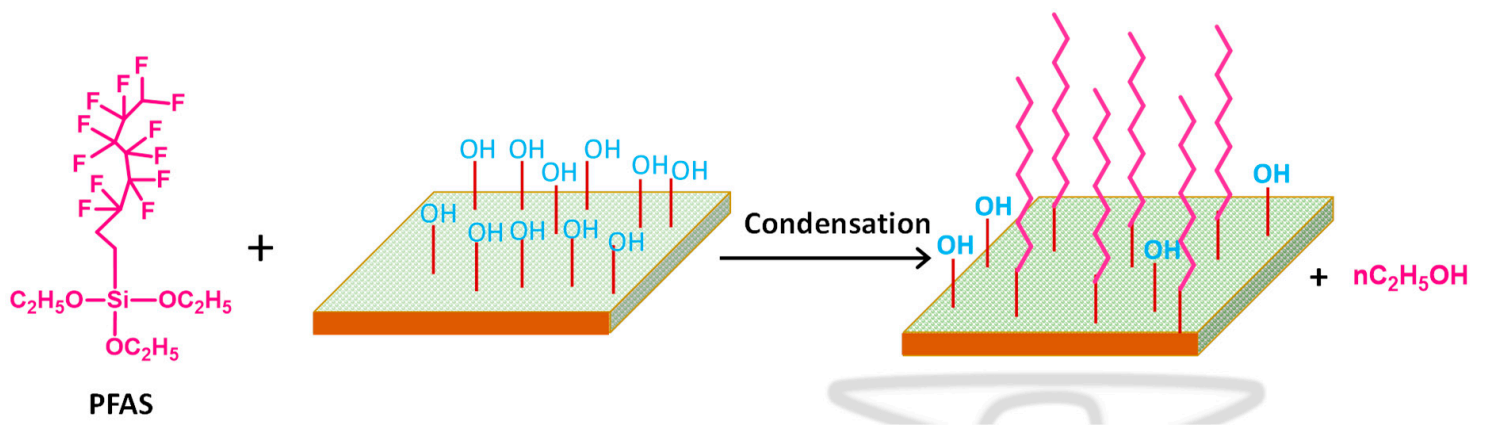

Figure 23. Scheme of modification process by PFAS molecules.

In this context, Larbot et al. reported the synthesis and applications of hydrophobic ceramic membranes via grafting of different FAS onto the surface of alumina, titania, zirconia, and silica membranes [264,270,274-276]. 


\subsubsection{Metal Oxide Membranes}

Ceramic membranes are composed of a wide range of insoluble oxides, of which zirconiaand titania-based mesoporous membranes find extensive commercial applications. From the very beginning, porous metal oxide-based ceramic membrane is composed of the multi-layer asymmetric structure containing a thicker supportive layer of comparatively larger pores $(\sim 500 \mathrm{~nm})$ for attainment of the mechanical integrity, an intermediate layer, which reduces pore size into mesoporous dimensions $(2-5 \mathrm{~nm})$, and a thinner top layer possessing small pores $(<1 \mathrm{~nm})$ responsible for selective separation $[277,278]$. Metal-oxide based ceramic membranes are predominantly synthesized via sol-gel method, which can further be classified into two categories, i.e., colloidal and polymeric sol-gel routes, depending on the solvent used. In colloidal sol-gel method, water is used as solvent, whereas in polymeric method, organic solvents are utilized. Therefore, colloidal method is more environment friendly than polymeric sol-gel method [279]. Synthesis of ceramic membranes from oxide precursors via colloidal sol-gel method comprises of two steps, of which the first step is associated with the precipitation of a condensed, hydroxylated species from hydrolyzed precursors. However, in the second step, the as-prepared precipitate is converted into a stable sol via a peptization reaction with basic or acidic electrolytes [280].

Mesoporous $\gamma$-alumina membrane, one of the most widely investigated ceramic membranes, is usually considered as the interlayers for ceramic membranes. Though most of the mesoporous $\gamma$-alumina membranes contain the average pore size within 3-5 $\mathrm{nm}$ [280], membranes showing average pore sizes of $\sim 1 \mathrm{~nm}$ has also been studied. However, such low pore dimensions restrict the permeation of water through membranes resulting in very low permeance, which is not suitable at all for industrial applications. However, such a problem was surmounted by Wang et al., via synthesizing solvent resistant alumina NF membrane of $1.61 \mathrm{~nm}$ thickness, possessing the permeability as high as $17.4 \mathrm{~L} \mathrm{~m}^{-2} \mathrm{~h}^{-1}$ bar $^{-1}$ [281]. Though the orthodox metal oxide-based ceramic membranes possess three layers, the newly developed ceramic membranes contain mesoporous top layer for pervaporative desalination [278,282-286]. These membranes contain several advantages, such as low cost-synthetic technique, since these membranes are devoid of an extra top layer and involvement of cheap reactants, and reduced membrane thickness, which can enhance the water flux via minimizing the resistance against water diffusion through the membrane. In this context, coal fly ash, the by-product of combustion of raw coal in power plants, was used as raw materials for fabricating mullite$\left(3 \mathrm{Al}_{2} \mathrm{O}_{3} \cdot 2 \mathrm{SiO}_{2}\right)$ and cordierite- $\left(2 \mathrm{MgO} \cdot 2 \mathrm{Al}_{2} \mathrm{O}_{3} \cdot 5 \mathrm{SiO}_{2}\right)$-based ceramic membrane supports, along with the addition of dolomite for controlling porosity, pore size distribution, and microstructures [287-289].

Selective desalination through the majority of porous metal oxide-based ceramic membranes is fabricated via increment in size by hydration, followed by electrostatic effects at the pores [290]. For decontamination of raw industrial wastewater bearing the mixtures of toxic metal ions, organics, and inorganic substances, the selectivity is primarily achieved via electrostatic interactions between pollutants and positively-charged metal oxide ceramic membranes [291]. Electrostatic interaction, $\mathrm{pH}$ of the feed solution, and modulation of the membrane surface charge influence the rejection mechanism.

Though the maximum ceramic membranes possess uniform meso-/micro-porous structure, some oxide-based ceramic membranes, especially amorphous silica membranes exhibit trimodal pore size distribution, containing smaller (i.e., $3 \AA$ ) and larger (i.e., 8 and $12 \AA$ ) pores, responsible for selective permeation [282]. Desalination is primarily achieved by the restriction of hydrated ions through pores, allowing the passage of water molecules (Figure 24a). However, selective permeation through mesoporous portions connected with the microporous shrinking or to another mesoporous region may allow the passage of small amount of salts in the permeate side (Figure 24b), which would reduce the selectivity towards desalination.

Additionally, removal efficiency of membranes can be enhanced via combination of filtration and adsorptive phenomenon of the reactive surface functional groups, such as the active silanol group present onto the surface of nanosilica membrane, can impart adsorptive active sites to adsorb pollutants from aqueous solution [292]. Since superficial properties play the pivotal role to affect 
several membrane-based intrinsic properties, such as hydrophobicity, surface charges, hydrodynamics, and fouling rate [293], extensive investigations have been devoted for the proper characterization of superficial properties of the ceramic membranes.

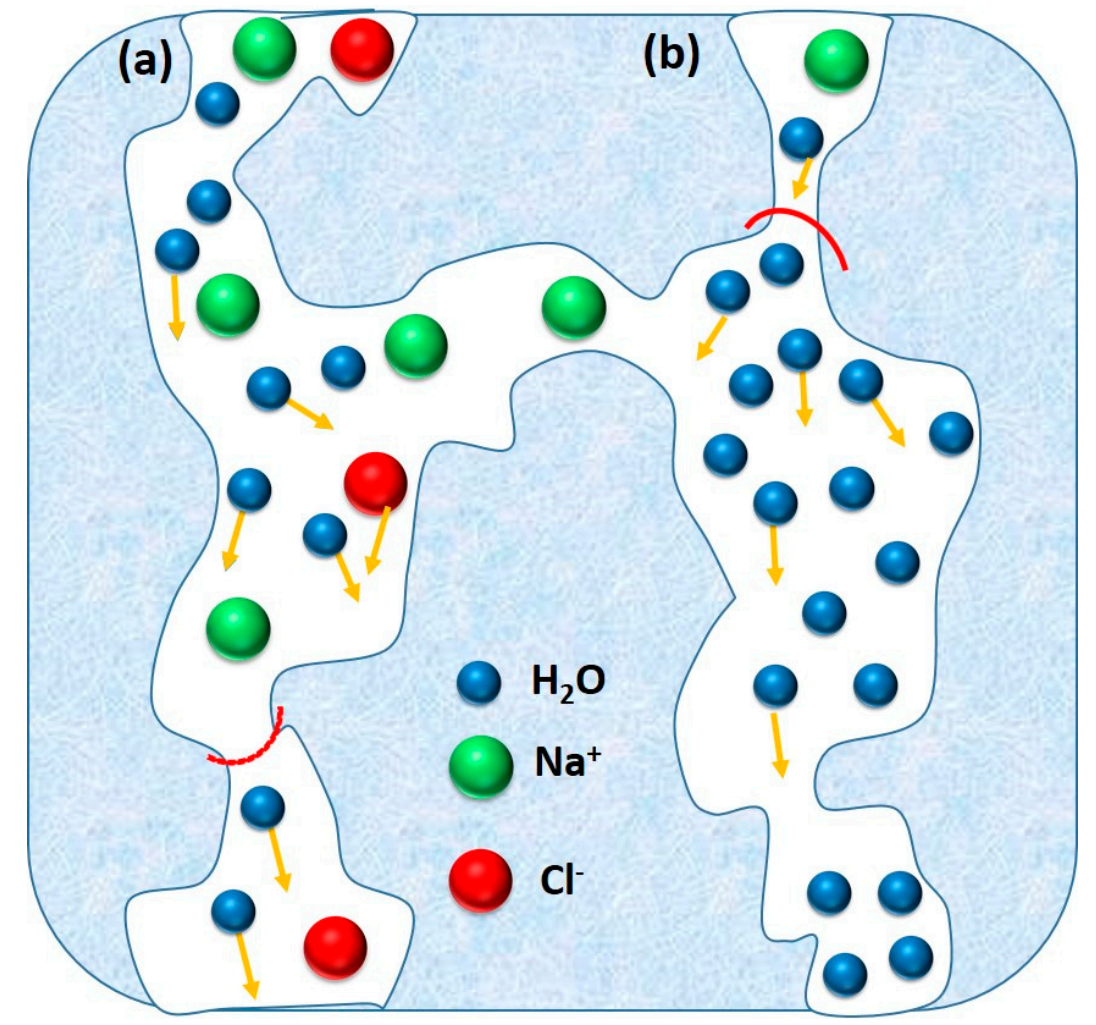

Figure 24. Illustration of percolative porous pathway and diffusion of water and hydrated salt ions through (a) mesoporous region that non-selective to small amount of hydrated salt ions, and (b) microporous constrictions that only allows the passage of water molecules.

The surfaces of the metal oxide-based ceramic membranes usually possess significant numbers of O-H enhancing the hydrophilicity of membranes [294]. These O-H located on membrane surface provide the necessary reactive sites to graft hydrophobic organic moieties, necessary for the introduction of hydrophobicity into the predominant hydrophilic membrane. Such hydrophobized ceramic membranes find widespread applications in membrane-based operations, such as desalination, distillation, and PV, as compared to the native hydrophilic metal oxide membranes [295].

The hydrophobicity and/or shrinking pore size of ceramic membranes carrying chemically active surface functional groups, such as silane groups, can be controlled by grafting FAS to the metal oxide and/or membrane surfaces [296-299]. As stated earlier, the dual functionalities of FAS, i.e., hydrolyzable groups in one end and organic moieties on the other, can easily react with $\mathrm{O}-\mathrm{H}$ located onto metal oxide surface to form stable Al-O-Si type covalent bonds. Kujawa and coworkers reported the modification of tubular and planar ceramic titania membranes and powders of $\mathrm{Al}_{2} \mathrm{O}_{3}, \mathrm{TiO}_{2}$, and $\mathrm{ZrO}_{2}$ using varied FAS molecules to obtain hydrophobic membranes of enhanced thermal stabilities [296-299]. Alternatively, in the presence of water, the reaction between hydrolyzable groups of the organosilanes and other organosilanes for producing a polymeric layer can be another plausible binding route for hydrophobization.

Few researchers have reported the coating of a thin polymeric layer onto commercialized macroporous ceramic membranes for improving the desalination performance of the ceramic membranes [300-307]. The polymeric chains are covalently bonded with the ceramic support surface in such composite membranes, wherein the desired flux and selectivity are achieved from the thin coating and the ceramic support renders the structural fragility and reduces the pore size of the 
ceramic support $[278,308,309]$. Since the polymer solution may penetrate into the ceramic pores, preparation of a dense and defect-free composite membrane is highly challenging. Moreover, it is highly essential to rationalize the mechanism of polymer layer formation at the adhesion surface to optimize the desalinating performance, since selectivity and permeation through polymeric membranes are predominantly dependent on the composition, synthetic method, thickness, and operating conditions [310]. In fact, such surface modification modulates permeability characteristics and enhances flux in response to temperature [311-315], $\mathrm{pH}$ and controlled phase inversion parameter determining pore structures [316-319], and ionic strength of the feed stream [320-324]. Polymer coating onto ceramic membranes is carried out mainly via dip-coating method, in which a coating solution containing polymer, solvent, and crosslinker is prepared, followed by coating onto the outer surface of the tubular ceramic support and heat treatment. In order to enhance the surface smoothness and ensure supreme quality of the resultant polymer-ceramic composite membranes, the ceramic supports are thoroughly polished prior to the dip-coating [301]. Additionally, tubular $\alpha$-alumina ceramic membrane has also been coated using CA to reduce the original ceramic pore size in order to increase the efficiency of the composite membranes [300]. The coated polymer layer also plays an important role in controlling the pore-type diffusion and sorption of components onto the coated surface to attaining the better removal efficiency.

\subsubsection{Zeolite Membranes}

Zeolites and crystalline aluminosilicates carrying well-defined pore/channel structures are gaining high insight for alternative inorganic membrane-based gas [325] and liquid phase separations [326] and pervaporative desalination [306,327-338]. The prevalence of several mono-/divalent cations, such as $\mathrm{Na}^{+}, \mathrm{K}^{+}, \mathrm{Ca}^{2+}$, and $\mathrm{Mg}^{2+}$, enable the cation-exchange phenomenon during desalination. The main advantages of zeolite membranes are directly related to their high separation performance, catalytic activity, good thermal and chemical stabilities, and low fouling tendencies $[339,340]$. Such membranes are believed to provide desired separation potential for molecules comprising of the variable sizes and adsorptive properties [242].

Zeolite membranes are more advantageous over the conventional polymeric membranes, since the pore sizes of zeolite membranes can be tuned precisely to achieve perfect molecular size and shape for obtaining the high separation [341]. Zeolite membranes are advantageous for desalination because of their ability to remove ions from aqueous saline solutions, leading to high salt rejection [334]. Most importantly, separation efficiency has been found to be directly proportional to the valency ion, indicating that the separation mechanism is based on rejection of the hydrated ions by size exclusion and ions interactions, which are influenced by the charged double layer formed in inter-crystalline gaps of zeolite membranes [139]. If salt rejection cannot be obtained via pore size exclusion, functionalization of zeolite cage can be carried out alternatively to enhance the membrane separation efficiency, as observed in Al-rich zeolite membranes [342], wherein the membrane properties, such as surface hydrophobicity and charge are significantly changed [343].

The mechanism of selective diffusion of water from the salt solution is based on the differences of molecular sizes of water and hydrated ions. The molecular dimensions of water, $\mathrm{Na}^{+}$, and $\mathrm{Cl}^{-}$are 2.6, 7.2, and 6.6 $\AA$, respectively $[139,142]$. Therefore, zeolite membranes of pore sizes within $2.7-6.5 \AA$ should be ideal for salt rejection.

Of different zeolite membranes NaA and MFI membranes are found to possess pore sizes of $\sim 4 \AA$ [344] and $\sim 5.5 \AA$ [345], respectively. Thus these membranes are perfectly suitable for seawater desalination. MFI-type zeolite possesses orthorhombic crystal symmetry with almost cylindrical 10-member ring channels with aperture size within $0.54-0.56 \mathrm{~nm}$ and intracrystalline pores within 1.1-1.2 nm [346-348]. Indeed, flat, tubular mono, and multi-channel MFI membranes with varied sizes have been fabricated for pervaporative desalination. In addition to the production of high-quality reusable water, MFI-type membranes possess high tolerance level towards long-term strong chlorine cleaning. 
Additionally, hydrophilic zeolites, such as LTA membranes, have been found to possess good ion rejection efficiency, yet poor water flux for seawater desalination, because of small pore opening of $\sim 0.4 \mathrm{~nm}$ [349], restricts their use for desalination. Additionally, some other classes of zeolite membranes, such as LTA and FAU [350,351], have also been fabricated for membrane-based water purification and desalination.

In recent past, zeolite membranes possessing variable morphologies, compositions, and separation prospects have been synthesized. However, the synthesis of zeolite membranes can be carried out either in one step (Figure 25) or via secondary growth approach (Figure 26) [242]. Zeolite nanocrystals, better known as nanozeolites, can readily be used as nanoseeds to fabricate dense zeolite films and membranes via secondary growth based on the superior colloidal properties of their suspensions [352,353]. During secondary growth method, coating of zeolite seeds on the support surface is carried out prior to hydrothermal synthesis to fabricate high quality zeolite membranes. Such method of synthesis gives the better control on membrane formation because of the separation of crystal nucleation and growth within a small crystallization time [354-356]. Additionally, the secondary growth method enables the growth of zeolite crystals onto the support rather than in the solution that confines the nucleation transformation to other crystals [357,358]. However, two major challenges appear during membrane synthesis via secondary growth method. The first one is how the colloidal suspension of zeolite particles are prepared, whereas the second concern is how the coating of seeds are carried out onto the support surface.

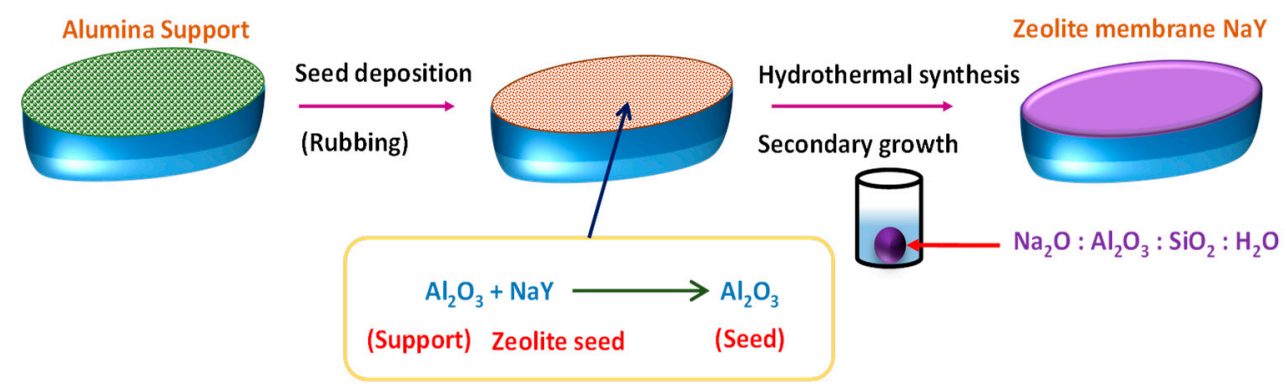

Figure 25. One-step method for the preparation of the zeolite membrane.

\section{Seeding}

Seeded

support

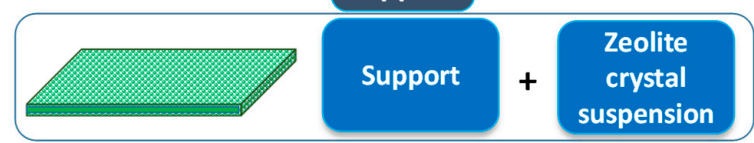

Synthesis solution

$\begin{gathered}\text { Tetraethoxy } \\ \text { silane }\end{gathered}+\begin{gathered}\text { Tetrapropyl } \\ \text { ammonium } \\ \text { hydroxide }\end{gathered}+\begin{gathered}\text { Sodium } \\ \text { hydroxide }\end{gathered}+\begin{gathered}\text { Deionized } \\ \text { water }\end{gathered}$

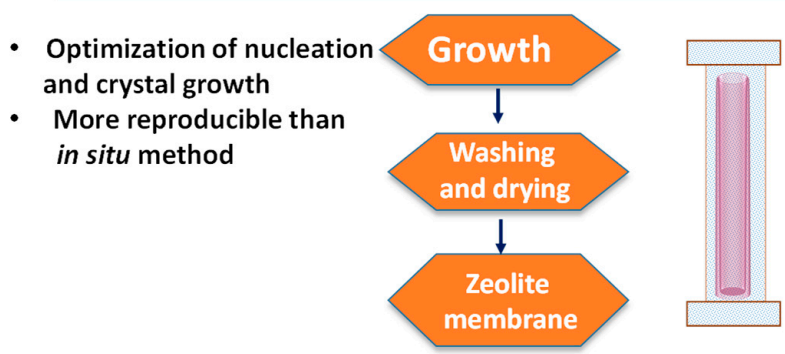

Figure 26. Secondary growth for preparation of the zeolite membrane. 
Coating of seeds onto the support surface may be carried via dip coating [359-362], rub coating [363], spray coating [364], spin coating [365], and pulsed laser deposition [366,367]. Of these, dip coating is the most widely used method. However, the close attachment of zeolite seeds with the support surface is not possible and, hence, the colloidal suspensions can easily drizzle during removal of supports from suspension. Thus, it is highly difficult to obtain uniform and continuous seeding layer. Moreover, the same coating process is to be repeated several times for obtaining seeding layer with good coverage [368]. Furthermore, the fragility of the substrate and poor compatibility between the zeolite thin film and substrate has imposed the probability of defect formation, which hampers the practical application in commercial desalination. Therefore, fabrication of natural, dense zeolite membranes, devoid of macroporosity or fragile crystal grain boundaries, is gaining high insight.

Dense clinoptilolite has been chosen as one of the promising geomorphic natural zeolites, which shows the desired mechanical robustness in industrial applications. Microwave-assisted heating based on secondary growth has also been attempted to synthesize LTA, MFI, AFI, FAU, SOD, and ETS-4 type zeolite membranes. Such microwave irradiation is more profitable as the method is kinetically fast, in which the resulting membrane is devoid of intracrystalline defect with high salt rejection efficiency [369]. The overall membrane thickness can be controlled in the microwave irradiation method which facilitates the permeation of water at the zeolite film-substrate interface, enhancing the water flux [57].

Though the use of zeolite membranes was initially limited towards GS and ethanol-water separation through PV [346], presently the use of zeolite membranes for desalination is gaining high insight [349]. Historically, Li et al. first reported desalination using MFI silicalite-1 zeolite membrane that exhibited $\sim 77 \%$ salt rejection and very low water flux [329]. Therefore, subsequent modifications have been carried out to modify the zeolite structure to improve the salt rejection efficiency, since desalination through zeolite membranes is devoid of the costly pretreatment for polymeric RO membranes. To improve hydrophilicity, the Si:Al ratio of zeolite membranes should be kept as low as possible. In fact, at higher Si:Al ratio, the thermo-chemical stability of zeolite membranes are not satisfactory because of the higher stability of $\mathrm{Si}-\mathrm{O}$ as compared to $\mathrm{Al}-\mathrm{O}$ bond [370]. Hence, optimization of the Si:Al ratio is highly essential to stabilize the polycrystalline structure, along with to enhance the wettability and membrane surface charge, resulting in high flux and salt rejection. In case of Al-rich zeolite membranes, functionalization of the zeolite cage can also be carried out to enhance the membrane performance. Instead of the extensive utilization of hydrophilic membranes imparting higher water fluxes, the hydrophobic character of the zeolite sub-nanometer pore structure plays the pivotal role to offer a desired internal surface chemistry, facilitating the higher mass flow across the zeolite membranes [347]. Duke et al. [334] reported seawater desalination using MFI zeolite membranes of variable Si:Al ratios.

The defect-free zeolites are highly preferable as the diffusion can only take place through the intra-crystalline pores within the zeolite cage resulting in the excellent separation performance. Unfortunately, the preparation of such defect-free zeolite thin film with no micro-defect is always hampered by the defects of synthesis including the insufficient intergrowth of crystals. Moreover, since zeolite membranes are polycrystalline films of nano-sized inter-crystal pores, the interactions between zeolite and ions in feed solution restrict the permeance of some ions into the zeolitic pores during the passage through pores and boundaries reducing the permeability. Additionally, during the attachment of ions onto the external surface and microporous inter-crystal boundaries, coinciding double layers tend to accumulate that severely hampered the ion transportation [329]. In the maximum situations, the ion rejection and water flux are related to the size and charge density of the solute ion, double layer thickness, ionic strength, and temperature of the solution. In this context, Zhou et al. reported that FAU zeolites with greater hydrophilicity can overcome the water flux and ion selectivity tradeoff via producing improved water adsorption and diffusion through their relatively large pore size [349]. 


\subsubsection{Silica Membranes}

Another widely used inorganic membrane for salt desalination is the silicate membrane. Li et al. [329] reported a silicalite membrane of $\sim 1 \mathrm{~nm}$ pore diameter and high chemical stability for desalination. For a $0.1(\mathrm{M}) \mathrm{NaCl}$ solution, the said silicalite membrane showed time-dependent transient water flux and $\mathrm{Na}^{+}$rejection up to $0.112 \mathrm{~kg} \mathrm{~m}^{-2} \mathrm{~h}^{-1}$ and $76.7 \%$, respectively. For a mixture of salt solution containing $0.1(\mathrm{M})$ each of $\mathrm{NaCl}, \mathrm{KCl}, \mathrm{NH}_{4} \mathrm{Cl}, \mathrm{CaCl}_{2}$, and $\mathrm{MgCl}_{2}$, the water flux of $0.058 \mathrm{~kg} \mathrm{~m}^{-2} \mathrm{~h}^{-1}$ and rejections for $\mathrm{Na}^{+}, \mathrm{K}^{+}, \mathrm{NH}_{4}{ }^{+}, \mathrm{Ca}^{2+}$, and $\mathrm{Mg}^{2+}$ up to 58.1, 62.6, 79.9, 80.7, and $88.4 \%$, respectively, were observed. Li et al. also investigated the influence of salt concentration, especially counter cations, on water flux and ion rejection [371]. A drastic decline of $\mathrm{Na}^{+}$rejection and water flux, in the aid of multivalent cations, such as $\mathrm{Ca}^{2+}$ and $\mathrm{Al}^{3+}$, was observed because of the adsorption of multivalent cations. Due to the screening effect of the adsorbed cations on the surface charge, an increment of the effective pore diameter was observed. Fortunately, such increment in pore diameter enhanced the permeation of small $\mathrm{Na}^{+}$ions, resulting in the increase in $\mathrm{Na}^{+}$rejection. Skluzacek et al. [372] reported the salt rejection using an iron-modified silica membrane of $15 \AA$ pore diameter. Interestingly, salts rejections within $60-80 \%$ were reported for $\mathrm{NaCl}$ and $\mathrm{Na}_{2} \mathrm{SO}_{4}$ solutions, whereas up to $10 \%$ salt rejection was observed for solutions of $\mathrm{MgCl}_{2}$ and $\mathrm{MgSO}_{4}$. Poor salt rejection in $\mathrm{Mg}^{2+}$-salt solutions could be explained on the basis of the charge exclusion mechanism induced by charge reversal because of the selective adsorption of $\mathrm{Mg}^{2+}$. Alami-Younssi et al. [373] reported metal-complex desalination using a $\gamma$-alumina membrane with a $7 \AA$ pore diameter, in which fluxes and salt rejections were found to be the functions of $\mathrm{pH}$ of solution as well as size charge of the complexes. Fluxes were influenced by the electrostatic interactions between complex and membrane surface, whereas the rejections depend on size and charge of the complex. Samuel de Lint et al. [374] reported the electrolyte separation from $1(\mathrm{M}) \mathrm{NaCl}$ using $\gamma$-alumina-supported silica membrane bearing $8 \AA$ pore diameter. The $\mathrm{Na}^{+}$and $\mathrm{Cl}^{-}$rejections based on charge exclusion mechanism strongly depend on the $\mathrm{pH}$ of the solution. Gazagnes et al. [375] reported seawater desalination using a zirconia membrane with a $50 \mathrm{~nm}$ pore diameter, showing high rejection and flux of $>95 \%$ and $38.4 \mathrm{~L} \mathrm{day}^{-1} \mathrm{~m}^{-2}$.

Duke et al. [334] reported PV desalination using $\alpha$-alumina, $\gamma$-alumina, and silica membranes of 5000 , 40, and 3-5 A pore diameters, respectively, in which water flux and $\mathrm{NaCl}$ rejection were functions of salt concentration and PV time. However, water flux and $\mathrm{NaCl}$ rejection were found to depend closely on membrane pore size and surface charge. The silica membranes comprising of the pore diameters within 3-5 $\AA$ and the $\mathrm{pH}$ at point of zero charge (i.e., $\mathrm{pH}_{\mathrm{PZC}}$ ) of 2 showed low fluxes and positive rejections, whereas $\gamma$-alumina membrane carrying $40 \AA$ pore diameter and a similar $\mathrm{pH}_{\mathrm{PZC}}$ manifested much higher fluxes and negative rejections. Duke et al. achieved more than 97\% rejection [334] for seawater desalination using MFI zeolite membranes of varying Si:Al ratios. The variation in flux was explained by joint pore structure/surface charge/ion exchange/thermal expansion mechanism and the rejection through joint charge exclusion/size exclusion/surface evaporation mechanism. In another study, the same group reported high $\mathrm{NaCl}$ rejection of $\sim 97 \%$ and water flux of $3 \mathrm{~kg} \mathrm{~m}^{-2} \mathrm{~h}^{-1}$ in PV using a carbonized template silica membrane [109]. Malekpour et al. [111] reported very high salt rejections up to $99 \%$ during desalination of radioactive solutions (i.e., 0.001 (M) of $\mathrm{Cs}^{+}, \mathrm{Sr}^{2+}$, and $\mathrm{MoO}_{4}{ }^{2-}$ ) using $\mathrm{NaA}$ zeolite membranes. With the increase in PV time, the total flux was found to decrease because of the precipitation of salts into the non-zeolitic pores. Again, Khajavi et al. investigated the desalination of seawater using hydroxyl-sodalite membrane comprising of small diameter $=2.65 \AA$. The membrane showed high rejections in seawater and $\mathrm{NaCl}$ and $\mathrm{NaNO}_{3}$ solutions. The water flux for seawater was observed to be higher than that for pure water because of the exchange of $\mathrm{O}^{-}$with $\mathrm{Cl}^{-}$. In this context, Khajavi et al. [376] observed the gradual decrease in water flux with the increase in $\mathrm{NaOH}$ concentration for the hydroxyl-sodalite membrane.

\section{Conclusions and Future Perspectives}

PV technology employed for the separation and purification of water and organic components secures a unique position in food, chemical, and pharmaceutical industries. Despite several limitations, 
hundreds of PV companies have been successfully involved in chemical separation throughout the world. Recent development in PV methodology has visualized a clean and invulnerable opportunity that propels the awareness of energy conservation and environmental protection, accompanied by the maximum recovery from the waste stream and minimum waste generation worldwide. The process has been employed successfully to breakdown the azeotropic mixtures and separation of close boiling solvents, recovery of trace elements or contaminants from the liquid mixtures, along with handling heat sensitive bio-components, and found to be the most energy-efficient and clean technology. In spite of the significant advancement in many countries during the last few decades, rapid industrial and economic growth, shortage in energy resources, intensifying necessities of increasing populations are triggering enormous danger to the surrounding environment. Indeed, substantial research going on in the field of membrane based desalination emphasizing use of the minimum energy, along with the excellent efficiency during generation of pure water.

Although conventional distillation methods have desalinated water for a long time, the low energy consumption, high selectivity, lower capital and maintenance costs, and compact modular design make the membrane-based desalination technologies more attractive and the preferred choice instead of thermal desalination techniques. The RO process has already been commercialized throughout the world for desalination purposes. However, manufacturing robust, but thinner, chemically stable, and fouling resistant $\mathrm{RO}$ composite membranes remains the challenging task. Moreover, the RO process required significant amount of energy to overcome the osmotic pressure, which increases largely with water salinity. In contrast, PV has emerged as a high potential alternative method for energy efficient desalination. The energy conversation in PV desalination, along with its ability to handle high salinity water, was found to be very high. The difference in solubility and diffusivity of feed components allows a particular component to pass through the PV membrane. Similar to MD, permeate can be removed from the downstream side by applying vacuum or sweep gas. It is noteworthy to mention that the PV process exhibits low permeation rate, and is usually applied to remove the component, which is present in smaller amount in the feed mixture. However, in the case of water desalination, the membranes in PV are usually hydrophilic and preferentially allow water to absorb into the membrane matrix through specific dipole-dipole interactions or hydrogen bonding, followed by diffusion across the membrane. In PV, preferential membrane affinity, membrane morphology, and thickness play important roles for the permeation of water. The lower water permeation rate through the membrane matrix is attributed to the high mass transfer resistance appeared during the diffusion step, a critical issue hindering the commercialization of the PV process. Moreover, the 'trade-off' relationship between flux and selectivity limits the use of membranes at the industrial scale.

Although commercial applications of PV have been employed successfully in solvent dehydration, the commercial application of PV technology in desalination has not been found to date. The availability of superior commercial membranes is the most vital restraint in the development and employment of large-scale PV desalination. However, with the development of high-affinity PV membranes, along with suitable morphology for water transport, containing ideal FFV space, the water permeation rate could enhance over the theoretical values calculated from transport equations. Incorporation of advanced nanostructured materials not only provide mechanical strength, but also exhibited superior performances in terms of water flux and salt rejection. The employment of these nanomaterial-enabled membranes will continue to capture the growth of cost efficient PV system and stable modular design to reduce the capital and operational cost, help to construct a robust desalination technology with the minimum energy requirement and environmental impact. Moreover, the application of PV is less extensive, for which salt rejection rate, especially for monovalent ions, are observed to be very high, usually above $99 \%$, wherein the performances do not depend much on the operating conditions. Additionally, being a water selective membrane process, PV does not allow any other organic VOCs or impurities present in the feed system. The major problems associated with other membrane-based separation systems, such as membrane wetting, concentration polarization, temperature polarization, membrane fouling, and pore-plugging, are not severe in PV, helping the attainment of consistent 
membrane performances for a longer period of time. PV could be feasible in treating highly concentrated salt water, including produced water from mineral oil and natural gas plants, as the energy requirement of PV dehydration does not depend on the salt concentration of feed. The water recovery can possibly be very high so that the highly concentrated PV-reject may be utilized concomitantly resulting in zero liquid discharge and the minimum environmental pollution.

So far, the researchers have made significant improvement in PV desalination process and several difficulties need to be addressed before the attainment of successful implementation. The development of proper membrane and modular design, optimization of operating conditions, increase in mass transfer coefficient could possibly enhance the competitiveness of the process, which eventually led to finding a solution to global water scarcity. For further attainment of a high-performance PV-desalination system showing elevated salt-rejection efficiency, attempts can be made to develop long-lasting, multi-stage, multi-functional, fouling resistant, stimuli-responsive, smart nanocomposite hybrid membranes capable of long-term, high-flux pervaporative desalination of multi-component concentrated salty-water.

Author Contributions: The overall design of this Review Paper was commenced by N.R.S.; N.R.S., P.K.C., and co-workers prepared the Sections 1 and 3-5 (including all the tables and figures) of this manuscript. S.R. contributed Section 2 (excluding Table 1), a part of Section 1, and conclusion of this manuscript. The entire manuscript has been thoroughly revised by N.R.S.

Funding: This research was funded by the Department of Science and Technology (DST), Government of India [grant number: YSS/2015/000886] and DST, Government of West Bengal [grant number: 99(Sanc.)/ST/P/S\&T/15G-2/2015].

Acknowledgments: The authors gratefully acknowledge the Department of Higher Education, Government of West Bengal for giving the opportunity to participate in inter-institutional collaboration with the University of Calcutta. M.K. and M.M. are grateful to the DST (ref. no. IF160386), Government of India and the University Grants Commission (ser. no. 2061410291, ref. no. 22/06/2014 (i) EU-V, and roll no. 137632), respectively, for giving the fellowships.

Conflicts of Interest: There are no conflicts to declare.

$\begin{array}{ll}\text { Abbreviations } \\ \text { TDS } & \text { Total dissolved solids } \\ \text { RO } & \text { Reverse osmosis } \\ \text { NF } & \text { Nanofiltration } \\ \text { UF } & \text { Ultrafiltration } \\ \text { MF } & \text { Microfiltration } \\ \text { FO } & \text { Forward osmosis } \\ \text { PRO } & \text { Pressure retarded osmosis } \\ \text { MD } & \text { Membrane distillation } \\ \text { PV } & \text { Pervaporation } \\ \text { VOCs } & \text { Volatile organic compounds } \\ \text { MSFD } & \text { Multistage flash distillation } \\ \text { DVP } & \text { Vapor pressure difference } \\ \text { PVA } & \text { Polyvinyl alcohol } \\ \text { MED } & \text { Multi effect distillation } \\ \text { TFC } & \text { Thin film composite } \\ \text { GO } & \text { Graphene oxide } \\ \text { PAN } & \text { Polyacrylonitrile } \\ \text { NPs } & \text { Nanoparticles } \\ \text { PDMS } & \text { Polydimethyl siloxane } \\ \text { CMS } & \text { Carbon molecular sieves } \\ \text { MA } & \text { Maleic acid } \\ \text { TEOS } & \text { Tetraethoxysilane } \\ \text { FFV } & \text { Fractional free volume } \\ \text { PET } & \text { Polyethylene terephthalate } \\ \text { PMDA } & \text { Pyromellitic dianhydride } \\ \end{array}$




$\begin{array}{ll}\text { SSA } & \text { Sulfosuccinic Acid } \\ \text { SPTA } & \text { 4-Sulfophthalic acid } \\ \text { PEBA } & \text { Poly(ether block amide) } \\ \text { NCP } & \text { Nanocomposite } \\ \text { GNPs } & \text { Graphene nanoplates } \\ \text { PI } & \text { Polyimide } \\ \text { CS } & \text { Chitosan } \\ \text { MMMs } & \text { Mixed matrix membranes } \\ \text { PVS } & \text { Polyvinyl sulfone } \\ \text { MOFs } & \text { Metal organic frameworks } \\ \text { ZIFs } & \text { Zeolitic-imidazolate frameworks } \\ \text { PEBAX } & \text { Polyether block polyamide } \\ \text { PVDF } & \text { Polyvinlyidene fluoride } \\ \text { MWCNT } & \text { Multi-walled carbon nanotube } \\ \text { PMMA } & \text { Poly(methyl methacrylate) } \\ \text { PE } & \text { Polyester } \\ \text { PSF } & \text { Polysulfone } \\ \text { NMP } & \text { N-Methyl-2-pyrrolidinone } \\ \text { DMF } & \text { Dimethylformamide } \\ \text { GA } & \text { Glutaraldehyde } \\ \text { Tg } & \text { Glass transition temperature } \\ \text { TS } & \text { Tensile strength } \\ \text { EAB } & \text { Elongation-at-break } \\ \text { CD } & \text { Crosslink density } \\ \text { SR } & \text { Swelling ratio } \\ \text { CNTs } & \text { Carbon nanotubes } \\ \text { GS } & \text { Gas separation } \\ \text { FAS } & \text { Fluoroalkylsilanes } \\ \text { CA } & \text { Cellulose acetate } \\ \text { LTA } & \text { Linde Type A } \\ & \end{array}$

\section{References}

1. Singha, N.R.; Karmakar, M.; Mahapatra, M.; Mondal, H.; Dutta, A.; Deb, M.; Mitra, M.; Roy, C.; Chattopadhyay, P.K. An in situ approach for the synthesis of a gum ghatti-g-interpenetrating terpolymer network hydrogel for the high-performance adsorption mechanism evaluation of $\mathrm{Cd}(\mathrm{II}), \mathrm{Pb}(\mathrm{II}), \mathrm{Bi}(\mathrm{III})$ and $\mathrm{Sb}$ (III). J. Mater. Chem. A 2018, 6, 8078-8100. [CrossRef]

2. Singha, N.R.; Karmakar, M.; Mahapatra, M.; Mondal, H.; Dutta, A.; Roy, C.; Chattopadhyay, P.K. Systematic synthesis of pectin-g-(sodium acrylate-co-N-isopropylacrylamide) interpenetrating polymer network for superadsorption of dyes/M(II): Determination of physicochemical changes in loaded hydrogels. Polym. Chem. 2017, 8, 3211-3237. [CrossRef]

3. Singha, N.R.; Mahapatra, M.; Karmakar, M.; Dutta, A.; Mondal, H.; Chattopadhyay, P.K. Synthesis of guar gum-g-(acrylic acid-co-acrylamide-co-3-acrylamido propanoic acid) IPN via in situ attachment of acrylamido propanoic acid for analyzing superadsorption mechanism of $\mathrm{Pb}(\mathrm{II}) / \mathrm{Cd}(\mathrm{II}) / \mathrm{Cu}(\mathrm{II}) / \mathrm{MB} / \mathrm{MV}$. Polym. Chem. 2017, 8,6750-6777. [CrossRef]

4. Karmakar, M.; Mondal, H.; Mahapatra, M.; Chattopadhyay, P.K.; Chatterjee, S.; Singha, N.R. Pectin-grafted terpolymer superadsorbent via $\mathrm{N}-\mathrm{H}$ activated strategic protrusion of monomer for removals of $\mathrm{Cd}(\mathrm{II}), \mathrm{Hg}(\mathrm{II})$, and $\mathrm{Pb}(\mathrm{II})$. Carbohyd. Polym. 2019, 206, 778-791. [CrossRef] [PubMed]

5. Mondal, H.; Karmakar, M.; Chattopadhyay, P.K.; Singha, N.R. Starch-g-tetrapolymer hydrogel via in situ attached monomers for removals of $\mathrm{Bi}(\mathrm{III})$ and/or $\mathrm{Hg}$ (II) and dye(s): RSM-based optimization. Carbohyd. Polym. 2019. [CrossRef] 
6. Singha, N.R.; Mahapatra, M.; Karmakar, M.; Mondal, H.; Dutta, A.; Deb, M.; Mitra, M.; Roy, C.; Chattopadhyay, P.K.; Maiti, D.K. In situ allocation of a monomer in pectin-g-terpolymer hydrogels and effect of comonomer compositions on superadsorption of metal ions/dyes. ACS Omega 2018, 3, 4163-4180. [CrossRef]

7. Roy, S.; Ragunath, S. Emerging membrane technologies for water and energy sustainability: Future prospects, constraints and challenges. Energies 2018, 11, 2997. [CrossRef]

8. Roy, S.; Thongsukmak, A.; Tang, J.; Sirkar, K.K. Concentration of aqueous hydrogen peroxide solution by pervaporation. J. Membr. Sci. 2012, 389, 17-24. [CrossRef]

9. Goh, P.S.; Matsuura, T.; Ismail, A.F.; Ng, B.C. The water-energy Nexus: Solutions towards energy-efficient desalination. Energy Technol. 2017, 5, 1136-1155. [CrossRef]

10. Goh, P.S.; Ismail, A.F. Review: Is interplay between nanomaterial and membrane technology the way forward for desalination? J. Chem. Technol. Biotechnol. 2015, 90, 971-980. [CrossRef]

11. Baker, R.W. Membrane Technology and Applications; John Wiley \& Sons: New York, NY, USA, 2012.

12. Ho, W.S.W.; Sirkar, K.K. (Eds.) Membrane Handbook; Van Nostrand Reinhold: New York, NY, USA, 1992.

13. Bodzek, M.; Bohdziewicz, J.; Konieczny, K. Techniki Membranowe W Ochronie Srodowiska; Wydawnictwo Politechniki Slaskiej: Gliwice, Poland, 1997.

14. Mulder, M.H.V. Basic Principles of Membrane Technology; Kluwer Academic Publishers: Dordrecht, The Netherlands; Boston, MA, USA; London, UK, 1991.

15. Feng, X.; Huang, R.Y.M. Liquid separation by membrane pervaporation: A review. Ind. Eng. Chem. Res. 1997, 36, 1048-1066. [CrossRef]

16. Slater, C.S. A review of: "Pervaporation membrane separation processes". Sep. Purif. Methods 1991, 20, $109-111$. [CrossRef]

17. Peñate, B.; García-Rodríguez, L. Current trends and future prospects in the design of seawater reverse osmosis desalination technology. Desalination 2012, 284, 1-8. [CrossRef]

18. Chong, T.H.; Loo, S.; Krantz, W.B. Energy-efficient reverse osmosis desalination process. J. Membr. Sci. 2015, 473, 177-188. [CrossRef]

19. Stover, R.L. High recovery, low fouling, and low energy reverse osmosis. Desalin. Water Treat. 2016, 55, 26501-26506. [CrossRef]

20. Ghaffour, N.; Missimer, T.M.; Amy, G.L. Technical review and evaluation of the economics of water desalination: Current and future challenges for better water supply sustainability. Desalination 2013, 309, 197-207. [CrossRef]

21. Muntha, S.T.; Kausar, A.; Siddiq, M. Advances in polymeric nanofiltration membrane: A review. Polym.-Plast. Technol. Eng. 2017, 56, 841-856. [CrossRef]

22. Mohammad, A.W.; Teow, Y.H.; Ang, W.L.; Chung, Y.T.; Oatley-Radcliffe, D.L.; Hilal, N. Nanofiltration membranes review: Recent advances and future prospects. Desalination 2015, 356, 226-254. [CrossRef]

23. Singh, D.; Sirkar, K.K. Desalination of brine and produced water by direct contact membrane distillation at high temperatures and pressures. J. Membr. Sci. 2012, 389, 380-388. [CrossRef]

24. Adham, S.; Hussain, A.; Matar, J.M.; Dores, R.; Janson, A. Application of membrane distillation for desalting brines from thermal desalination plants. Desalination 2013, 314, 101-108. [CrossRef]

25. Alkhudhiri, A.; Darwish, N.; Hilal, N. Produced water treatment: Application of air gap membrane distillation. Desalination 2013, 309, 46-51. [CrossRef]

26. Mahapatra, M.; Karmakar, M.; Mondal, B.; Singha, N.R. Role of ZDC/S ratio for pervaporative separation of organic liquids through modified EPDM membranes: Rational mechanistic study of vulcanization. RSC Adv. 2016, 6, 69387-69403. [CrossRef]

27. Karmakar, M.; Mahapatra, M.; Singha, N.R. Separation of tetrahydrofuran using RSM optimized accelerator-sulfur-filler of rubber membranes: Systematic optimization and comprehensive mechanistic study. Korean J. Chem. Eng. 2017, 34, 1416-1434. [CrossRef]

28. Mahapatra, M.; Karmakar, M.; Dutta, A.; Singha, N.R. Fabrication of composite membranes for pervaporation of tetrahydrofuran-water: Optimization of intrinsic property by response surface methodology and studies on vulcanization mechanism by density functional theory. Korean J. Chem. Eng. 2018, 35, 1889-1910. [CrossRef]

29. Roy, S.; Singha, N.R. Polymeric Nanocomposite Membranes for Next Generation Pervaporation Process: Strategies, Challenges and Future Prospects. Membranes 2017, 3, 53. [CrossRef] 
30. Singha, N.R.; Parya, T.K.; Ray, S.K. Dehydration of 1, 4-dioxane by pervaporation using filled and crosslinked polyvinyl alcohol membrane. J. Membr. Sci. 2009, 340, 35-44. [CrossRef]

31. Ray, S.; Singha, N.R.; Ray, S.K. Removal of tetrahydrofuran (THF) from water by pervaporation using homo and blend polymeric membranes. Chem. Eng. J. 2009, 149, 153-161. [CrossRef]

32. Singha, N.R.; Ray, S.; Ray, S.K.; Konar, B.B. Removal of pyridine from water by pervaporation using filled SBR Membranes. J. Appl. Polym. Sci. 2011, 121, 1330-1334. [CrossRef]

33. Singha, N.R.; Ray, S.K. Removal of pyridine from water by pervaporation using crosslinked and filled natural rubber membranes. J. Appl. Polym. Sci. 2012, 124, E99-E107. [CrossRef]

34. Singha, N.R.; Kar, S.; Ray, S.; Ray, S.K. Separation of isopropyl alcohol-water mixtures by pervaporation using crosslink IPN membranes. Chem. Eng. Process. 2009, 48, 1020-1029. [CrossRef]

35. Kuila, S.B.; Ray, S.K.; Das, P.; Singha, N.R. Synthesis of full interpenetrating network membranes of poly(acrylic acid-co-acrylamide) in the matrix of polyvinyl alcohol for dehydration of ethylene glycol by pervaporation. Chem. Eng. Process. 2011, 50, 391-403. [CrossRef]

36. Singha, N.R.; Kar, S.; Ray, S.K. Synthesis of chemically modified polyvinyl alcohol membranes for dehydration of dioxane by pervaporation. Sep. Sci. Technol. 2009, 44, 422-446. [CrossRef]

37. Singha, N.R.; Ray, S.K. Separation of toluene-methanol mixtures by pervaporation using semi-IPN polymer membranes. Sep. Sci. Technol. 2010, 45, 2298-2307. [CrossRef]

38. Singha, N.R.; Kar, S.; Ray, S.K. Synthesis of novel polymeric membrane for separation of MTBE-methanol by pervaporation. Sep. Sci. Technol. 2009, 44, 1970-1990. [CrossRef]

39. Ray, S.; Ray, S.K. Effect of copolymer type and composition on separation characteristics of pervaporation membranes-a case study with separation of acetone-water mixtures. J. Membr. Sci. 2006, 270, 73-87. [CrossRef]

40. Ray, S.; Ray, S.K. Pervaporative dehydration of dimethyl formamide (DMF) by crosslinked copolymer membranes. Ind. Eng. Chem. Res. 2006, 45, 7210-7218. [CrossRef]

41. Korin, E.; Ladizhensky, I.; Korngold, E. Hydrophilic hollow fibre membranes for water desalination by the pervaporation method. Chem. Eng. Process. 1996, 35, 451-457. [CrossRef]

42. Korngold, E.; Korin, E.; Ladizhensky, I. Water desalination by pervaporation with hollow fibre membranes. Desalination 1996, 107, 121-129. [CrossRef]

43. Zwijnenberg, H.J.; Koops, G.H.; Wessling, A. Solar driven membrane pervaporation for desalination processes. J. Membr. Sci. 2005, 250, 235-246. [CrossRef]

44. García-Payo, M.C.; Izquierdo-Gil, M.A.; Fernández-Pineda, C. Wetting study of hydrophobic membranes via liquidentry pressure measurements with aqueous alcohol solutions. J. Colloid Interface Sci. 2000, 230, 420-431. [CrossRef]

45. Tijing, L.D.; Woo, Y.C.; Choi, J.; Lee, S.; Kim, S.; Shon, H.K. Fouling and its control in membrane distillation-A review. J. Membr. Sci. 2015, 475, 215-244. [CrossRef]

46. Xie, Z.; Hoang, M.; Duong, T.; Ng, D.; Dao, B.; Gray, S. Sol-gel derived poly(vinyl alcohol)/maleic acid/silica hybrid membrane for desalination by pervaporation. J. Membr. Sci. 2011, 383, 96-103. [CrossRef]

47. Lee, S.; Boo, C.; Elimelech, M.; Hong, S. Comparison of fouling behavior in forward osmosis (FO) and reverse osmosis (RO). J. Membr. Sci. 2010, 365, 34-39. [CrossRef]

48. Pearce, G.K. SWRO pre-treatment: Markets and experience. Filtr. Sep. 2010, 47, 30-33. [CrossRef]

49. Drioli, E.; Stankiewicz, A.I.; Macedonio, F. Membrane engineering in process intensification-An overview. J. Membr. Sci. 2011, 380, 1-8. [CrossRef]

50. Liang, B.; Zhan, W.; Qi, G.; Lin, S.; Nan, Q.; Liu, Y.; Cao, B.; Pan, K. High performance graphene oxide/polyacrylonitrile composite pervaporation membranes for desalination applications. J. Mater. Chem. A 2015, 3, 5140-5147. [CrossRef]

51. Wang, H.J.; Ding, S.B.; Zhu, H.L.; Wang, F.; Guo, Y.H.; Zhang, H.P.; Chen, J.Y. Effect of stretching ratio and heating temperature on structure and performance of PTFE hollow fiber membrane in VMD for RO brine. Sep. Purif. Technol. 2014, 126, 82-94. [CrossRef]

52. Khawaji, A.D.; Kutubkhanah, I.K.; Wie, J. Advances in seawater desalination technologies. Desalination 2008, 221, 47-69. [CrossRef]

53. Alghoul, M.A.; Poovanaesvaran, P.; Sopian, K.; Sulaiman, M.Y. Review of brackish water reverse osmosis (BWRO) system designs. Renew. Sustain. Energ. Rev. 2009, 13, 2661-2667. [CrossRef] 
54. Greenlee, L.F.; Lawler, D.F.; Freeman, B.D.; Marrot, B.; Moulin, P. Reverse osmosis desalination: Water sources, technology, and today's challenges. Water Res. 2009, 43, 2317-2348. [CrossRef]

55. Drobek, M.; Yacou, C.; Motuzas, J.; Julbe, A.; Ding, L.; Da Costa, J.C.D. Long term pervaporation desalination of tubular MFI zeolite membranes. J. Membr. Sci. 2012, 415-416, 816-823. [CrossRef]

56. Lin, C.X.C.; Ding, L.P.; Smart, S.; Da Costa, J.C.D. Cobalt oxide silica membranes for desalination. J. Colloid Interface Sci. 2012, 368, 70-76. [CrossRef]

57. Smitha, B.; Suhanya, D.; Sridhar, S.; Ramakrishna, M. Separation of organic-organic mixtures by pervaporation-A review. J. Membr. Sci. 2004, 241, 1-21. [CrossRef]

58. Jiang, L.Y.; Wang, Y.; Chung, T.S.; Qiao, X.Y.; Lai, J.Y. Polyimides membranes for pervaporation and biofuels separation. Prog. Polym. Sci. 2009, 34, 1135-1160. [CrossRef]

59. Das, P.; Ray, S.K.; Kuila, S.B.; Samanta, H.S.; Singha, N.R. Systematic choice of crosslinker and filler for pervaporation membrane: A case study with dehydration of isopropyl alcohol-water mixtures by polyvinyl alcohol membranes. Sep. Purif. Technol. 2011, 81, 159-173. [CrossRef]

60. Mujiburohman, M.; Feng, X. Permselectivity, solubility and diffusivity of propyl propionate/water mixtures in poly(ether block amide)membranes. J. Membr. Sci. 2007, 300, 95-103. [CrossRef]

61. Singha, N.R.; Kuila, S.B.; Das, P.; Ray, S.K. Separation of toluene-methanol mixtures by pervaporation using crosslink IPN membranes. Chem. Eng. Process. Process Intensif. 2009, 48, 1560-1565. [CrossRef]

62. Singha, N.R.; Das, P.; Ray, S.K. Recovery of pyridine from water by pervaporation using filled and crosslinked EPDM membranes. J. Ind. Eng. Chem. 2013, 19, 2034-2045. [CrossRef]

63. Pereira, C.C.; Claudio, P.R.; Ronaldo, N.; Cristiano, P.B. Pervaporative recovery of volatile aroma compounds from fruit juices. J. Membr. Sci. 2006, 274, 1-23. [CrossRef]

64. Samanta, H.S.; Ray, S.K.; Das, P.; Singha, N.R. Separation of acid-water mixtures by pervaporation using nanoparticle filled mixed matrix copolymer membranes. J. Chem. Technol. Biotechnol. 2012, 87, 608-622. [CrossRef]

65. Kahlenberg, L. On the nature of the process of osmosis and osmotic pressure with observation concerning dialysis. J. Phys. Chem. 1906, 10, 141-209. [CrossRef]

66. Shao, P.; Huang, R.Y.M. Polymeric membrane pervaporation. J. Membr. Sci. 2007, 287, 162-179. [CrossRef]

67. Koschikowski, J.; Wieghaus, M.; Rommel, M. Solar thermal-driven desalination plants based on membrane distillation. Desalination 2003, 156, 295-304. [CrossRef]

68. Heintz, A.; Stephan, W. A generalized solution-diffusion model of the pervaporation process through composite membranes. Part I. Prediction of mixture solubilities in the dense active layer using the UNIQUAC model. J. Membr. Sci. 1994, 89, 143-151. [CrossRef]

69. Heintz, A.; Stephan, W. A generalized solution-diffusion model of the pervaporation process through composite membranes. Part II. Concentration polarization, coupled diffusion and the influence of the porous support layer. J. Membr. Sci. 1994, 89, 153-169. [CrossRef]

70. Lipnizki, F.; Trägårdh, G. Modeling of pervaporation: Models to analyze and predict the mass transport in pervaporation. Sep. Purif. Rev. 2001, 30, 49-125. [CrossRef]

71. Marriott, J.; Sørensen, E. A general approach to modelling membrane modules. Chem. Eng. Sci. 2003, 58, 4975-4990. [CrossRef]

72. Schaetzel, P.; Vauclair, C.; Nguyen, Q.T.; Bouzerar, R. A simplified solution-diffusion theory in pervaporation: The total solvent volume fraction model. J. Membr. Sci. 2004, 244, 117-127. [CrossRef]

73. Sukitpaneenit, P.; Chung, T.-S.; Jiang, L.Y. Modified pore-flow model for pervaporation mass transport in PVDF hollow fiber membranes for ethanol-water separation. J. Membr. Sci. 2010, 362, 393-406. [CrossRef]

74. Rautenbach, R.; Herion, C.; Meyer-Blumentoth, U. Pervaporation Membrane Separation Processes; Elsevier: Amsterdam, The Netherlands; Oxford, UK, 1990.

75. Mizsey, P.; Koczka, K.; Deák, A.; Fonyó, Z. Simulation of pervaporation using the "solution-diffusion" model. Hung. Chem. J. 2005, 7, 239-242.

76. Lovasz, A.; Mizsey, P.; Fonyo, Z. Methodology for parameter estimation of modelling of pervaporation in flowsheeting environment. Chem. Eng. J. 2007, 133, 219-227. [CrossRef]

77. Cséfalvay, E.; Szitkai, Z.; Mizsey, P.; Fonyó, Z. Experimental data based modelling and simulation of isopropanol dehydration by pervaporation. Desalination 2008, 229, 94-108. [CrossRef]

78. Valentínyi, N.; Cséfalvaya, E.; Mizsey, P. Modelling of pervaporation: Parameter estimation and model development. Chem. Eng. Res. Des. 2013, 91, 174-183. [CrossRef] 
79. Khajavi, S.; Jansen, J.C.; Kapteijn, F. Production of ultra-pure water by desalination of seawater using a hydroxy sodalite membrane. J. Membr. Sci. 2010, 356, 52-57. [CrossRef]

80. Liang, B.; Pan, K.; Li, L.; Giannelis, C. High performance hydrophilic pervaporation composite membranes for water desalination. Desalination 2014, 347, 199-206. [CrossRef]

81. Cho, C.H.; Oh, K.Y.; Kim, S.K.; Yeo, J.G.; Sharma, P. Pervaporative seawater desalination using NaA zeolite membrane: Mechanisms of high water flux and high salt rejection. J. Membr. Sci. 2011, 37, 226-238. [CrossRef]

82. Ong, Y.K.; Shi, G.M.; Le, N.L.; Tang, Y.P.; Zuo, J.; Nunes, S.P.; Chung, T.-S. Recent membrane development for pervaporation processes. Prog. Polym. Sci. 2016, 57, 1-31. [CrossRef]

83. Wan, C.F.; Yang, T.; Lipscomb, G.G.; Stookey, D.J.; Chung, T.-S. Design and fabrication of hollow fiber membrane modules. J. Membrane Sci. 2017, 538, 96-107. [CrossRef]

84. Fini, M.N.; Soroush, S.; Montazer-Rahmati, M.M. Synthesis and optimization of chitosan ceramic-supported membranes in pervaporation ethanol dehydration. Membranes 2018, 8, 119. [CrossRef]

85. Wei, Z.; Liu, Q.; Wu, C.; Wang, H.; Wang, H. Viscosity-driven in situ self-assembly strategy to fabricate cross-linked ZIF-90/PVA hybrid membranes for ethanol dehydration via pervaporation. Sep. Sci. Technol. 2018, 201, 256-267. [CrossRef]

86. Yoon, K.; Kim, K.; Wang, X.; Fang, D.; Hsiao, B.S.; Chu, B. High flux ultrafiltration membranes based on electrospun nanofibrous PAN scaffolds and chitosan coating. Polymer 2006, 47, 2434-2441. [CrossRef]

87. Yoon, K.; Hsiao, B.S.; Chu, B. High flux ultrafiltration nanofibrous membranes based on polyacrylonitrile electrospun scaffolds and crosslinked polyvinyl alcohol coating. J. Membr. Sci. 2009, 338, 145-152. [CrossRef]

88. Tang, Z.; Wei, J.; Yung, L.; Ji, B.; Ma, H.; Qiu, C.; Yoon, K.; Wan, F.; Fang, D.; Hsiao, B.S.; et al. UV-cured poly(vinyl alcohol) ultrafiltration nanofibrous membrane based on electrospun nanofiber scaffolds. J. Membr. Sci. 2009, 328, 1-5. [CrossRef]

89. Yoon, K.; Hsiao, B.S.; Chu, B. High flux nanofiltration membranes based on interfacially polymerized polyamide barrier layer on polyacrylonitrile nanofibrous scaffolds. J. Membr. Sci. 2009, 326, 484-492. [CrossRef]

90. Yung, L.; Ma, H.; Wang, X.; Yoon, K.; Wang, R.; Hsiao, B.S.; Chu, B. Fabrication of thin-film nanofibrous composite membranes by interfacial polymerization using ionic liquids as additives. J. Membr. Sci. 2010, 365, 52-58. [CrossRef]

91. Song, X.; Liu, Z.; Sun, D.D. Nano gives the answer: Breaking the bottleneck of internal concentration polarization with a nanofiber composite forward osmosis membrane for a high water production rate. Adv. Mater. 2011, 23, 3256-3260. [CrossRef]

92. Reid, C.E.; Breton, E.J. Water and ion flow across cellulosic membranes. J. Appl. Polym. Sci. 1959, 1, $133-143$. [CrossRef]

93. Loeb, G.S.; Sourirajan, S. (Eds.) Sea Water Demineralization by Means of an Osmotic Membrane; Advances in Chemistry Series; American Chemical Society: Washington, DC, USA, 1963; Volume 38, p. 117.

94. Kober, P.A. Pervaporation, perstillation and percrystallization. J. Am. Chem. Soc. 1917, 39, 944-948. [CrossRef]

95. Binning, R.; Lee, R.; Jennings, J.; Martin, E. Separation of liquid mixtures by permeation. Ind. Eng. Chem. 1961, 53, 45-50. [CrossRef]

96. Aptel, P.; Cuny, J.; Jozefonvicz, J.; Morel, G.; Neel, J. Liquid transport through membranes prepared by grafting of polar monomers onto poly (tetrafluoroethylene) films. II. some factors determining pervaporation rate and selectivity. J. Appl. Polym. Sci. 1974, 18, 351-364. [CrossRef]

97. Vane, L.M.; Mairal, A.P.; Ng, A.; Alvarez, F.R.; Baker, R.W. Separation Process Using Pervaporation and Dephlegmation. U.S. Patent US6755975B2, 29 June 2004.

98. Cox, G.; Baker, R. Pervaporation. Ind. Wastewater 1998, 6, 35-37.

99. Elma, M.; Yacou, C.; Wang, D.K.; Smart, S.; Da Costa, J.C.D. Microporous silica based membranes for desalination. Water 2012, 4, 629-649. [CrossRef]

100. Xie, Z.; Ng, D.; Hoang, M.; Duong, T.; Gray, S. Separation of aqueous salt solution by pervaporation through hybrid organic-inorganic membrane: Effect of operating conditions. Desalination 2011, 273, $220-225$. [CrossRef]

101. Huth, E.; Muthu, S.; Ruff, L.; Brant, J.A. Feasibility assessment of pervaporation for desalinating high-salinity brines. J. Water Reuse Desal. 2014, 4, 109-124. [CrossRef]

102. Sule, M.; Jiang, J.; Templeton, M.; Huth, E.; Brant, J.; Bond, T. Salt rejection and water flux through a tubular pervaporative polymer membrane designed for irrigation applications. Environ. Technol. 2013, 34, 1329-1339. [CrossRef] 
103. Peng, F.; Jiang, Z.; Hu, C.; Wang, Y.; Xu, H.; Liu, J. Removing benzene from aqueous solution using CMS-filled PDMS pervaporation membranes. Sep. Purif. Technol. 2016, 48, 229-234. [CrossRef]

104. Peng, F.; Hub, C.; Jiang, Z. Novel poly(vinyl alcohol)/carbon nanotube hybrid membranes for pervaporation separation of benzene/cyclohexane mixtures. J. Membr. Sci. 2007, 297, 236-242. [CrossRef]

105. Peng, F.; Lu, L.; Hu, C.; Wu, H.; Jiang, Z. Significant increase of permeation flux and selectivity of poly(vinyl alcohol) membranes by incorporation of crystalline flake graphite. J. Membr. Sci. 2005, 259, 65-73. [CrossRef]

106. Pan, F.; Peng, F.; Jiang, Z. Diffusion behavior of benzene/cyclohexane molecules in poly(vinyl alcohol)-graphite hybrid membranes by molecular dynamics simulation. Chem. Eng. Sci. 2007, 62, 703-710. [CrossRef]

107. An, W.; Zhou, X.; Liu, X.; Chai, P.W.; Kuznicki, T.; Kuznicki, S.M. Natural zeolite clinoptilolite-phosphate composite membranes for water desalination by pervaporation. J. Membr. Sci. 2014, 470, 431-438. [CrossRef]

108. Malekpour, A.; Millani, M.R.; Kheirkhah, M. Synthesis and characterization of a NaA zeolite membrane and its applications for desalination of radioactive solutions. Desalination 2008, 225, 199-208. [CrossRef]

109. Wijaya, S.; Duke, M.C.; de Costa, J.C.D. Carbonized template silica membranes for desalination. Desalination 2009, 236, 291-298. [CrossRef]

110. Li, D.; He, L.; Dong, D.; Forsyth, M.; Wang, H. Preparation of silicalite-polyamide composite membranes for desalination. Asia-Pac. J. Chem. Eng. 2011, 7, 434-441. [CrossRef]

111. Malekpour, A.; Samadi-Maybodi, A.; Sadati, M.R. Desalination of aqueous solutions by LTA and MFI zeolite membranes using pervaporation method. Braz. J. Chem. Eng. 2011, 28, 669-677. [CrossRef]

112. Ladewig, B.P.; Tan, Y.H.; Lin, C.X.; Ladewig, K.; Diniz Da Costa, J.C.; Smart, S. Preparation, characterisation and performance of templated silica membranes in non-osmotic desalination. Materials 2011, 4, 845-856. [CrossRef] [PubMed]

113. Swenson, P.; Tanchuk, B.; Gupta, A.; An, W.; Kuznicki, S.M. Pervaporative desalination of water using natural zeolite membranes. Desalination 2012, 285, 68-72. [CrossRef]

114. Chaudhri, S.G.; Rajai, B.H.; Singh, P.S. Preparation of ultra-thin poly(vinyl alcohol) membranes supported on polysulfone hollow fiber and their application for production of pure water from seawater. Desalination 2015, 367, 272-284. [CrossRef]

115. Singh, P.S.; Chaudhri, S.G.; Kansara, A.M.; Schetieger, W.; Selvam, T.; Reuss, S.; Kaswal, V. Cetyltrimethylammonium bromide-silica membrane for seawater desalination through pervaporation. Bull. Mater. Sci. 2015, 38, 565-572. [CrossRef]

116. Feng, B.; Xu, K.; Huang, A. Covalent synthesis of three-dimensional graphene oxide framework (GOF) membrane for seawater desalination. Desalination 2016, 394, 123-130. [CrossRef]

117. Feng, B.; Xu, K.; Huang, A. Synthesis of graphene oxide/polyimide mixed matrix membranes for desalination. RSC Adv. 2017, 7, 2211-2217. [CrossRef]

118. Chaudhri, S.G.; Chaudhari, J.C.; Singh, P.S. Fabrication of efficient pervaporation desalination membrane by reinforcement of poly(vinyl alcohol)-silica film on porous polysulfone hollow fiber. J. Appl. Polym. Sci. 2018, 135, 45718. [CrossRef]

119. Marian, S.A.; Asghari, M.; Amini, Z. Desalination of Kashan City's water using PEBA-based nanocomposite membranes via pervaporation. J. Water Environ. Nanotechnol. 2017, 2, 96-102.

120. Nigiz, F.U.; Veli, S.; Hilmioglu, N.D. Deep purification of seawater using a novel zeolite $3 \mathrm{~A}$ incorporated polyetherblock-amide composite membrane. Sep. Purif. Technol. 2017, 188, 90-97. [CrossRef]

121. Nigiz, F.U. Preparation of high-performance graphene nanoplate incorporated polyether block amide membrane and application for seawater desalination. Desalination 2018, 433, 164-171. [CrossRef]

122. Zhang, R.; Liang, B.; Qu, T.; Cao, B.; Li, P. High-performance sulfosuccinic acid crosslinked PVA composite pervaporation membrane for desalination. Environ. Technol. 2019, 40, 312-320. [CrossRef] [PubMed]

123. Li, L.; Hou, J.; Ye, Y.; Mansouri, J.; Chen, V. Composite PVA/PVDF pervaporation membrane for concentrated brine desalination: Salt rejection, membrane fouling and defect control. Desalination 2017, 422, 49-58. [CrossRef]

124. Shi, Q.; Zhang, K.; Lu, R.; Jiang, J. Water desalination and biofuel dehydration through a thin membrane of polymer of intrinsic microporosity: Atomistic simulation study. J. Membr. Sci. 2018, 545, 49-56. [CrossRef]

125. Yilman, B.; Nigiz, F.U.; Aytaç, A.; Hilmioglu, N.D. Multi-walled carbon nanotube doped PVA membrane for desalination. Water Supply 2018. [CrossRef]

126. Huang, A.; Feng, B. Synthesis of novel graphene oxide-polyimide hollow fiber membranes for seawater desalination. J. Membr. Sci. 2018, 548, 59-65. [CrossRef] 
127. Zhang, R.; Xu, X.; Cao, B.; Li, P. Fabrication of high-performance PVA/PAN composite pervaporation membranes crosslinked by PMDA for wastewater desalination. Petrol. Sci. 2018, 15, 146-156. [CrossRef]

128. Liang, B.; Li, Q.; Cao, B.; Li, P. Water permeance, permeability and desalination properties of the sulfonic acid functionalized composite pervaporation membranes. Desalination 2018, 433, 132-140. [CrossRef]

129. Teow, Y.H.; Mohammad, A.W. New generation nanomaterials for water desalination: A review. Desalination 2019, 451, 2-17. [CrossRef]

130. Paugam, M.-F.; Buffle, J. Comparison of carrier-facilitated copper(II) ion transport mechanisms in a supported liquid membrane and in a plasticized cellulose triacetate membrane. J. Membr. Sci. 1998, 147, 207-215. [CrossRef]

131. Kuznetsov, Y.P.; Kruchinina, E.V.; Baklagina, Y.G.; Khripunov, A.K.; Tulupova, O.A. Deep desalination of water by evaporation through polymeric membranes. Russ. J. Appl. Chem. 2007, 80, 790-798. [CrossRef]

132. Naim, M.; Elewa, M.; El-Shafei, A. Desalination of simulated seawater by purge-air pervaporation using an innovative fabricated membrane. Water Sci. Technol. 2015, 72, 785-793. [CrossRef]

133. Liu, G.; Shen, J.; Liu, Q.; Liu, G.; Xiong, J.; Yang, J.; Jin, W. Ultrathin two-dimensional MXene membrane for pervaporation desalination. J. Membr. Sci. 2018, 548, 548-558. [CrossRef]

134. Li, L.; Hou, J.; Ye, Y.; Mansouri, J.; Zhang, Y.; Chen, V. Suppressing salt transport through composite pervaporation membranes for brine desalination. Appl. Sci. 2017, 7, 856. [CrossRef]

135. Li, Q.; Cao, B.; Li, P. Fabrication of high performance pervaporation desalination composite membranes by optimizing the support layer structures. Ind. Eng. Chem. Res. 2018, 57, 11178-11185. [CrossRef]

136. Qian, X.; Li, N.; Wang, Q.; Ji, S. Chitosan/graphene oxide mixed matrix membrane with enhanced water permeability for high-salinity water desalination by pervaporation. Desalination 2018, 438, 83-96. [CrossRef]

137. Quiňones-Bolaňos, E.; Zhou, H.D.; Soundararajan, R.; Otten, L. Water and solute transport in pervaporation hydrophilic membranes to reclaim contaminated water for micro-irrigation. J. Membr. Sci. 2005, 252, $19-28$. [CrossRef]

138. Kujawski, W.; Krajewska, S.; Kujawski, M.; Gazagnes, L.; Larbot, A.; Persin, M. Pervaporation properties of fluoroalkylsilane (FAS) grafted ceramic membranes. Desalination 2007, 205, 75-86. [CrossRef]

139. Li, D.; Wang, H. Recent developments in reverse osmosis desalination membranes. J. Mater. Chem. 2010, 20, 4551-4566. [CrossRef]

140. Xie, Z.; Hoang, M.; Ng, D.; Doherty, C.; Hill, A.; Gray, S. Effect of heat treatment on pervaporation separation of aqueous salt solution using hybrid PVA/MA/TEOS membrane. Sep. Purif. Technol. 2014, 127, 10-17. [CrossRef]

141. Volkov, A.G.; Paula, S.; Deamer, D.W. Two mechanism of permeation of small neutral molecules and hydrated ions across phospholipid bilayers. Bioelectrochem. Bioenerg. 1997, 42, 153-160. [CrossRef]

142. Lin, J.; Murad, S. A computer simulation study of the separation of aqueous solutions using thin zeolite membranes. Mol. Phys. 2001, 99, 1175-1181. [CrossRef]

143. Wijmans, J.G.; Baker, R.W. The solution diffusion model: A review. J. Membr. Sci. 1995, 107, 1-21. [CrossRef]

144. Feng, X.; Huang, R.Y.M. Estimation of activation for permeation in pervaporation processes. J. Membr. Sci. 1996, 118, 127-131. [CrossRef]

145. Barique, M.A.; Tsuchida, E.; Ohira, A.; Tashiro, K. Effect of elevated temperatures on the states of water and their correlation with the proton conductivity of Nafion. ACS Omega 2018, 3, 349-360. [CrossRef]

146. Ravindra, R.; Rao, A.K.; Khan, A. Processing of liquid propellant reaction liquors by pervaporation. J. Appl. Polym. Sci. 1999, 72, 141-149. [CrossRef]

147. Weng, Y.; Qiu, S.; Ma, L.; Liu, Q.; Ding, M.; Zhang, Q.; Zhang, Q.; Wang, T. Jet-fuel range hydrocarbons from biomass-derived sorbitol over Ni-HZSM-5/SBA-15 catalyst. Catalysts 2015, 5, 2147-2160. [CrossRef]

148. Moermans, B.; DeBeuckelaer, W.; Vankelecom, I.F.J.; Ravishankar, R.; Martens, J.A.; Jacobs, P.A. Incorporation of nano-sized zeolites in membranes. Chem. Commun. 2000, 0, 2467-2468. [CrossRef]

149. Zhan, X.; Lu, J.; Tan, T.; Li, J. Mixed matrix membranes with HF acid etched ZSM-5 for ethanol/water separation: Preparation and pervaporation performance. Appl. Surf. Sci. 2012, 259, 547-556. [CrossRef]

150. Khosravi, T.; Mosleh, S.; Bakhtiari, O.; Mohammadi, T. Mixed matrix membranes of Matrimid 5218 loaded with zeolite $4 \mathrm{~A}$ for pervaporation separation of water-isopropanol mixtures. Chem. Eng. Res. Des. 2012, 90, 2353-2363. [CrossRef] 
151. Qiu, S.; Wu, L.; Shi, G.; Zhang, L.; Chen, H.; Gao, C. Preparation and pervaporation property of chitosan membrane with functionalized multiwalled carbon nanotubes. Ind. Eng. Chem. Res. 2010, 49, 11667-11675. [CrossRef]

152. Jiang, L.Y.; Chung, T.-S.; Rajagopalan, R. Matrimid (R)/MgO mixed matrix membranes for pervaporation. AIChE J. 2007, 53, 1745-1757. [CrossRef]

153. Bhat, S.D.; Aminabhavi, T.M. Novel sodium alginate composite membranes incorporated with SBA- 15 molecular sieves for the pervaporation dehydration of aqueous mixtures of isopropanol and 1,4-dioxane at $30^{\circ} \mathrm{C}$. Microporous Mesoporous Mater. 2006, 91, 206-214. [CrossRef]

154. Flynn, E.J.; Keane, D.A.; Tabari, P.M.; Morris, M.A. Pervaporation performance enhancement through the incorporation of mesoporous silica spheres into PVA membranes. Sep. Purif. Technol. 2013, 118, 73-80. [CrossRef]

155. Kudasheva, A.; Sorribas, S.; Zornoza, B.; Téllez, C.; Coronas, J. Pervaporation of water/ethanol mixtures through polyimide based mixed matrix membranes containing ZIF-8, ordered mesoporous silica and ZIF-8-silica core-shell spheres. J. Chem. Technol. Biotechnol. 2015, 90, 669-677. [CrossRef]

156. Jeazet, H.B.T.; Staudt, C.; Janiak, C. Metal-organic frameworks in mixed matrix membranes for gas separation. Dalton Trans. 2012, 41, 14003-14027. [CrossRef]

157. Zornoza, B.; Tellez, C.; Coronas, J.; Gascon, J.; Kapteijn, F. Metal organic framework based mixed matrix membranes: An increasingly important field of research with a large application potential. Microporous Mesoporous Mater. 2013, 166, 67-78. [CrossRef]

158. Kang, C.-H.; Lin, Y.-F.; Huang, Y.-S.; Tung, K.-L.; Chang, K.-S.; Chen, J.-T.; Hung, W.-S.; Lee, K.-R.; Lai, J.-Y. Synthesis of ZIF-7/chitosan mixed-matrix membranes with improved separation performance of water/ethanol mixtures. J. Membr. Sci. 2013, 438, 105-111. [CrossRef]

159. Hua, D.; Ong, Y.K.; Wang, Y.; Yang, T.; Chung, T.-S. ZIF-90/P84 mixed matrix membranes for pervaporation dehydration of isopropanol. J. Membr. Sci. 2014, 453, 155-167. [CrossRef]

160. Kasik, A.; Lin, Y.S. Organic solvent pervaporation properties of MOF-5 membranes. Sep. Purif. Technol. 2014, 121, 38-45. [CrossRef]

161. Liu, X.; Jin, H.; Li, Y.; Bux, H.; Hu, Z.; Ban, Y.; Yang, W. Metal-organic framework ZIF-8 nanocomposite membrane for efficient recovery of furfural via pervaporation and vapor permeation. J. Membr. Sci. 2013, 428, 498-506. [CrossRef]

162. Liu, X.L.; Li, Y.S.; Zhu, G.Q.; Ban, Y.J.; Xu, L.Y.; Yang, W.S. An organophilic pervaporation membrane derived from metal-organic framework nanoparticles for efficient recovery of bio-alcohols. Angew. Chem. Int. Ed. 2011, 50, 10636-10639. [CrossRef]

163. Sorribas, S.; Kudasheva, A.; Almendro, E.; Zornoza, B.; la Iglesia, Ó.; Téllez, C.; Coronas, J. Pervaporation and membrane reactor performance of polyimide based mixed matrix membranes containing MOF HKUST-1. Chem. Eng. Sci. 2015, 124, 37-44. [CrossRef]

164. Wu, D.; Gao, A.; Zhao, H.; Feng, X. Pervaporative desalination of high-salinity water. Chem. Eng. Res. Des. 2018, 136, 154-164. [CrossRef]

165. Louie, J.S.; Pinnau, I.; Ciobanu, I.; Ishida, K.P.; Ng, A.; Reinhard, M. Effects of polyether-polyamide block copolymer coating on performance and fouling of reverse osmosis membranes. J. Membr. Sci. 2006, 280, 762-770. [CrossRef]

166. Orgaz-Orgaz, F. Gel to glass conversion: Densification kinetics and controlling mechanisms. J. Non-Cryst. Solids 1988, 100, 115-141. [CrossRef]

167. Ye, L.Y.; Liu, Q.L.; Zhang, Q.G.; Zhu, A.M.; Zhou, G.B. Pervaporation characteristics and structure of poly(vinyl alcohol)/poly(ethylene glycol)/tetraethoxysilane hybrid membranes. J. Appl. Polym. Sci. 2007, 105, 3640-3648. [CrossRef]

168. Uragami, T.; Okazaki, K.; Matsugi, H.; Miyata, T. Structure and permeation characteristics of an aqueous ethanol solution of organic-inorganic hybrid membranes composed of poly(vinyl alcohol) and tetraethoxysilane. Macromolecules 2002, 35, 9156-9163. [CrossRef]

169. Hummers, W.S.; Offeman, R.E. Preparation of Graphitic Oxide. J. Am. Chem. Soc. 1958, 80, 1339. [CrossRef]

170. Zhang, G.; Meng, H.; Ji, S. Hydrolysis differences of polyacrylonitrile support membrane and its influences on polyacrylonitrile-based membrane performance. Desalination 2009, 242, 313-324. [CrossRef]

171. Marcano, D.C.; Kosynkin, D.V.; Berlin, J.M.; Sinitskii, A.; Sun, Z.; Slesarev, A.; Alemany, L.B.; Lu, W.; Tour, J.M. Improved synthesis of graphene oxide. ACS Nano 2010, 4, 4806-4814. [CrossRef] 
172. Destaye, A.G.; Lin, C.K.; Lee, C.K. Glutaraldehyde vapor cross-linked nanofibrous PVA Mat with in situ formed silver nanoparticles. ACS Appl. Mater. Interfaces 2013, 5, 4745-4752. [CrossRef]

173. Zhang, L.; Yu, P.; Luo, Y. Separation of caprolactam-water system by pervaporation through crosslinked PVA membranes. Sep. Purif. Technol. 2006, 52, 77-83. [CrossRef]

174. Kulkarni, S.S.; Kittur, A.A.; Aralaguppi, M.I.; Kariduraganavar, M.Y. Synthesis and characterization of hybrid membranes using poly(vinyl alcohol) and tetraethylorthosilicate for the pervaporation separation of water-isopropanol mixtures. J. Appl. Polym. Sci. 2004, 94, 1304-1315. [CrossRef]

175. Dlamini, D.S.; Mamba, B.B.; Li, J. The role of nanoparticles in the performance of nano-enabled composite membranes-A critical scientific perspective. Sci. Total Environ. 2019, 656, 723-731. [CrossRef]

176. Wang, Z.H.; Yu, H.R.; Xia, J.F.; Zhang, F.F.; Li, F.; Xia, Y.Z.; Li, Y.H. Novel GO-blended PVDF ultrafiltration membranes. Desalination 2012, 299, 50-54. [CrossRef]

177. Hung, W.; Tsou, C.; Guzman, M.D.; An, Q.; Liu, Y.; Zhang, Y.; Hu, C.; Lee, K.; Lai, J. Cross-Linking with Diamine Monomers to Prepare Composite Graphene Oxide-Framework Membranes with Varying d-spacing. Chem. Mater. 2014, 26, 2983-2990. [CrossRef]

178. Dreyer, D.R.; Park, S.; Bielawski, C.W.; Ruoff, R.S. The chemistry of graphene oxide. Chem. Soc. Rev. 2010, 39, 228-240. [CrossRef]

179. Singha, N.R.; Dutta, A.; Mahapatra, M.; Karmakar, M.; Mondal, H.; Chattopadhyay, P.K.; Maiti, D.K. Guar Gum-Grafted Terpolymer Hydrogels for Ligand-Selective Individual and Synergistic Adsorption: Effect of Comonomer Composition. ACS Omega 2018, 3, 472-494. [CrossRef]

180. Mondal, H.; Karmakar, M.; Dutta, A.; Mahapatra, M.; Deb, M.; Mitra, M.; Roy, J.S.D.; Roy, C.; Chattopadhyay, P.K.; Singha, N.R. Tetrapolymer network hydrogels via gum ghatti-grafted and $\mathrm{N}-\mathrm{H} / \mathrm{C}-\mathrm{H}$-activated allocation of monomers for composition-dependent superadsorption of metal ions. ACS Omega 2018, 3, 10692-10708. [CrossRef]

181. Singha, N.R.; Roy, C.; Mahapatra, M.; Dutta, A.; Roy, J.S.D.; Mitra, M.; Chattopadhyay, P.K. Scalable synthesis of collagenic-waste and natural rubber-based biocomposite for removal of $\mathrm{Hg}$ (II) and dyes: Approach for cost-friendly waste management. ACS Omega 2019, 4, 421-436. [CrossRef]

182. Chatterjee, S.; Gupta, A.; Mohanta, T.; Mitra, R.; Samanta, D.; Mandal, A.B.; Majumder, M.; Rawat, R.; Singha, N.R. Scalable synthesis of hide substance-chitosan-hydroxyapatite: Novel biocomposite from industrial wastes and its efficiency in dye removal. ACS Omega 2018, 3, 11486-11496. [CrossRef]

183. Roy, C.; Dutta, A.; Mahapatra, M.; Karmakar, M.; Roy, J.S.D.; Mitra, M.; Chattopadhyay, P.K.; Singha, N.R. Collagenic waste and rubber based resin-cured biocomposite adsorbent for high-performance removal(s) of $\mathrm{Hg}(\mathrm{II})$, safranine, and brilliant cresyl blue: A cost-friendly waste management approach. J. Hazard. Mater. 2019, 369, 199-213. [CrossRef]

184. Kim, D.S.; Park, H.B.; Rhim, J.W.; Lee, Y.M. Preparation and characterization of crosslinked PVA/SiO ${ }_{2}$ hybrid membranes containing sulfonic acid groups for direct methanol fuel cell applications. J. Membr. Sci. 2004, 240,37-48. [CrossRef]

185. Singha, N.R.; Dutta, A.; Mahapatra, M.; Roy, J.S.D.; Mitra, M.; Deb, M.; Chattopadhyay, P.K. in situ attachment of acrylamido sulfonic acid-based monomer in terpolymer hydrogel optimized by response surface methodology for individual and/or simultaneous removal(s) of M(III) and cationic dyes. ACS Omega 2019, 4, 1763-1780. [CrossRef]

186. Mahapatra, M.; Karmakar, M.; Dutta, A.; Mondal, H.; Roy, J.S.D.; Chattopadhyay, P.K.; Singha, N.R. Microstructural analyses of loaded and/or unloaded semisynthetic porous material for understanding of superadsorption and optimization by response surface methodology. J. Environ. Chem. Eng. 2018, 6, $289-310$. [CrossRef]

187. Karmakar, M.; Mahapatra, M.; Dutta, A.; Chattopadhyay, P.K.; Singha, N.R. Fabrication of semisynthetic collagenic materials for mere/synergistic adsorption: A model approach of determining dye allocation by systematic characterization. Int. J. Biol. Macromol. 2017, 102, 438-456. [CrossRef]

188. Mitra, M.; Mahapatra, M.; Dutta, A.; Roy, J.S.D.; Karmakar, M.; Deb, M.; Mondal, H.; Chattopadhyay, P.K.; Bandyopadhyay, A.; Singha, N.R. Carbohydrate and collagen-based doubly-grafted interpenetrating terpolymer hydrogel via $\mathrm{N}-\mathrm{H}$ activated in situ allocation of monomer for superadsorption $\mathrm{Of} \mathrm{Pb}(\mathrm{II})$, $\mathrm{Hg}(\mathrm{II})$, dyes, vitamin-C, and p-nitrophenol. J. Hazard. Mater. 2018. [CrossRef]

189. Elakkiya, T.; Sheeja, R.; Ramadhar, K.; Natarajan, T.S. Biocompatibility studies of electrospun nanofibrous membrane of PLLA-PVA blend. J. Appl. Polym. Sci. 2013, 128, 2840-2846. [CrossRef] 
190. Park, J.; Park, J.; Ruckenstein, E. Thermal and dynamic mechanical analysis of PVA/MC blend hydrogels. Polymer 2001, 42, 4271-4280. [CrossRef]

191. Lai, D.; Wei, Y.; Zou, L.; Xu, Y.; Lu, H. Wet spinning of PVA composite fibers with a large fraction of multi-walled carbon nanotubes. Prog. Nat. Sci. Mater. 2015, 25, 445-452. [CrossRef]

192. Chanthad, C.; Wootthikanokkhan, J. Effects of crosslinking time and amount of sulfophthalic acid on properties of the sulfonated poly(vinyl alcohol) membrane. J. Appl. Polym. Sci. 2006, 101, 1931-1936. [CrossRef]

193. Bolto, B.; Tran, T.; Hoang, M.; Xie, Z. Crosslinked poly(vinyl alcohol) membranes. Prog. Polym. Sci. 2009, 34, 969-981. [CrossRef]

194. Mahendia, S.; Heena, G.; Kandhol, U.P.; Deshpande, S.K. Determination of glass transition temperature of reduced graphene oxide-poly(vinyl alcohol) composites using temperature dependent Fourier transform infrared spectroscopy. J. Mol. Struct. 2016, 1111, 46-54. [CrossRef]

195. Kim, H.M.; Lee, H.S. Water and oxygen permeation through transparent ethylene vinyl alcohol/(graphene oxide) membranes. Carbohydr. Lett. 2014, 15, 50-56. [CrossRef]

196. Zhao, C.; Xu, X.; Chen, J.; Yang, F. Optimization of preparation conditions of poly (vinylidene fluoride)/graphene oxide microfiltration membranes by the Taguchi experimental design. Desalination 2014, 334, 17-22. [CrossRef]

197. Achaby, M.E.; Arrakhiz, F.Z.; Vaudreuil, S.; Essassi, E.M.; Qaiss, A. Piezoelectric $\beta$-polymorph formation and properties enhancement in graphene oxide-PVDF nanocomposite films. Appl. Surf. Sci. 2012, 258, 7668-7677. [CrossRef]

198. Shao, L.; Chang, X.; Zhang, Y.; Huang, Y.; Yao, Y.; Guo, Z. Graphene oxide cross-linked chitosan nanocomposite membrane. Appl. Surf. Sci. 2013, 280, 989-992. [CrossRef]

199. Wang, X.; Wang, X.; Xiao, P.; Li, J.; Tian, E.; Zhao, Y.; Ren, Y. High water permeable free-standing cellulose triacetate/graphene oxide membrane with enhanced antibiofouling and mechanical properties for forward osmosis. Colloids Surf. A 2016, 508, 327-335. [CrossRef]

200. Panahian, S.; Raisi, A.; Aroujalian, A. Multilayer mixed matrix membranes containing modified-MWCNTs for dehydration of alcohol by pervaporation process. Desalination 2015, 355, 45-55. [CrossRef]

201. Peppas, N.A.; Merrill, E.W. Crosslinked poly(vinyl alcohol) hydrogels as swollen elastic networks. J. Appl. Polym. Sci. 1977, 21, 1763-1770. [CrossRef]

202. Xie, W.; Cook, J.; Park, H.B.; Freeman, B.D.; Lee, C.H.; McGrath, J.E. Fundamental salt and water transport properties in directly copolymerized disulfonated poly(arylene ether sulfone) random copolymers. Polymer 2011, 52, 2032-2043. [CrossRef]

203. Suhas, D.P.; Raghu, A.V.; Jeong, H.M.; Aminabhavi, T.M. Graphene-loaded sodium alginate nanocomposite membranes with enhanced isopropanol dehydration performance via a pervaporation technique. RSC Adv. 2013, 3, 17120-17130. [CrossRef]

204. Dharupaneedi, S.P.; Anjanapura, R.V.; Han, J.M.; Aminabhavi, T.M. Functionalized graphene sheets embedded in chitosan nanocomposite membranes for ethanol and isopropanol dehydration via pervaporation. Ind. Eng. Chem. Res. 2014, 53, 14474-14484. [CrossRef]

205. Choi, J.; Jegal, J.; Kim, W.; Choi, H. Incorporation of multiwalled carbon nanotubes into poly(vinyl alcohol) membranes for use in the pervaporation of water/ethanol mixtures. J. Appl. Polym. Sci. 2009, 111, 2186-2193. [CrossRef]

206. Dassios, K.G.; Galiotis, C. Polymer-nanotube interaction in MWCNT/poly(vinyl alcohol) composite mats. Carbon 2012, 50, 4291-4294. [CrossRef]

207. Maiti, J.; Kakati, N.; Lee, S.H.; Jee, S.H.; Viswanathan, B.; Yoon, Y.S. Where do poly(vinyl alcohol) based membranes stand in relation to Nafion ${ }^{\circledR}$ for direct methanol fuel cell applications? J. Power Sources 2012, 216, 48-66. [CrossRef]

208. Mauritz, K.A.; Moore, R.B. State of understanding of Nafion. Chem. Rev. 2004, 104, 4535-4585. [CrossRef]

209. Xue, Y.1.; Lau, C.H.; Cao, B.; Li, P. Elucidating the impact of polymer crosslinking and fixed carrier on enhanced water transport during desalination using pervaporation membranes. J. Membr. Sci. 2019, 575, 135-146. [CrossRef]

210. Jiraratananon, R.; Chanachai, A.; Huang, R.Y.M.; Uttapap, D. Pervaporation dehydration of ethanol—water mixtures with chitosan/hydroxyethylcellulose (CS/HEC) composite membranes: I. Effect of operating conditions. J. Membr. Sci. 2002, 195, 143-151. [CrossRef] 
211. Elewa, M.M.; El-Shafei, A.A.; Moneer, A.A.; Naim, M.M. Effect of cell hydrodynamics in desalination of saline water by sweeping air pervaporation technique using innovated membrane. Desalin. Water Treat. 2016, 57, 23293-23307. [CrossRef]

212. Geng, Y.; Zhang, P.; Wang, Q.; Liu, Y.; Pan, K. Novel PAN/PVP Janus ultrafine fiber membrane and its application for biphasic drug release. J. Mater. Chem. B 2017, 5, 5390-5396. [CrossRef]

213. Peng, P.; Fane, A.G.; Li, X. Desalination by membrane distillation adopting a hydrophilic membrane. Desalination 2005, 173, 45-54. [CrossRef]

214. Dotrement, C.; Van den Ende, S.; Vandemmele, H.; Vandecsteele, C. Concentration polarization and other boundary layer effects in the pervaporation of chlorinated hydrocarbons. Desalination 1994, 95, 91-113. [CrossRef]

215. Martínez, L. Comparison of membrane distillation performance using different feeds. Desalination 2004, 168, 359-365. [CrossRef]

216. Lawson, K.W.; Lloyd, D.R. Membrane distillation. J. Membr. Sci. 1997, 124, 1-25. [CrossRef]

217. Qtaishat, M.; Matsuura, T.; Kruczek, B.; Khayet, M. Heat and mass transfer analysis in direct contact membrane distillation. Desalination 2008, 219, 272-292. [CrossRef]

218. Wang, Q.; Li, N.; Bolto, B.; Hoang, M.; Xie, Z. Desalination by pervaporation: A review. Desalination 2016, 387, 46-60. [CrossRef]

219. Fu, Y.; Lai, C.; Chen, J.; Liu, C.; Huang, S. Hydrophobic composite membranes for separating of water-alcohol mixture by pervaporation at high temperature. Chem. Eng. Sci. 2014, 111, 203-210. [CrossRef]

220. Peters, T.A.; Poeth, C.H.S.; Benes, N.E.; Buijs, H.C.W.M.; Vercauteren, F.F.; Keurentjes, J.T.F. Ceramic-supported thin PVA pervaporation membranes combining high flux and high selectivity; contradicting the flux-selectivity paradigm. J. Membr. Sci. 2006, 276, 42-50. [CrossRef]

221. Thomson, G.W. The Antoine equation for vapour-pressure data. Chem. Rev. 1946, 38, 1-39. [CrossRef]

222. Burshe, M.C.; Sawant, S.B.; Joshi, J.B.; Pangarkar, V.G. Sorption and permeation of binary water-alcohol systems through PVA membranes crosslinked with multifunctional crosslinking agents. Sep. Purif. Technol. 1997, 12, 145-156. [CrossRef]

223. Fujita, H.; Kishimoto, A.; Matsumo, K. Concentration and temperature dependence of diffusion coefficients. Trans. Faraday Soc. 1960, 56, 424-437. [CrossRef]

224. Isklan, N.; Sanl, O. Separation characteristics of acetic acid-water mixtures by pervaporation using poly(vinyl alcohol) membranes modified with malic acid. Chem. Eng. Process. 2005, 44, 1019-1027. [CrossRef]

225. Hyder, M.N.; Huang, R.Y.M.; Chen, P. Effect of selective layer thickness on pervaporation of composite poly(vinyl alcohol)-poly(sulfone) membranes. J. Membr. Sci. 2008, 318, 387-396. [CrossRef]

226. Zhang, C.; Fu, L.; Tian, Z.; Cao, B.; Li, P. Post-crosslinking of triptycene-based Tröger's base polymers with enhanced natural gas separation performance. J. Membr. Sci. 2018, 556, 277-284. [CrossRef]

227. George, S.C.; Thomas, S. Transport phenomena through polymeric systems. Prog. Polym. Sci. 2001, 26,985-1017. [CrossRef]

228. Boukhvalov, D.W.; Katsnelson, M.I.; Son, Y. Origin of anomalous water permeation through graphene oxide membrane. Nano Lett. 2013, 13, 3930-3935. [CrossRef]

229. Xu, C.; Cui, A.J.; Xu, Y.L.; Fu, X.Z. Graphene oxide- $\mathrm{TiO}_{2}$ composite filtration membranes and their potential application for water purification. Carbon 2013, 62, 465-471. [CrossRef]

230. Hung, W.; An, Q.; Guzman, M.D.; Lin, H.; Huang, S.; Liu, W.; Hu, C.; Lee, K.; Lai, J. Pressure-assisted self-assembly technique for fabricating composite membranes consisting of highly ordered selective laminate layers of amphiphilic graphene oxide. Carbon 2014, 68, 670-677. [CrossRef]

231. Wei, Y.; Xu, Z.; Qusay, F.A.; Wu, K. Polyvinyl alcohol/polysulfone (PVA/PSF) hollow fiber composite membranes for pervaporation separation of ethanol/water solution. J. Appl. Polym. Sci. 2005, 98, 247-254. [CrossRef]

232. Inamuddin; Thomas, S.; Mishra, R.K.; Asiri, A.M. Sustainable Polymer Composites and Nanocomposites; Springer: Cham, Switzerland, 2019.

233. van Gemert, R.W.; Petrus-Cuperus, F. Newly developed ceramic membranes for dehydration and separation of organic mixtures by pervaporation. J. Membr. Sci. 1995, 105, 287-291. [CrossRef]

234. Verkerk, A.W.; van Male, P.; Vorstman, M.A.G.; Keurentjes, J.T.F. Properties of high flux ceramic pervaporation membranes for dehydration of alcohol/water mixtures. Sep. Purif. Technol. 2001, 22-23, 689-695. [CrossRef]

235. Wynn, N. Dehydration with silica pervaporation membranes. Membr. Technol. 2001, 2001, 10-11. [CrossRef] 
236. Zhu, Y.; Wang, D.; Jiang, L.; Jin, J. Recent progress in developing advanced membranes for emulsified oil/water separation. NPG Asia Mater. 2014, 6, 1-11. [CrossRef]

237. Zakrzewska-Trznadel, G. A dvances in membrane technologies for the treatment of liquid radioactive waste. Desalination 2013, 321, 119-130. [CrossRef]

238. Rana, D.; Matsuura, T.; Kassim, M.A.; Ismail, A.F. Radioactive decontamination of water by membrane processes-A review. Desalination 2013, 321, 77-92. [CrossRef]

239. Mustafa, G.; Wyns, K.; Buekenhoudt, A.; Meynen, V. Antifouling grafting of ceramic membranes validated in a variety of challenging wastewaters. Water Res. 2016, 104, 242-253. [CrossRef]

240. Amin, S.K.; Abdallah, H.A.M.; Roushdy, M.H.; El-Sherbiny, S.A. An overview of production and development of ceramic membranes. Int. J. Appl. Eng. Res. 2016, 11, 7708-7721.

241. Dong, H.; Zhao, L.; Zhang, L.; Chen, H.; Gao, C.; Ho, W.S.W. High-flux reverse osmosis membranes incorporated with $\mathrm{NaY}$ zeolite nanoparticles for brackish water desalination. J. Membr. Sci. 2015, 476, 373-383. [CrossRef]

242. Lee, K.P.; Arnot, T.C.; Mattia, D. A review of reverse osmosis membrane materials for desalination-Development to date and future potential. J. Membr. Sci. 2011, 370, 1-22. [CrossRef]

243. Uhlhorn, R.J.R.; Keizer, K.; Burggraaf, A.J. Gas transport and separation with ceramic membranes. Part II. Synthesis and separation properties of microporous membranes. J. Membr. Sci. 1992, 66, 271-287. [CrossRef]

244. De Lange, R.S.A.; Hekkink, J.H.A.; Keizer, K.; Burggraaf, A.J. Formation and characterization of supported microporous ceramic membranes prepared by sol-gel modification techniques. J. Membr. Sci. 1995, 99, 57-75. [CrossRef]

245. Lorente-Ayza, M.M.; Perez-Fernandez, O.; Alcala, R.; Sanchez, E.; Mestre, S.; Coronas, J.; Menéndez, M. Comparison of porosity assessment techniques for low-cost ceramic membranes. Bol. Soc. Esp. Ceram. Vidrio 2016, 56, 29-38. [CrossRef]

246. Lorente-Ayza, M.M.; Mestre, S.; Sanz, V.; Sanchez, E. On the underestimated effect of the starch ash on the characteristics of low cost ceramic membranes. Ceram. Int. 2016, 42, 18944-18954. [CrossRef]

247. Kaur, H.; Bulasara, V.K.; Gupta, R.K. Effect of carbonates composition on the permeation characteristics of low-cost ceramic membrane supports. J. Ind. Eng. Chem. 2016, 44, 185-194. [CrossRef]

248. Hedfi, I.; Hamdi, N.; Rodriguez, M.A.; Srasra, E. Development of a low cost microporous ceramic membrane from kaolin and alumina, using the lignite as porogen agent. Ceram. Int. 2016, 42, 5089-5093. [CrossRef]

249. Lorente-Ayza, M.M.; Sánchez, E.; Sanz, V.; Mestre, S. Influence of starch content on the properties of low-cost microfiltration ceramic membranes. Ceram. Int. 2015, 41, 13064-13073. [CrossRef]

250. Quinones-Bolanos, E.; Zhou, H.D.; Parkin, G. Membrane pervaporation for wastewater reuse in microirrigation. J. Environ. Eng. ASCE 2005, 131, 1633-1643. [CrossRef]

251. Michaels, A.S.; Bixler, H.J.; Hodges Jr., R. M. Kinetics of water and salt transport in cellulose acetate reverse osmosis desalination membranes. J. Colloid Sci. 1965, 20, 1034-1056. [CrossRef]

252. Voros, N.G.; Maroulis, Z.B.; Marinos-Kouris, D. Salt and water permeability in reverse osmosis membranes. Desalination 1996, 104, 141-154. [CrossRef]

253. Zhang, X.; Cahill, D.G.; Coronell, O.; Mariñas, B.J. Partitioning of salt ions in FT30 reverse osmosis membranes. Appl. Phys. Lett. 2007, 91, 181904-181907. [CrossRef]

254. Ju, H.; Sagle, A.C.; Freeman, B.D.; Mardel, J.I.; Hill, A.J. Characterization of sodium chloride and water transport in crosslinked poly(ethylene oxide) hydrogels. J. Membr. Sci. 2010, 358, 131-141. [CrossRef]

255. Nigiz, F.U.; Hilmioglu, N.D. Pervaporative desalination of seawater by using composite and blended poly(vinyl alcohol) membranes. Desalin. Water Treat. 2016, 57, 4749-4755. [CrossRef]

256. Duke, M.C.; Mee, S.; Diniz da Costa, J.C.D. Performance of porous inorganic membranes in nonosmotic desalination. Water Res. 2007, 41, 3998-4004. [CrossRef]

257. Darmawan, A.; Karlina, L.; Astuti, Y.; Sriatun, J.M.; Wang, D.K.; da Costa, J.C.D. Structural evolution of nickel oxide silica sol-gel for the preparation of interlayer-free membranes. J. Non-Cryst. Solids 2016, 447, 9-15. [CrossRef]

258. Fernández, E.; Benito, J.M.; Pazos, C.; Coca, J. Ceramic membrane ultrafiltration of anionic and nonionic surfactant solutions. J. Membr. Sci. 2005, 246, 1-6. [CrossRef]

259. Larbot, A.B. Fundamentals on inorganic membranes: Present and new developments. Pol. J. Chem. Technol. 2003, 6, 8-13.

260. Tavolaro, A.; Drioli, E. Zeolite Membranes. Adv. Mater. 1999, 11, 975-996. [CrossRef] 
261. Cot, L.; Ayral, A.; Durand, J.; Guizard, C.; Hovnanian, N.; Julbe, A.; Larbot, A. Inorganic membranes and solid state sciences. Solid State Sci. 2000, 2, 313-334. [CrossRef]

262. Alami-Younssi, S.; Kiefer, C.; Larbot, A.; Persin, M.; Sarrazin, J. Grafting $\gamma$ alumina microporous membranes by organosilanes: Characterisation by pervaporation. J. Membr. Sci. 1998, 143, 27-36. [CrossRef]

263. Jou, J.; Yoshida, W.; Cohen, Y. A novel ceramic supported polymer membrane for pervaporation of dilute volatile organic compounds. J. Membr. Sci. 1999, 162, 269-284. [CrossRef]

264. Picard, C.; Larbot, A.; Guida-Pietrasanta, F.; Boutevin, B.; Ratsimihety, A. Grafting of ceramic membranes by fluorinated silanes: Hydrophobic features. Sep. Purif. Technol. 2001, 25, 65-69. [CrossRef]

265. Caro, J.; Noack, M.; Kolsch, P. Chemically modified ceramic membranes. Microporous Mesoporous Mater. 1998, 22, 321-332. [CrossRef]

266. Yoshida, W.; Cohen, Y. Ceramic-supported polymer membranes for pervaporation of binary organic/organic mixtures. J. Membr. Sci. 2003, 213, 145-157. [CrossRef]

267. Yoshida, W.; Cohen, Y. Removal of methyl tertbutyl ether from water by pervaporation using ceramic-supported polymer membranes. J. Membr. Sci. 2004, 229, 27-32. [CrossRef]

268. Leger, C.; Lira, H.D.L.; Paterson, R. Preparation and properties of surface modified ceramic membranes. Part II. Gas and liquid permeabilities of $5 \mathrm{~nm}$ alumina membranes modified by a monolayer of bound polydimethylsiloxane (PDMS) silicone oil. J. Membr. Sci. 1996, 120, 135-146. [CrossRef]

269. Dafinov, A.; Garcia-Valls, R.; Font, J. Modification of ceramic membranes by alcohol adsorption. J. Membr. Sci. 2002, 196, 69-77. [CrossRef]

270. Krajewski, S.R.; Kujawski, W.; Dijoux, F.; Picard, C.; Larbot, A. Grafting of $\mathrm{ZrO}_{2}$ powder and $\mathrm{ZrO}_{2}$ membrane by fluoroalkylsilanes. Colloids Surf. A 2004, 243, 43-47. [CrossRef]

271. Schondelmaier, D.; Cramm, S.; Klingeler, R.; Morenzin, J.; Zilkens, C.; Eberhardt, W. Orientation and self-assembly of hydrophobic fluoroalkylsilanes. Langmuir 2002, 18, 6242-6245. [CrossRef]

272. Akamatsu, Y.; Makita, K.; Inaba, H.; Minami, T. Water-repellent coating films on glass prepared from hydrolysis and polycondensation reactions of fluroalkyltrialkoxysilane. Thin Solid Films 2001, 289, 138-145. [CrossRef]

273. Yoshida, W.; Cohen, Y. Topological AFM characterization of graft polymerized silica membranes. J. Membr. Sci. 2003, 215, 249-264. [CrossRef]

274. Larbot, A.; Gazagnes, L.; Krajewski, S.; Bukowska, M.; Kujawski, W. Water desalination using ceramic membrane distillation. Desalination 2004, 168, 367-372. [CrossRef]

275. Picard, C.; Larbot, A.; Tronel-Peyroz, E.; Berjoan, R. Characterisation of hydrophilic ceramic membranes modified by fluoroalkylsilanes into hydrophobic membranes. Solid State Sci. 2004, 6, 605-612. [CrossRef]

276. Janknecht, P.; Widerer, P.A.; Picard, C.; Larbot, A. Ozone-water contacting by ceramic membranes. Sep. Purif. Technol. 2001, 25, 341-346. [CrossRef]

277. Ren, C.; Fang, H.; Gu, J.; Winnubst, L.; Chen, C. Preparation and characterization of hydrophobic alumina planar membranes for water desalination. J. Eur. Ceram. Soc. 2015, 35, 723-730. [CrossRef]

278. Yacou, C.; Smart, S.; da Costa, J.C.D. Mesoporous $\mathrm{TiO}_{2}$ based membranes for water desalination and brine processing. Sep. Purif. Technol. 2015, 147, 166-171. [CrossRef]

279. Sakka, S. Handbook of Sol-Gel Science and Technology: Processing, Characterization and Applications; Kluwer Academic Publishers: Dordrecht, The Netherlands, 2005.

280. Chen, X.; Zhang, W.; Lin, Y.; Cai, Y.; Qiu, M.; Fan, Y. Preparation of high-flux $\gamma$-alumina nanofiltration membranes by using a modified sol-gel method. Microporous Mesoporous Mater. 2015, 214, 195-203. [CrossRef]

281. Wang, Z.; Wei, Y.; Xu, Z.; Cao, Y.; Dong, Z.; Shi, X. Preparation, characterization and solvent resistance of $\gamma$-Al2O3/ $\alpha-\mathrm{Al} 2 \mathrm{O} 3$ inorganic hollow fiber nanofiltration membrane. J. Membr. Sci. 2016, 503, 69-80. [CrossRef]

282. Elma, M.; Yacou, C.; da Costa, J.C.D.; Wang, D.K. Performance and long term stability of mesoporous silica membranes for desalination. Membranes 2013, 3, 136-150. [CrossRef]

283. Chua, Y.T.; Ji, G.; Birkett, G.; Lin, C.X.C.; Kleitz, F.; Smart, S. Nanoporous organosilica membrane for water desalination: Theoretical study on the water transport. J. Membr. Sci. 2015, 482, 56-66. [CrossRef]

284. Chua, Y.T.; Lin, C.X.C.; Kleitz, F.; Zhao, X.S.; Smart, S. Nanoporous organosilica membrane for water desalination. Chem. Commun. 2013, 49, 4534-4536. [CrossRef]

285. Elma, M.; Wang, D.K.; Yacou, C.; da Costa, J.C.D. Interlayer-free P123 carbonised template silica membranes for desalination with reduced salt concentration polarization. J. Membr. Sci. 2015, 475, 376-383. [CrossRef] 
286. Elma, M.; Wang, D.K.; Yacou, C.; Motuzas, J.; da Costa, J.C.D. High performance interlayer-free mesoporous cobalt oxide silica membranes for desalination applications. Desalination 2015, 365, 308-315. [CrossRef]

287. Liu, J.; Dong, Y.; Dong, X.; Hampshire, S.; Zhu, L.; Zhu, Z.; Li, L. Feasible recycling of industrial waste coal fly ash for preparation of anorthite-cordierite based porous ceramic membrane supports with addition of dolomite. J. Eur. Ceram. Soc. 2016, 36, 1059-1071. [CrossRef]

288. Qin, G.; Lü, X.; Wei, W.; Li, J.; Cui, R.; Hu, S. Microfiltration of kiwifruit juice and fouling mechanism using fly-ash-based ceramic membranes. Food Bioprod. Process. 2015, 96, 278-284. [CrossRef]

289. Namburath, M.; Joshi, G.; Cholemari, M.; Shet, C.; Sreekrishnan, T.R.; Veeravalli, S. Feasibility study of indigenously developed fly ash membrane in municipal wastewater treatment. Aquat. Procedia 2015, 4, 1492-1499. [CrossRef]

290. Verweij, H. Inorganic membranes. Curr. Opin. Chem. Eng. 2012, 1, 156-162. [CrossRef]

291. Silva, K.K.O.S.; Paskocimas, C.A.; Oliveira, F.R.; Nascimento, J.H.O.; Zille, A. Development of porous alumina membranes for treatment of textile effluent. Desalin. Water Treat. 2016, 57, 2640-2648. [CrossRef]

292. Tolba, G.M.K.; Bastaweesy, A.M.; Ashour, E.A.; Abdelmoez, W.; Khalil, K.A.; Barakat, N.A.M. Effective and highly recyclable ceramic membrane based on amorphous nanosilica for dye removal from the aqueous solutions. Arab. J. Chem. 2015, 9, 287-296. [CrossRef]

293. Ni, L.; Meng, J.; Li, X.; Zhang, Y. Surface coating on the polyamide TFC RO membrane for chlorine resistance and antifouling performance improvement. J. Membr. Sci. 2014, 451, 205-215. [CrossRef]

294. Gentleman, M.M.; Ruud, J.A. Role of hydroxyls in oxide wettability. Langmuir 2010, 26, 1408-1411. [CrossRef]

295. Kujawski, W.; Kujawa, J.; Wierzbowska, E.; Cerneaux, S.; Bryjak, M.; Kujawski, J. Influence of hydrophobization conditions and ceramic membranes pore size on their properties in vacuum membrane distillation of water-organic solvent mixtures. J. Membr. Sci. 2016, 499, 442-451. [CrossRef]

296. Kujawa, J.; Cerneaux, S.; Kujawski, W. Investigation of the stability of metal oxide powders and ceramic membranes grafted by perfluoroalkylsilanes. Colloids Surf. A 2014, 443, 109-117. [CrossRef]

297. Kujawa, J.; Cerneaux, S.; Kujawski, W. Characterization of the surface modification process of $\mathrm{Al}_{2} \mathrm{O}_{3}, \mathrm{TiO}_{2}$ and $\mathrm{ZrO}_{2}$ powders by PFAS molecules. Colloids Surf. A 2014, 447, 14-22. [CrossRef]

298. Kujawa, J.; Kujawski, W.; Koter, S.; Rozicka, A.; Cerneaux, S.; Persin, M.; Larbot, A. Efficiency of grafting of $\mathrm{Al}_{2} \mathrm{O}_{3}, \mathrm{TiO}_{2}$ and $\mathrm{ZrO}_{2}$ powders by perfluoroalkylsilanes. Colloids Surf. A 2013, 420, 64-73. [CrossRef]

299. Pazokifard, S.; Mirabedini, S.M.; Esfandeh, M.; Farrokhpay, S. Fluoroalkylsilane treatment of $\mathrm{TiO}_{2}$ nanoparticles in difference $\mathrm{pH}$ values: Characterization and mechanism. Adv. Powder Technol. 2012, 23, 428-436. [CrossRef]

300. Nataraj, S.K.; Roy, S.; Patil, M.B.; Nadagouda, M.N.; Rudzinski, W.E.; Aminabhavi, T.M. Cellulose acetate-coated $\alpha$-alumina ceramic composite tubular membranes for wastewater treatment. Desalination 2011, 281, 348-353. [CrossRef]

301. Liu, G.; Wei, W.; Jin, W.; Xu, N. Polymer/ceramic composite membranes and their application in pervaporation process. Chin. J. Chem. Eng. 2012, 20, 62-70. [CrossRef]

302. Wei, W.; Xia, S.; Liu, G.; Dong, X.; Jin, W.; Xu, N. Effects of polydimethylsiloxane (PDMS) molecular weight on performance of PDMS/ceramic composite membranes. J. Membr. Sci. 2011, 375, 334-344. [CrossRef]

303. Wu, T.; Wang, N.; Li, J.; Wang, L.; Zhang, W.; Zhang, G.; Ji, S. Tubular thermal crosslinked-PEBA/ceramic membrane for aromatic/aliphatic pervaporation. J. Membr. Sci. 2015, 486, 1-9. [CrossRef]

304. Wang, L.; Wang, N.; Zhang, G.; Ji, S. Covalent crosslinked assembly of tubular ceramic-based multilayer nanofiltration membranes for dye desalination. AIChE J. 2013, 59, 3834-3842. [CrossRef]

305. Castro, R.P.; Monbouquette, H.G.; Cohen, Y. Polyvinylpyrrolidone-silica membranes for the treatment of oil-in-water emulsions. J. Membr. Sci. 1996, 115, 179-190. [CrossRef]

306. Wang, Z.; Ge, O.; Shao, J.; Yan, Y. High performance zeolite LTA pervaporation membranes on ceramic hollow fibers by dipcoating-wiping seed deposition. J. Am. Chem. Soc. 2009, 131, 6910-6911. [CrossRef]

307. Carreon, M.A.; Li, S.; Falconer, J.L.; Noble, R.D. Alumina-supported SAPO-34 membranes for $\mathrm{CO}_{2} / \mathrm{CH}_{4}$ separation. J. Am. Chem. Soc. 2008, 130, 5412-5413. [CrossRef]

308. Ockwig, N.W.; Nenoff, T.M. Membranes for hydrogen separation. Chem. Rev. 2007, 107, 4078-4110. [CrossRef]

309. Rana, D.; Matsuura, T. Surface modifications for antifouling membranes. Chem. Rev. 2010, 110, $2448-2471$. [CrossRef]

310. Samei, M.; Iravaninia, M.; Mohammadi, T.; Asadi, A.A. Solution diffusion modeling of a composite PVA/fumed silica ceramic supported membrane. Chem. Eng. Process. 2016, 109, 11-19. [CrossRef] 
311. Randon, J.; Blanc, P.; Paterson, R. Modification of ceramic membrane surfaces using phosphoric acid and alkyl phosphonic acids and its effects on ultrafiltration of BSA protein. J. Membr. Sci. 1995, 98, 119-129. [CrossRef]

312. Nakajima, A.; Fujishima, A.; Hashimoto, K.; Watanabe, T. Preparation of transparent superhydrophobic boehmite and silica films by sublimation of aluminum acetylacetonate. Adv. Mater. 1999, 11, 1365-1368. [CrossRef]

313. Yoshino, N.; Sasaki, A.; Seto, T. Synthesis of a silane coupling agent containing a 4-(perfluoroalkyl)phenyl group and its application to the surface modification of glass. J. Fluor. Chem. 1995, 71, 21-29. [CrossRef]

314. Pesek, J.J.; Leigh, I. (Eds.) Chemically Modified Surfaces; The Royal Society of Chemistry: London, UK, 1994.

315. Strathmann, H.; Kock, K.; Amar, P.; Bake, R.W. The formation mechanism of asymmetric membranes. Desalination 1975, 16, 179-203. [CrossRef]

316. Bottino, A.; Camera-Roda, G.; Capannelli, G.; Munari, S. The formation of microporous polyvinylidene difluoride membranes by phase separation. J. Membr. Sci. 1991, 57, 1-20. [CrossRef]

317. Tsay, C.S.; McHugh, A.J. Mass transfer modeling of asymmetric membrane formation by phase inversion. J. Polym. Sci. Part B Polym. Phys. 1990, 28, 1327-1365. [CrossRef]

318. Kang, Y.S.; Kim, H.J.; Kim, U.Y. Asymmetric membrane formation via immersion precipitation method. I. Kinetic effect. J. Membr. Sci. 1991, 60, 219-232.

319. Young, T.H.; Chen, L.W. A diffusion-controlled model for wet-casting membrane formation. J. Membr. Sci. 1991, 59, 169-181. [CrossRef]

320. Rezac, M.E.; Roux, J.D.L.; Chen, H.; Paul, D.R.; Koros, W.J. Effect of mild solvent posttreatments on the gas transport properties of glassy polymer membranes. J. Membr. Sci. 1994, 90, 213-229. [CrossRef]

321. Vasarhelyi, K.; Ronner, J.A.; Mulder, M.H.V.; Smolders, C.A. Development of wet-dry reversible reverse osmosis membranes with high performance from cellulose acetate and cellulose triacetate blends. Desalination 1987, 61, 211-235. [CrossRef]

322. Pinnau, I.; Hellums, M.W.; Koros, W.J. Gas transport through homogeneous and asymmetric polyestercarbonate membranes. Polymer 1991, 32, 2612-2617. [CrossRef]

323. Wijmans, J.G.; Baaij, J.P.B.; Smolders, C.A. The mechanism of formation of microporous or skinned membranes produced by immersion precipitation. J. Membr. Sci. 1983, 14, 263-274. [CrossRef]

324. Mulder, M.H.V.; Hendrikman, J.O.; Wijmans, J.G.; Smolders, C.A. A rationale for the preparation of asymmetric pervaporation membranes. J. Appl. Polym. Sci. 1985, 30, 2805-2820. [CrossRef]

325. Venna, S.R.; Carreon, M.A. Highly Permeable Zeolite Imidazolate Framework-8 Membranes for $\mathrm{CO}_{2} / \mathrm{CH}_{4}$ Separation. J. Am. Chem. Soc. 2010, 132, 76-78. [CrossRef]

326. Wu, Z.; Zhang, C.; Peng, L.; Wang, X.; Kong, Q.; Gu, X. Enhanced Stability of MFI Zeolite Membranes for Separation of Ethanol/Water by Eliminating Surface Si-OH Groups. ACS Appl. Mater. Interfaces 2018, 10, 3175-3180. [CrossRef]

327. Garofalo, A.; Carnevale, M.C.; Donato, L.; Drioli, E.; Alharbi, O.; Aljlil, S.A.; Criscuoli, A.; Algieri, C. Scale-up of MFI zeolite membranes for desalination by vacuum membrane distillation. Desalination 2016, 397, $205-212$. [CrossRef]

328. Kazemimoghadam, M.; Mohammadi, T. Synthesis of MFI zeolite membrane for water desalination. Desalination 2007, 206, 547-553. [CrossRef]

329. Li, L.X.; Dong, J.H.; Nenoff, T.M.; Lee, R. Desalination by reverse osmosis using MFI zeolite membranes. J. Membr. Sci. 2004, 243, 401-404. [CrossRef]

330. Palinkas, G.; Radnai, T.; Szasz, G.I.; Heinzinger, K. The structure of an aqueous ammonium chloride solution. J. Chem. Phys. 1981, 84, 3522-3526. [CrossRef]

331. Li, L.; Liu, N.; McPherson, B.; Lee, R. Enhanced water permeation of reverse osmosis through MFI-type zeolite membrane with high aluminum contents. Ind. Eng. Chem. Res. 2007, 46, 1584-1589. [CrossRef]

332. Xia, S.; Peng, Y.; Lu, H.; Wang, Z. The influence of nanoseeds on the pervaporation performance of MFI-type zeolite membranes on hollow fibers. Microporous Mesoporous Mater. 2016, 222, 128-137. [CrossRef]

333. Zhu, B.; Hong, Z.; Milne, N.; Doherty, C.M.; Zou, L.; Lin, Y.S.; Hill, A.J.; Gu, X.; Duke, M. Desalination of sea water ion complexes by MFI-type zeolite membranes: Temperature and long term stability. J. Membr. Sci. 2014, 453, 126-135. [CrossRef] 
334. Duke, M.C.; O'brien-Abraham, J.; Milne, N.; Zhu, B.; Lin, J.Y.S.; da Costa, J.C.D. Seawater desalination performance of MFI type membranes made by secondary growth. Sep. Purif. Technol. 2009, 68, 343-350. [CrossRef]

335. Zhu, B.; Myat, D.T.; Shin, J.W.; Na, Y.H.; Moon, I.S.; Connor, G.; Maeda, S.; Morris, G.; Gray, S.; Duke, M. Application of robust MFI-type zeolite membrane for desalination of saline wastewater. J. Membr. Sci. 2015, 475, 167-174. [CrossRef]

336. Li, L.; Dong, J.H.; Nenoff, T.M.; Lee, R. Reverse osmosis of ionic aqueous solutions on a MFI zeolite membrane. Desalination 2004, 170, 309-316. [CrossRef]

337. Zhu, B.; Morris, G.; Moon, I.; Gray, S.; Duke, M. Diffusion behaviour of multivalent ions at low $\mathrm{pH}$ through a MFI-type zeolite membrane. Desalination 2018, 440, 88-98. [CrossRef]

338. Shin, W.; Tye, L.; Thian, C.; Bhatia, S. Synthesis, characterization and pervaporation properties of microwave synthesized zeolite A membrane. Desalination 2011, 277, 383-389.

339. McLeary, E.E.; Jansen, J.C.; Kaptijn, F. Zeolite based films, membranes and membrane reactors: Progress and prospects. Microporous Mesoporous Mater. 2006, 90, 198-220. [CrossRef]

340. van Bekkum, H.; Cejka, J.; Corma, A.; Schuth, F. (Eds.) Studies in Surface Science and Catalysis; Elsevier: Amsterdam, The Netherlands, 2007.

341. Bowen, T.C.; Noble, R.D.; Falconer, J.L. Fundamentals and applications of pervaporation through zeolite membranes. J. Membr. Sci. 2004, 245, 1-33. [CrossRef]

342. Tuan, V.A.; Li, S.; Falconer, J.L.; Noble, R.D. Separating organics from water by pervaporation with isomorphously-substituted MFI zeolite membranes. J. Membr. Sci. 2002, 196, 111-123. [CrossRef]

343. Noack, M.; Kölsch, P.; Dittmar, A.; Stöhr, M.; Georgi, G.; Eckelt, R.; Caro, J. Effect of crystal intergrowth supporting substances (ISS) on the permeation properties of MFI membranes with enhanced Al-content. Microporous Mesoporous Mater. 2006, 97, 88-96. [CrossRef]

344. Shah, D.; Kissick, K.; Ghorpade, A.; Hannah, R.; Bhattacharyya, D. Pervaporation of alcohol-water and dimethyl formamide-water mixtures using hydrophilic zeolite NaA membranes: Mechanisms and experimental results. J. Membr. Sci. 2000, 179, 185-205. [CrossRef]

345. Lai, Z.; Bonilla, G.; Diaz, I.; Nery, J.G.; Sujaoti, K.; Amat, M.A.; Kokkoli, E.; Terasaki, O.; Thompson, R.W.; Tsapatsis, M.; et al. Microstructural optimization of a zeolite membrane for organic vapor separation. Science 2003, 300, 456-460.

346. Xu, C.; Lu, X.; Wang, Z. Effects of sodium ions on the separation performance of pure-silica MFI zeolite membranes. J. Membr. Sci. 2017, 524, 124-131. [CrossRef]

347. Humplik, T.; Raj, R.; Maroo, S.C.; Laoui, T.; Wang, E.N. Effect of hydrophilic defects on water transport in MFI zeolites. Langmuir 2014, 30, 6446-6453. [CrossRef]

348. Zhu, B.; Kim, J.H.; Na, Y.H.; Moon, I.S.; Connor, G.; Maeda, S.; Morris, G.; Gray, S.; Duke, M. Temperature and pressure effects of desalination using a MFI-type zeolite membrane. Membranes 2013, 3, 155-168. [CrossRef]

349. Zhou, C.; Zhou, J.; Huang, A. Seeding-free synthesis of zeolite FAU membrane for seawater desalination by pervaporation. Microporous Mesoporous Mater. 2016, 234, 377-383. [CrossRef]

350. Kumakiri, I.; Yamaguchi, T.; Nakao, S. Preparation of zeolite A and faujasite membranes from a clear solution. Ind. Eng. Chem. Res. 1999, 38, 4682-4688. [CrossRef]

351. Kumakiri, I.; Hashimoto, K.; Nakagawa, Y.; Inoue, Y.; Kanehiro, Y.; Tanaka, K.; Kita, H. Application of FAU zeolite membranes to alcohol/acrylate mixture systems. Catal. Today 2014, 236, 86-91. [CrossRef]

352. Mastropietro, T.F.; Drioli, E.; Candamano, S.; Poerio, T. Crystallization and assembling of FAU nanozeolites on porous ceramic supports for zeolite membrane synthesis. Microporous Mesoporous Mater. 2016, 228, 141-146. [CrossRef]

353. Naskar, M.K.; Das, A.; Kundu, D.; Chatterjee, M. Emulsion-based synthesis of NaA zeolite nanocrystals and its integration towards NaA membranes. Bull. Mater. Sci. 2011, 34, 651-659. [CrossRef]

354. Tsapatsis, M.; Lovallo, M.C.; Okubo, T.; Davis, M.E.; Sadakata, M. Characterization of zeolite L nanoclusters. Chem. Mater. 1995, 7, 1734-1741. [CrossRef]

355. Xu, X.C.; Yang, W.S.; Liu, J.; Lin, L.W. Synthesis and perfection evaluation of NaA zeolite membrane. Sep. Purif. Technol. 2001, 25, 475-485. [CrossRef]

356. Warzywoda, J.; Edelman, R.D.; Thompson, R.W. Crystallization of high-silica ZSM-5 in the presence of seeds. Zeolites 1991, 11, 318-324. [CrossRef] 
357. Tsokanis, E.A.; Thompson, R.W. Further investigations of nucleation by initial breeding in the Al-free $\mathrm{NH}_{4}$-ZSM-5 system. Zeolites 1992, 12, 369-373. [CrossRef]

358. Gora, L.; Thompson, R.W. Controlled addition of aged mother liquor to zeolite NaA synthesis solution. Zeolites 1997, 18, 132-141. [CrossRef]

359. Lai, R.; Gavalas, G.R. Surface seeding in ZSM-5 membrane preparation. Ind. Eng. Chem. Res. 1998, 37, 4275-4283. [CrossRef]

360. Boudreau, L.C.; Kuck, J.A.; Tsapatsis, M. Deposition of oriented zeolite A films: In situ and secondary growth. J. Membr. Sci. 1999, 152, 41-59. [CrossRef]

361. Xu, X.C.; Yang, W.S.; Liu, J.; Lin, L.W. Synthesis of NaA zeolite membranes from clear solution. Microporous Mesoporous Mater. 2001, 43, 299-311. [CrossRef]

362. Engstrom, V.; Mihailova, B.; Hedlund, J.; Holmgren, A.; Sterte, J. The effect of seed size on the growth of silicalite-1 films on gold surfaces. Microporous Mesoporous Mater. 2000, 38, 51-60. [CrossRef]

363. Kusakabe, K.; Kuroda, T.; Murata, A.; Morooka, S. Formation of a Y-type zeolite membrane on a porous -alumina tube for gas separation. Ind. Eng. Chem. Res. 1997, 36, 649-655. [CrossRef]

364. Zhang, X.F.; Wang, J.Q.; Yin, D.H.; Liu, C.H. Synthesis of ZSM-5 zeolite membrane and its influencing factors by a novel method. Chin. J. Catal. 2000, 21, 451.

365. Mintova, S.; Bein, T. Microporous films prepared by spin-coating stable colloidal suspensions of zeolites. Adv. Mater. 2001, 13, 1880-1883. [CrossRef]

366. Balkus, K.J., Jr.; Munoz, T.; Gimon-Kinsel, M.E. Preparation of zeolite UTD-1 films by pulsed laser ablation: Evidence for oriented crystal growth. Chem. Mater. 1998, 10, 464-466. [CrossRef]

367. Balkus, K.J., Jr.; Scott, A.S.; Gimon-Kinsel, M.E.; Blanco, J.H. Oriented films of mesoporous MCM-41 macroporous tubules via pulsed laser deposition. Microporous Mesoporous Mater. 1999, 11, 97-105.

368. Bernal, M.P.; Xomeritakis, G.; Tsapatsis, M. Tubular MFI zeolite membranes made by secondary (seeded) growth. Catal. Today 2001, 67, 101-107. [CrossRef]

369. Li, Y.; Yang, W. Microwave synthesis of zeolite membranes: A review. J. Membr. Sci. 2008, 316, 3-17. [CrossRef]

370. Garofalo, A.; Donato, L.; Drioli, E.; Criscuoli, A.; Carnevale, M.C.; Alharbi, O.; Aljlil, S.A.; Algieri, C. Supported MFI zeolite membranes by cross flow filtration for water treatment. Sep. Purif. Technol. 2014, 137, 28-35. [CrossRef]

371. Li, L.; Liu, N.; McPherson, B.; Lee, R. Influence of counter ions on the reverse osmosis through MFI zeolite membranes: Implications for produced water desalination. Desalination 2008, 228, 217-225. [CrossRef]

372. Skluzacek, J.M.; Tejedor, M.I.; Anderson, M.A. An iron-modified silica nanofiltration membrane: Effect of solution composition on salt rejection. Microporous Mesoporous Mater. 2006, 94, 288-294. [CrossRef]

373. Alami-Younssi, S.; Larbot, A.; Persin, M.; Sarrazin, J.; Cot, L. Gamma alumina nanofiltration membrane applications to the rejection of metallic cations. J. Membr. Sci. 1994, 91, 87-95. [CrossRef]

374. de Lint, W.B.S.; Zivkovic, T.; Benes, N.E.; Buwmeester, H.J.M.; Blank, D.H.A. Electrolyte retention of supported bi-layered nanofiltration membranes. J. Membr. Sci. 2006, 277, 18-27.

375. Gazagnes, L.; Cerneaux, S.; Persin, M.; Prouzet, E.; Larbot, A. Desalination of sodium chloride solutions and seawater with hydrophobic ceramic membranes. Desalination 2007, 217, 260-266. [CrossRef]

376. Khajavi, S.; Jansen, J.C.; Kapteijn, F. Performance of hydroxyl sodalite membranes as absolute water selective materials under acidic and basic conditions. J. Membr. Sci. 2010, 356, 1-6. [CrossRef]

(C) 2019 by the authors. Licensee MDPI, Basel, Switzerland. This article is an open access article distributed under the terms and conditions of the Creative Commons Attribution (CC BY) license (http://creativecommons.org/licenses/by/4.0/). 